\title{
CAMELLOS LAMINOS DEL MIOCENO TARDÍO (HENFILIANO TEMPRANO) DE LA FORMACIÓN CURRÉ, SAN GERARDO DE LIMONCITO, CANTÓN DE COTO BRUS, PROVINCIA DE PUNTARENAS, COSTA RICA
}

\author{
LAMINE CAMELS FROM THE LATE MIOCENE (EARLY HEMPHILLIAN) OF \\ THE CURRÉ FORMATION, SAN GERARDO DE LIMONCITO, COTO BRUS \\ CANTON, PUNTARENAS PROVINCE, COSTA RICA
}

\author{
César A. Laurito*1\&2 \& Ana L. Valerio ${ }^{3}$ \\ ${ }^{1}$ INA, Instituto Nacional de Aprendizaje \\ ${ }^{2}$ Investigador asociado-Departamento de Historia Natural, Museo Nacional de Costa Rica \\ ${ }^{3}$ Departamento de Historia Natural, Museo Nacional de Costa Rica \\ Apdo. postal 749-1000, San José; E-mail: avalerio@museocostarica.go.cr \\ *Autor para contacto: cesarlaurito@ice.co.cr
}

(Recibido: 23/09 /2015; aceptado: 25/02/2016)

\begin{abstract}
This work describes abundant fossil remains of a species of lamine camel, recovered from the San Gerardo de Limoncito local fauna in southern Costa Rica. The material corresponds to dental pieces and postcranial bones of Hemiauchenia vera Matthew, 1909 species, which is basically recognized by the biometry of the astragali and the anterior phalanx I, besides dental morphology. This new fossil record also permits to accurate the biochronologic age of the outcrop and its correlation with other Early Hemphillian localities of North America.

Keywords: Camelidae, Lamini, Hemiauchenia vera, Costa Rica, Upper Miocene, Curré Formation.

RESUMEN: En el presente trabajo, se describen abundantes restos fósiles de una especie de camello lamino procedentes de la fauna local de San Gerardo de Limoncito en el sur de Costa Rica. El material corresponde a piezas dentales y huesos postcraneales de la especie Hemiauchenia vera Matthew, 1909, la cual se reconoce, principalmente, por la biometría de los astrágalos y de la falange I anterior, además de la morfología dental. Este nuevo registro fósil permite afinar la edad biocronológica del afloramiento y su correlación con otras localidades fosilíferas del Henfiliano Temprano de América del Norte.

Palabras clave: Camelidae, Lamini, Hemiauchenia vera, Costa Rica, Mioceno Superior, Formación Curré.
\end{abstract}




\section{INTRODUCCIÓN}

Los camellos evolucionaron en América del Norte durante el Eoceno medio y permanecieron restringidos a ese subcontinente por cerca de 36 Ma; se diversificaron ampliamente en el Mioceno temprano, originando alrededor de 20 géneros e iniciaron su dispersión a Asia y Europa a través de Bering, hace apenas $6 \mathrm{Ma}$, y alcanzaron África en el Plioceno temprano (Morales et al., 1980; Pickford et al., 1993; Flynn, 1997; Honey et al., 1998; van der Made et al., 2002; Prothero \& Schoch, 2002; Titov \& Logvynenko, 2006; Titov, 2008a; Gibert et al., 2013; Likius et al., 2003); alcanzaron América Central Meridional en algún momento del Oligoceno Tardío (Rincón et al., 2012) e invadieron América del Sur hace unos 3,1- 3,2 Ma (Barrancalobiano), luego del establecimiento del Istmo de Panamá (Cione \& Tonni, 1995; Reguero et al., 2007). Se propone que las modernas tribus Lamini y Camelini divergieron hace $17 \mathrm{Ma}$, en el Mioceno temprano y se extinguieron en América del Norte durante el Pleistoceno tardío, los lamini persisten en la actualidad en América del Sur y los camelini en las regiones áridas del norte de África e interior de Asia (Pickford et al., 1993, 1995; Honey et al., 1998; Rybczynski et al., 2013), extinguiéndose en casi toda Europa en el Pleistoceno medio a excepción de algunas pocas localidades Pleistoceno tardías, limítrofes con Asia, donde se ha encontrado evidencia del arribo del camello bactriano desde Asia (Titov, 2008b; Titov com. escrita, 04/12/14).

La tribu Lamini (Webb, 1965) incluye las llamas actuales, vicuñas, guanacos y alpacas (cf. Hoffstetter, 1952). El registro fósil más antiguo de un lamino, está representado por el género Pleiolama descubierto en la Formación Ash Hollow de Nebraska en el Clarendoniano tardío y los estratos de Clarendon, Panhandle, Texas; en las Grandes Planicies de América del Norte (Webb \& Meachen, 2004), aproximadamente hace unos $11 \mathrm{Ma}$ (Meachen, 2005).

Los hallazgos de camélidos en América Central, aunque escasos, no son infrecuentes y abarcan un rango temporal relativamente amplio desde el Oligoceno tardío hasta el Pleistoceno temprano; los más antiguos provienen del Oligoceno tardío - Mioceno temprano (Arikareaano) de la Formación Las Cascadas en el área del Canal de Panamá, donde se registran las especies de camellos floridatragulinae Aguascalientia panamaensis y A. minuta (cf. Rincón et al., 2012). A estos hallazgos les sigue el registro de Protolabis cf. heterodontus (Cope), Procamelus sp. y Procamelus cf. grandis Gregory en la Formación Gracias (la presencia de estos Procamelinae en Honduras ya había sido previamente mencionados por Frick,1933) y Camelops sp. en la localidad de Yecoronte, ambas en Honduras (Frick, 1933; Olson \& McGrew, 1941; McGrew, 1942; Webb \& Perrigo, 1984), y Procamelus sp. cf. $P$. grandis en la localidad de Corinto, Departamento de Morazán en El Salvador, todas estas localidades están asignadas a una edad henfiliana temprana (Webb \& Perrigo, 1984). Más recientemente, Cisneros (2005) registra en la localidad de Tomayate, en El Salvador, los camelidae lamini Hemiauchenia macrocephala y Palaeolama sp., de edad Pleistoceno Temprano.

Por último, Pérez (2013), registra Palaeolama mirifica Simpson (1929) en el Lacustre de Palmares, Costa Rica, de edad pleistocénica (Irvingtoniano temprano) y Valerio (2010) en su tesis, mencionó la presencia de camellos laminos en el sur Costa Rica, identificados como Hemiauchenia sp. 1 y Hemiauchenia sp. 2, procedentes de la localidad de San Gerardo de Limoncito de edad Mioceno tardío.

El principal propósito de este trabajo es describir los restos de camellos fósiles recuperados en la localidad fosilífera de San Gerardo de Limoncito, previamente señalados; la misma se ubica en el cantón de Coto Brus, distrito $4^{\circ}$ Limoncito, provincia de Puntarenas, Costa Rica; en las coordenadas geográficas 851'19.6”N/8304'51.9”W (Fig. 1). Además de refinar la edad biocronológica de dicha localidad con base en los nuevos hallazgos.

El contexto sedimentológico en el que se recuperó el material del presente estudio es sublitoral, asociado a facies de abanicos deltaicos ("fan delta sequences"), caracterizados por conglomerados de intraclastos retrabajados de donde provienen la mayoría de los restos de vertebrados tanto terrestres como marinos y facies de areniscas finas a medias, infra litorales, con estructuras 

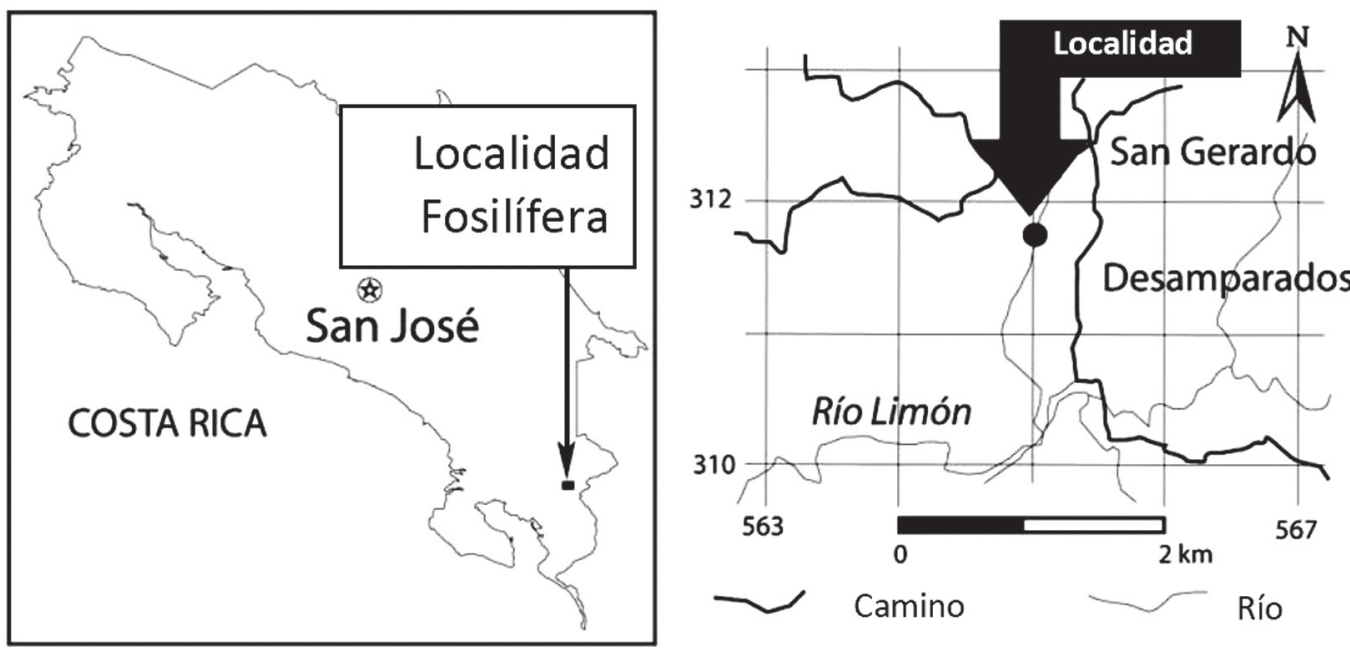

Fig. 1: Mapa de ubicación de la localidad fosilífera de San Gerardo de Limoncito.

sedimentarias bidireccionales y pequeños canales de marea. La fauna de vertebrados así como los escasos restos vegetales y la sedimentología, sugieren un ambiente de preservación, tipo estuario tropical, lo que se verifica con el diverso registro paleovertebradológico de cetáceos odontocetos, tortugas, cocodrilos, aves marinas, tiburones y rayas (Valerio, 2010; Valerio \& Laurito, 2008, 2012, 2013; Laurito et al., 2005), asociado a antiguos ecosistemas de sabanas arboladas con predominancia de pastizales en tierras bajas próximos a la costa, evidenciado por el registro de caballos, gomphotherios, tayasuidos y xenartras (Valerio, 2010; Laurito \& Valerio, 2005, 2010, 2013).

\section{MATERIALES Y MÉTODOS}

El material está depositado en la Colección de Fósiles de la Sección de Geología, del Museo Nacional de Costa Rica, San José, Costa Rica con los acrónimos CFM.

Los materiales descritos fueron comparados con varios especímenes de la Colección Nacional de Paleontología, en el Museo María del Carmen Perrilliat M. del Instituto de Geología, de la Universidad Nacional Autónoma de México, México D.F., Delegación Coyoacán.
Abreviaturas morfológicas: DPM/dpm molares deciduos, I/i incisivos, $\mathrm{C} / \mathrm{c}$ caninos, $\mathrm{P} / \mathrm{p}$ premolares y $\mathrm{M} / \mathrm{m}$ molares, en cada caso la letra en mayúscula corresponde a la posición superior y la minúscula a la posición inferior; en las notaciones $1 \mathrm{M}$ o p2, u otra cualquiera, el número a la derecha indica que el diente se ubica en el lado derecho y viceversa, p.e. la notación $3 \mathrm{dpm}$ indica que se trata de un tercer molar deciduo inferior izquierdo.

Abreviaturas institucionales: CFM, Colección de Fósiles del Museo Nacional de Costa Rica; IGCU, Instituto de Geología, Ciudad Universitaria; UNAM, Universidad Autónoma de México; UCMP, University of California Museum of Paleontology y UF, Vertebrate Paleontology Collection, Florida Museum of Natural History.

Abreviaturas adicionales: NALMA, North American land mammals ages o edades mamífero de América del Norte; B11 y B12 corresponden a Blancano temprano y tardío; $\mathrm{Cl1}, \mathrm{Cl} 2$ y $\mathrm{Cl} 3$ corresponden a Clarendoniano temprano, medio y tardío; Hh1, Hh2, Hh3 y Hh4 corresponden a Henfiliano temprano temprano, temprano tardío, tardío temprano y tardío tardío, respectivamente; RANCHO Rancholabreano e IRVING Irvingtoniano, PLEIST Pleistoceno; Gn marcas de Gnatichnia. 


\section{PALEONTOLOGÍA SISTEMÁTICA}

Clase Mammalia, Linnaeus 1758

Orden Artiodactyla, Owen 1848

Suborden Tylopoda, Illiger 1811

Familia Camelidae, Gray 1821

Subfamilia Camelinae Zittel, 1893

Tribu Lamini, Webb 1965

Género Hemiauchenia Gervais \& Ameghino 1880

Hemiauchenia vera Matthew, 1909

\section{Sinonimia}

Pliauchenia humphreysiana Cope en Wortman (1898), pág. 127.

Pliauchenia vera nueva especie en Matthew (1909), lista en pág. 117.

Tanupolama vera (Matthew) en Gregory (1942), pág. 367.

Tanupolama vera (Matthew) en Hibbard (1963), pág. 268, fig. 1.

Tanupolama vera (Matthew) en Webb (1965), pág. 40.

Hemiauchenia vera Matthew, 1909 en Webb (1974), págs. 199-200.

Hemiauchenia vera Matthew, 1909 en Breyer (1977), pág. 533, fig. 2A.

Hemiauchenia vera Matthew, 1909 en Dalquest (1980), págs. 115-117, figs.5 c-d, 6.

Hemiauchenia vera Matthew, 1909 en Montellano-Ballesteros (1989), págs. 361-363, fig. 2.

Hemiauchenia vera Matthew, 1909 en Honey et al. (1998), pág. 454.

Hemiauchenia vera Matthew, 1909 en Kelly (2000), págs. 15-16, fig. 7.

Pleiolama vera (Matthew, 1909), nueva combinación en Webb \& Meachen (2004), pág. 358, figs. 5-6.

Hemiauchenia vera, Matthew, 1909 en Jiménez-Hidalgo (2005), págs. 27- 36, cuadros 6-17; láms. III-V.

Hemiauchenia vera, Matthew, 1909 en May et al. (2011), págs. 51-52; figs. 58 y 60; cuadro 12.

Hemiauchenia vera, en Carranza-Castañeda et al. (2013), pág. 35, cuadro 12.

\section{Diagnosis}

La especie Hemiauchenia vera Matthew, 1909 es ligeramente más pequeña que Pleiolama mckennai Webb \& Meachen, 2004, pero presenta una larga diastema anterior a los molares superiores $(44 \mathrm{~mm})$ y una amplia sínfisis $(36 \mathrm{~mm}$ de ancho entre incisivos). El P3 es más corto, con la porción anterolingual de la medialuna lingual reducida. En la mandíbula el p1 está parcialmente suprimido y el p3 es vestigial. Esta especie es similar en muchos aspectos a Hemiauchenia blancoensis pero más pequeña, con incisivos inferiores más delicados, una corta diastema y molares de corona baja con poco cemento (cf. Webb \& Meachen, 2004).

\section{Material referido}

El material analizado en el presente trabajo correspondiente a la especie Hemiauchenia vera Matthew, 1909, está constituido por:

Dientes deciduos: el CFM-5242 es un posible dpm3 y el CFM-3729 es un dpm4.

Incisivos inferiores: el CFM-1865 un $2 \mathrm{i}$ y el CFM-3649 un i2; caninos superiores: el CFM-3837 un C izquierdo y CFM-3838 un C derecho; premolar: el CFM-1672 un 3 PM; molares superiores: el CFM-2198 un $1 \mathrm{M}$, dos $2 \mathrm{M}$ el CFM-1671 y el CFM-2877; tres fragmentos de molares de posición incierta CFM-2197, CFM-2613 y CFM-3006; molares inferiores: el CFM-1673 un m1, el CFM-1925 un m2, el CFM-3215 un ramo mandibular con $1 \mathrm{~m}-2 \mathrm{~m}$, el CFM-3845 un m3 y el CFM-2612 parte de una hemimandíbula con $\mathrm{m} 1-\mathrm{m} 3$.

\section{Miembros anteriores}

Radios: los CFM-3063 y CFM-3843 corresponden a fragmentos proximales derechos; los CFM-1106, CFM-1520, CFM-2479, CFM2611 y CFM-2836 corresponden a fragmentos proximales izquierdos, el CFM-1107 corresponden a un fragmento proximal izquierdo. Ulnas: 
los CFM-1194 y CFM-3075 son fragmentos derechos. Huesos carpales: los CFM-3097 y CFM-3487 son escafoides; el CFM-3559 es un unciforme. Metapodiales: los CFM-2153, CFM2154, CFM-2155 y CFM-2608 son superficies articulares distales o cóndilos; los CFM-1001, CFM-1002, CFM-1003, CFM-2034, CFM-3060 y CFM-3296 corresponden a metapodiales. Falanges: El CFM-1863 es una falange I completa; los CFM-1093, CFM-2483, CFM-2487 y CFM-2488 son fragmentos proximales de falanges I posiblemente de individuos juveniles; los CFM-2491, CFM-2609 y CFM-3099 son fragmentos proximales de falange I; el CFM-2783 es un fragmento distal de falange I; los CFM-1864 y CFM-2638 corresponden a falanges II y el CFM2489 a un fragmento proximal de falange II.

\section{Miembros posteriores}

Fémures: el CFM-1006 es un fragmento proximal derecho; el CFM-2999 corresponde a una cabeza de fémur; los CFM-3482 y CFM-3647 son fragmentos distales derechos y el CFM-1706 es un fragmento distal izquierdo. Tibias: los CFM1648, CFM-2492 y CFM-2798 corresponden a fragmentos proximales derechos; los ejemplares CFM-2492 y CFM-2798 posiblemente correspondan a ejemplares juveniles; los CFM-3059 y CFM-3104 corresponden a fragmentos proximales izquierdos de posibles individuos juveniles; los CFM-1715, CFM-2180, CFM-3062, CFM3105 y CFM-3730 corresponden a fragmentos distales derechos y los CFM-1794, CFM-2801, CFM-2838, CFM-3061, CFM-3556 y CFM-3789 a fragmentos distales izquierdos. Huesos tarsales: el CFM-1908 es un entocuneiforme. Astrágalos: los CFM-1004, CFM-1113 y CFM-2835 son derechos; el CFM-1113 posiblemente de un juvenil y los CFM-1005, CFM-1444, CFM-1521, CFM-1691, CFM-2156, CFM-2179 y CFM-3558 son izquierdos; el CFM-1444 se encuentra muy erosionado. Calcáneos: el CFM-1229 es un ejemplar completo y los CFM-2177 y CFM-2551 son fragmentos, todos derechos. El CFM-2954 es un ejemplar completo y los CFM-1303, CFM-2550,
CFM-2626 y CFM-3648 son fragmentos, todos izquierdos. Metatarsos: los CFM-2036, CFM2894, CFM-3272, CFM-3557 y CFM-3803 son fragmentos proximales derechos; los CFM-1638 y CFM-1690 son fragmentos proximales izquierdos.

\section{Descripción del material}

\section{Dientes deciduos}

El posible dpm3 (cf. los criterios dados por Loring \& Wood, 1969 para la dentición decidua) está muy desgastado y roto en su porción mesial, el esmalte es liso, se conservó solo una raíz de forma cilíndrica; el extremo labial es recto mientras que en el lingual se observa un pliegue de esmalte (fig. 2B).

El dpm4 tiene tres selenes que aumentan su tamaño hacia la porción posterior, con esmalte delgado y poco desgaste; las fosetas tienen forma de media luna ligeramente abierta, el anterocónido, protocónido e hipocónido son angulares, lo mismo que el metacónido y el entocónido (fig. 3). Se observa el alveolo para el dpm3.

\section{Incisivos}

Los incisivos tienen forma espatulada, la superficie oclusal es de forma ovalada con desgaste, la corona es ligeramente más pequeña que la raíz, con el límite entre ambos muy marcado. El esmalte del $2 \mathrm{i}$ (fig. 2 C) es liso, además, presenta el extremo de la raíz rota; mientras que en el i2 (fig. 2 D) se observa crenulación en algunos sectores.

\section{Caninos}

Los caninos tienen forma de media luna, ligeramente comprimida en sentido vestíbulo-lingual. La corona presenta esmalte liso con un borde posterior afilado y su altura abarca una tercera parte de la altura total del diente, siendo de 13,20 mm para el ejemplar CFM-3837 (fig. 4A) y de 10,37 mm para el CFM-3838 (fig. 4B), el límite entre 
la raíz y la corona es apenas perceptible. El ejemplar CFM-3837 mide 33,70 mm de longitud y es de color gris oscuro; mientras que el CFM-3838 mide $28,56 \mathrm{~mm}$, es de color gris claro, con el extremo apical parcialmente roto.

\section{Premolar}

El 3PM con contorno oclusal triangular y foseta con forma de media luna muy abierta (fig. 2A). El ejemplar solo conservó la corona, no tiene raíz, el esmalte es liso; las medidas se indican en el apéndice 1.

\section{Molares superiores}

Las medidas de los molares superiores se indican en el apéndice 1. El 1M (fig. 5), presenta superficie oclusal triangular, con las fosetas abiertas en forma de media luna. Las costillas están rotas, el esmalte de la corona es liso y la raíz se preservó parcialmente.

Los 2M (figs. 6 y 7) tienen la superficie oclusal de forma triangular, con las fosetas abiertas en forma de media luna, de las cóstulas sólo se preservó el metastilo el cual es prominente y angular, el esmalte presenta crenulación en algunos sectores, con las raíces parcialmente preservada.

\section{Molares inferiores}

Las medidas de los molares inferiores se indican en la apéndice 1. El m1 tiene la superficie oclusal rectangular, la corona con el esmalte liso, las fosetas son abiertas en forma de media luna. El parastilo es la única cóstula que se preservó y es de forma angulosa poco pronunciada. El protocónido y el hipocónido son triangulares (fig. 8B).

El ramo mandibular con 1m-2m (fig. 9); en el $1 \mathrm{~m}$ las fosetas tienen poco desgaste, el metacónido y el entocónido son ligeramente angulares, el parastílido, el metastílido y el entostílido están ligeramente desarrollados; el protocónido y el hipocónido son triangulares. El $2 \mathrm{~m}$ no tiene desgaste, el metacónido y el entocónido son poco angulares casi planos; el parastílido, el metastílido y el entostílido no están desarrollados, el protocónido y el hipocónido son triangulares. El 4pm no se preservó a excepción de sus alveolos (fig. 9A).

El m2 está muy desgastado, tiene el esmalte delgado, con poca crenulación (fig. 8A). La superficie oclusal es rectangular, las fosetas tienen forma de media luna cerrada, el metacónido y entocónido son ligeramente angulares, el parastílido y el entostílido no se conservaron, el metastílido está ligeramente desarrollado; el protocónido e hipocónido son triangulares.

El m3 está roto a la altura del metastilido, por lo que el ejemplar está dividido en dos. La raíz se preservó parcialmente, el esmalte de la corona es liso, el protocónido y el hipocónido son triangulares; mientras que el hipoconulido es ligeramente redondeado.

El fragmento de mandíbula está muy deteriorado, posiblemente corresponda a un $\mathrm{m} 1-\mathrm{m} 3$. El $\mathrm{m} 1$ está deteriorado, el $\mathrm{m} 2$ tiene la superficie oclusal rectangular, las fosas abiertas con forma de media luna, el protocolo y el hipocono de forma triangular. El m3 no está eruptado.

\section{Elementos de post-cráneo}

Se recuperaron elementos de los miembros locomotores anteriores y posteriores que se describen a continuación (Apéndice 2), para lo que se utiliza la nomenclatura de Webb (1965).

\section{Miembros anteriores}

\section{Radios}

Los fragmentos proximales de radio se encuentran dentro de las medidas aportadas por Dalquest (1980) para Hemiauchenia vera. El fragmento 

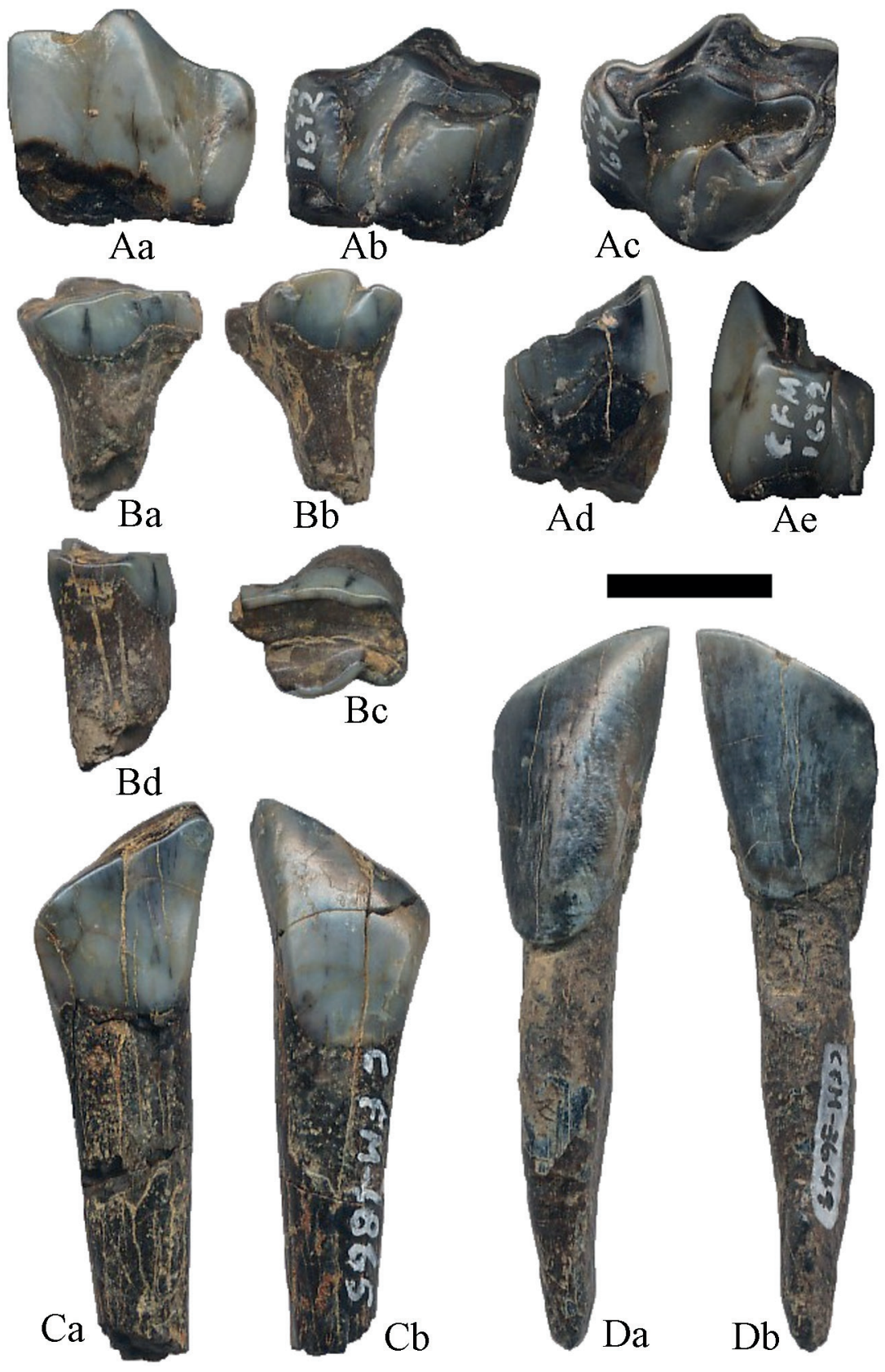

Fig. 2: Hemiauchenia vera Matthew, 1909: A. CFM-1672 un 3PM, B. CFM- 5242 un dpm3, C. CFM-1865 un 2i y D. CFM-3649 un i2; a en vistas labial, b lingual, c oclusal, d mesial y e distal. Escala gráfica $1 \mathrm{~cm}$. 


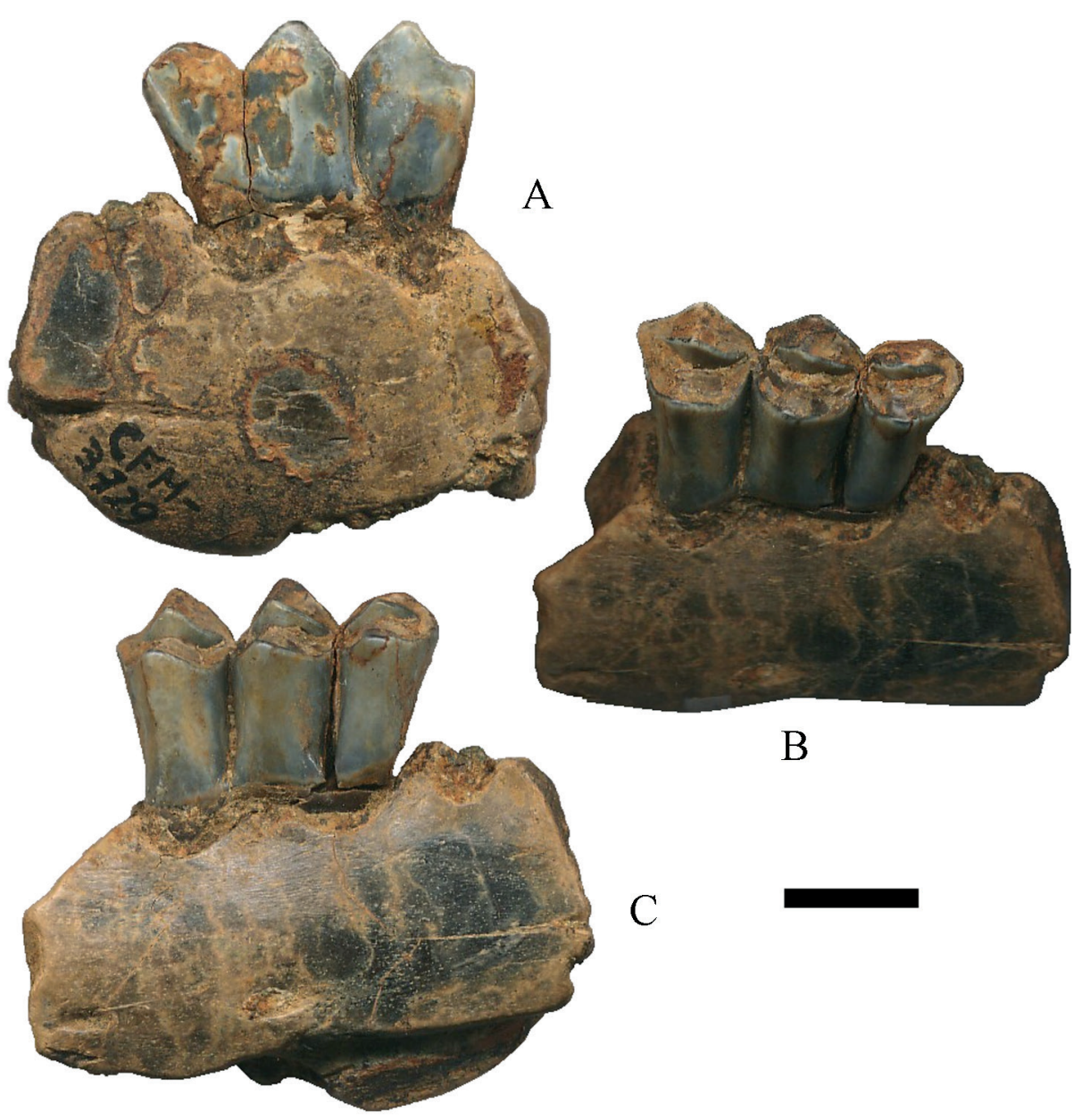

Fig. 3: Hemiauchenia vera Matthew, 1909, ejemplar CFM- 3729, un dpm4; en vistas A. labial, B. oclusal y C. lingual. Escala gráfica $1 \mathrm{~cm}$.

proximal derecho muestra marcas de Gnatichnia posiblemente de cocodrilo, con la tuberosidad lateral y la rugosidad bicipital apenas insinuadas, el foramen interóseo es elongado (fig. 10A). Mientras que los fragmentos de radio izquierdo (fig. 10B y 10C) presentan las superficies lisas con preservación regular, el foramen interóseo es elongado.

\section{Ulnas}

Dos fragmentos de ulnas derechas (fig. 11). El olécranon está comprimido lateralmente con la tuberosidad redondeada, el ejemplar ilustrado en la fig. 11B está roto a la altura del proceso anconal. 


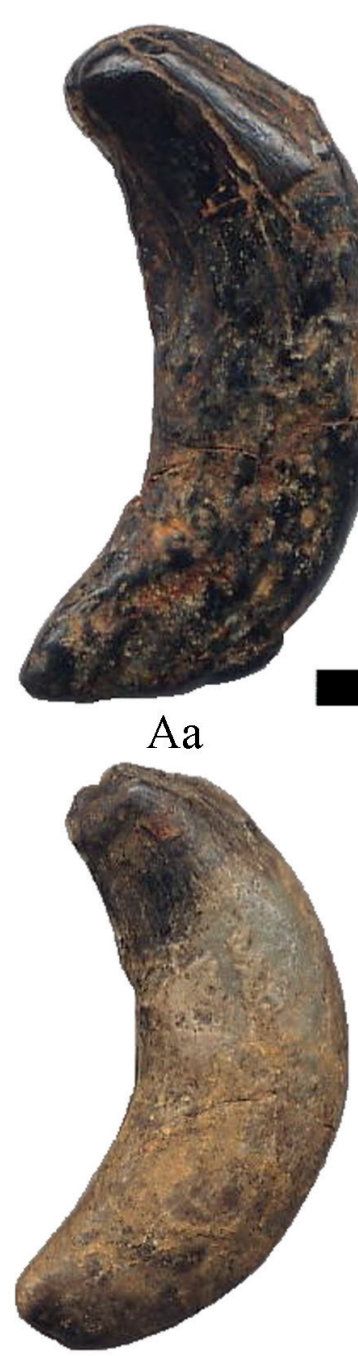

$\mathrm{Ba}$

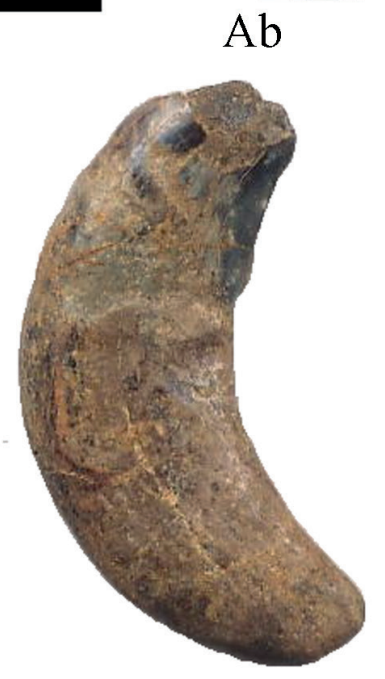

$\mathrm{Bb}$

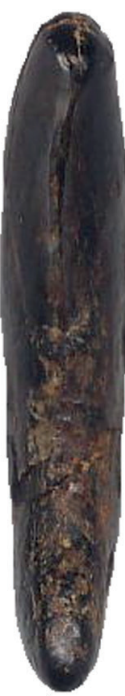

Ac

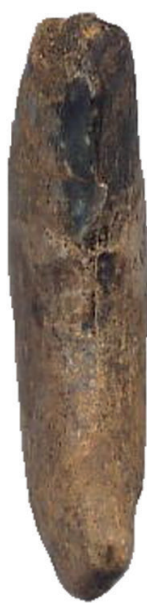

$\mathrm{Bc}$

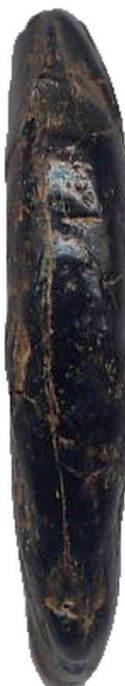

Ad

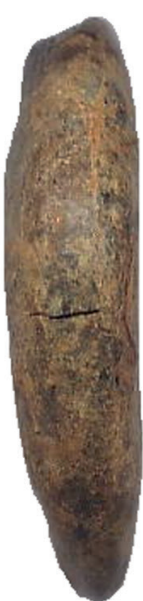

$\mathrm{Bd}$

Fig. 4: Hemiauchenia vera Matthew, 1909: caninos superiores A. CFM-3837 y B. CFM-3838, en vistas a labial, b lingual, c comisural y d mesial. Escala gráfica $1 \mathrm{~cm}$.

\section{Huesos carpales}

\section{Escafoides}

Los escafoides (fig. 12A-B) presentan buena conservación, son gruesos dorso-palmarmente y estrechos latero-medialmente. La superficie proximal, que se articula con el radio, es ligeramente cóncava latero-medialmente con una pequeña faceta inclinada en sentido dorsal, la superficie distal presenta una gran faceta dorsal plana. La superficie palmar es lisa, de forma cóncava alargada en sentido distal; mientras que la superficie dorsal, también lisa, es de forma 

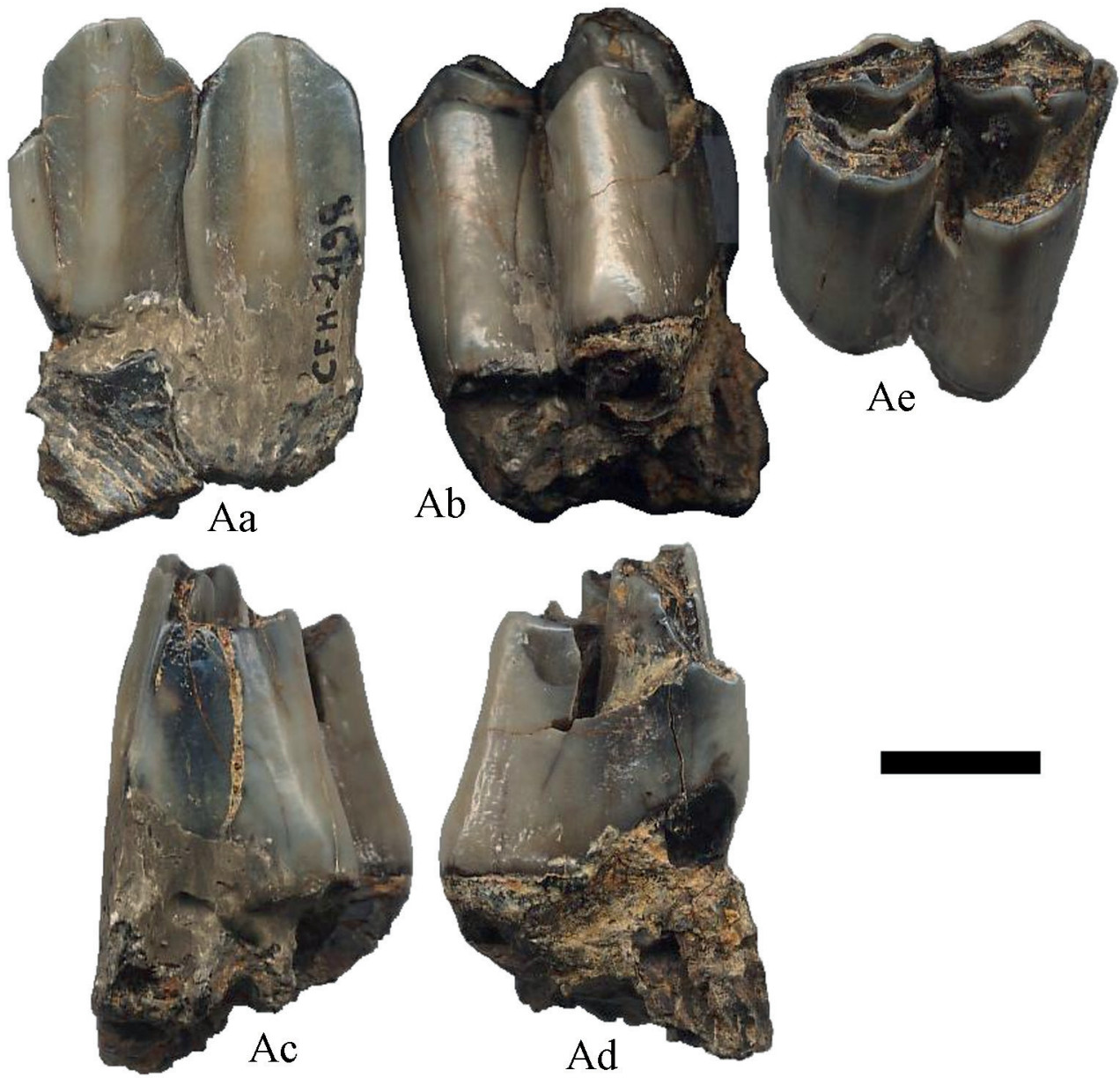

Fig. 5: Hemiauchenia vera Matthew, 1909, CFM-2198 un 1M en vistas a labial, b lingual, c distal, d mesial y e oclusal. Escala gráfica $1 \mathrm{~cm}$.

cóncava, ligeramente ovalada. Las caras laterales son rugosas, ligeramente convexas y el medial presenta un pequeño tubérculo.

\section{Unciforme}

El unciforme (fig. 12C) está bien preservado, en su superficie proximal se observa la faceta cuneiforme que corresponde a una faceta articular alargada, que cambia de una concavidad débil en el extremo antero-medial a una convexidad que se curva muy abajo en la cara postero-lateral. La faceta lunar está separada de la faceta cuneiforme por una cresta, presenta una inclinación poco pronunciada en sentido medial, es relativamente corta y termina posteriormente en una fosa profunda.

La cara distal presenta una faceta amplia, ligeramente cóncava, que no se extiende en el proceso unciforme, este último redondeado $\mathrm{y}$ bien conservado. Las superficies lateral y anterior son continuas y convexas, mientras que la posterior presenta una fosa profunda que se amplia en sentido distal. 


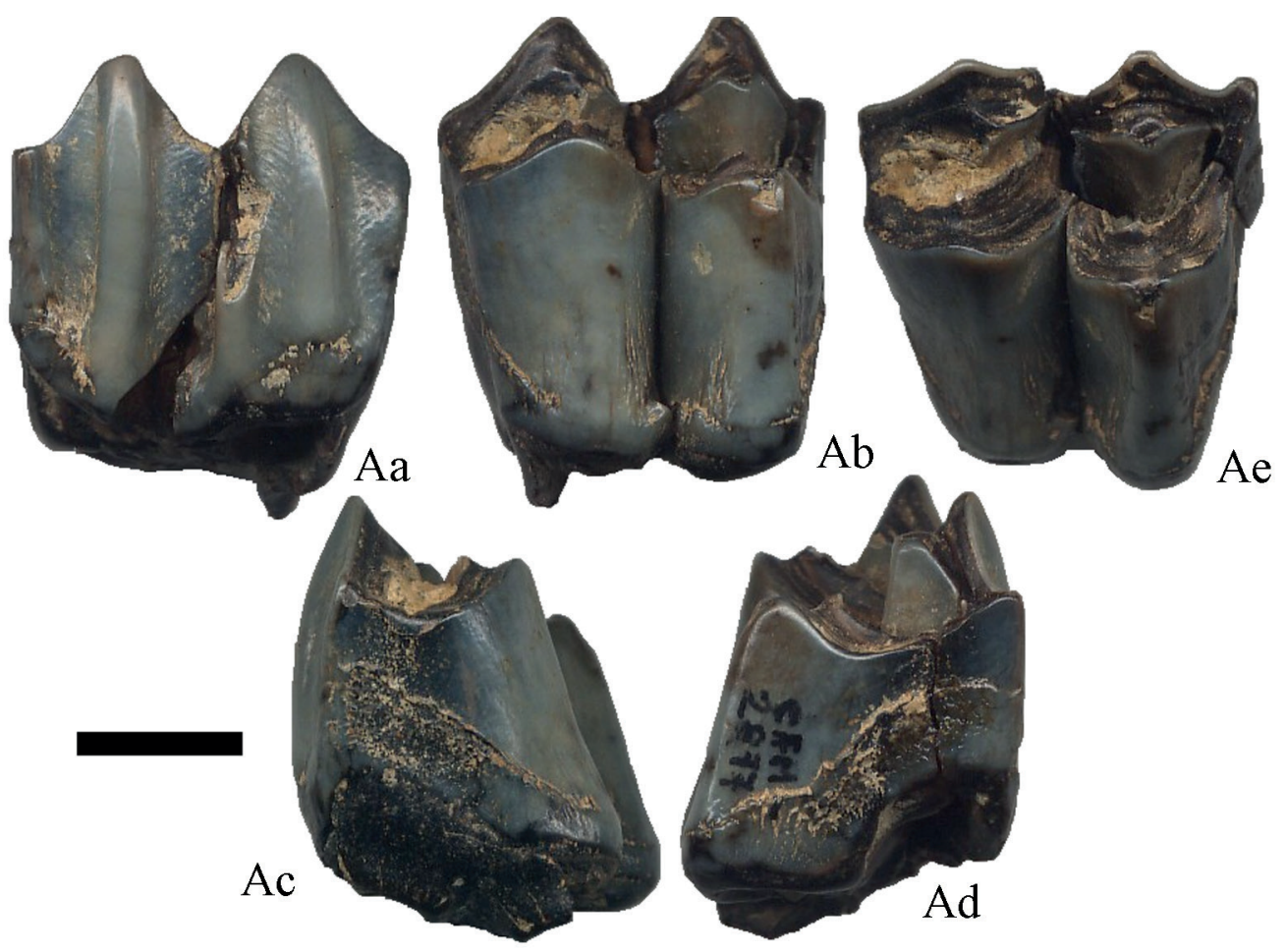

Fig. 6: Hemiauchenia vera Matthew, 1909, CFM-2877 un 2M en vistas a labial, b lingual, c distal, d mesial y e oclusal. Escala gráfica $1 \mathrm{~cm}$.

\section{Metapodiales}

Las superficies articulares distales o cóndilos por lo fragmentado del material es imposible determinar si corresponden a metatarsos o metacarpos. Los ejemplares presentan regular preservación, la superficie de la tróclea es lisa y algunos de ellos tienen marcas de Gnatichnia en la cara anterior (figs. 13B-C, 14B-C).

Los metapodiales (figs. 13, 14, 15A, 15B) corresponden a extremos distales fragmentados. Se caracterizan por tener la superficie anterior ligeramente cóncava con un canal longitudinal visible y somero que se profundiza y separa los extremos distales, estos últimos poco divergentes. Su superficie posterior es plana, atravesada por un canal longitudinal más visible que en la superficie anterior.

\section{Falanges}

La falange I (fig. 15C) tiene buena conservación, la superficie articular proximal es dorsoventralmente cóncava, con una depresión ventral para la quilla metapodial; la diáfisis es recta y delgada, la superficie articular distal es corta con una tróclea estrecha. Presenta la cicatriz del ligamento suspensor en forma de "W", que es diagnóstico del género Hemiauchenia (Meachen, 2005). Las medidas se indican en los apéndices 2 y 5 del apéndice; se asigna a $H$. vera por comparación con las medidas aportadas por Meachen (2003).

Los fragmentos proximales de falanges I (fig. 16) posiblemente de ejemplares juveniles, tienen la faceta articular proximal dorso-ventralmente cóncava, con una depresión ventral para la quilla metapodial, la diáfisis es recta y esbelta. La superficie 


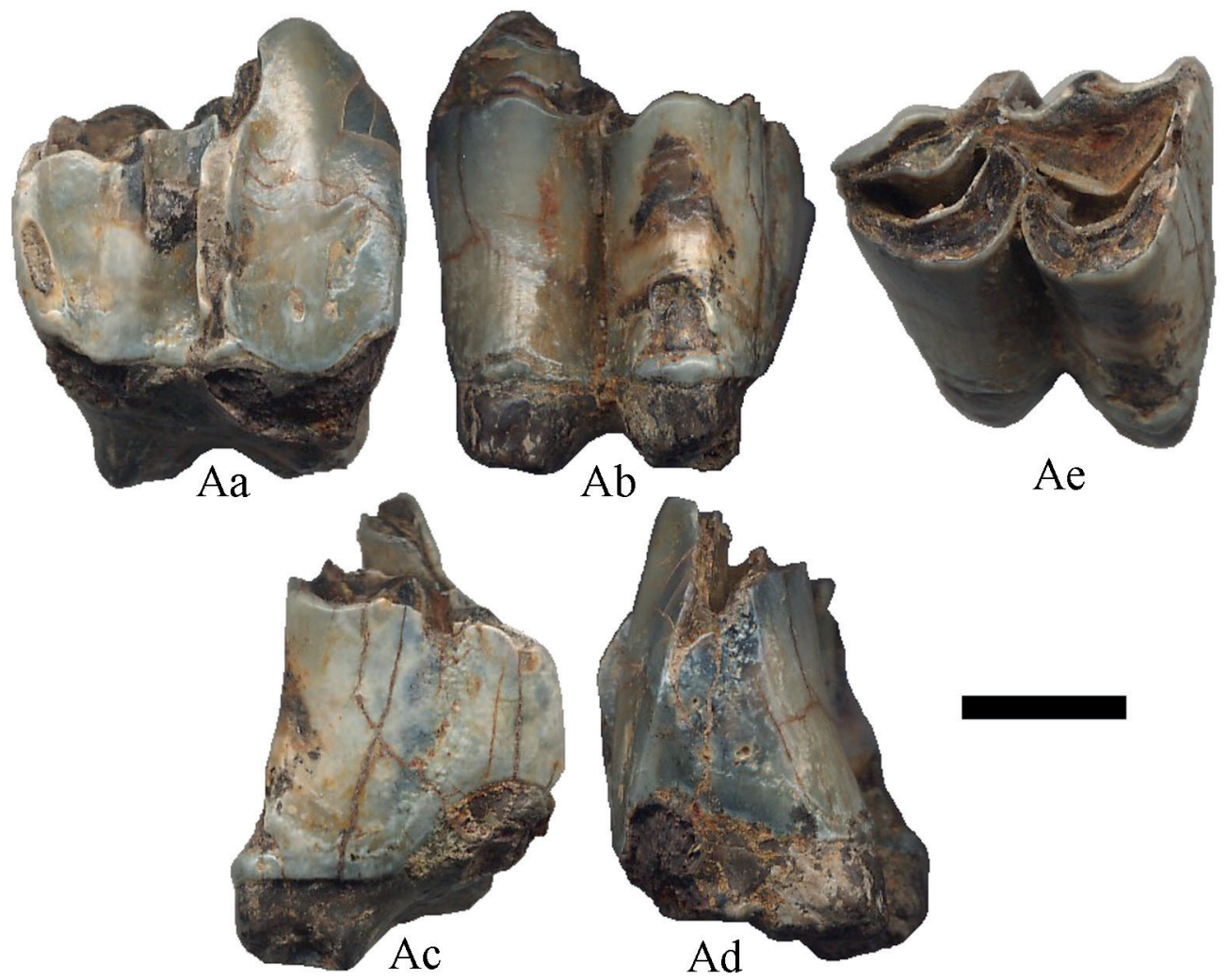

Fig. 7: Hemiauchenia vera Matthew, 1909, CFM-1671 un 2M en vistas a labial, b lingual, c distal, d mesial y e oclusal. Escala gráfica $1 \mathrm{~cm}$.

posterior es ligeramente cóncava y la superficie dorsal convexa. En el ejemplar ilustrado en la fig. 16C, se observan marcas de Gnatichnia posiblemente de cocodrilo. El ejemplar CFM-2609 (fig. 17A) tiene el ligamento suspensor en forma de "W" no simétrica; mientras que en el CFM-3099 (fig. 17B), el ligamento suspensor tiene forma de "W" simétrica. El único fragmento distal de falange I que se conservó, tiene regular conservación y tróclea estrecha. Las falanges II (fig. 17 C-D) con buena conservación, la faceta articular proximal es cóncava antero-posteriormente y la tróclea distal estrecha.

\section{Miembros posteriores}

\section{Fémures}

El fragmento proximal derecho (fig. 18A), presenta la cabeza redondeada y muestra buena preservación, la fóvea es alargada y profunda; el trocánter menor es prominente y forma una cresta vertical alargada, la zona del trocánter mayor está rota. La fosa inter-trocantérica es profunda y está abierta, porque no se preservó la cresta oblicua.

En el fragmento distal izquierdo (fig. 18B), el epicóndilo medio es bulboso, la fosa intercondiloide 


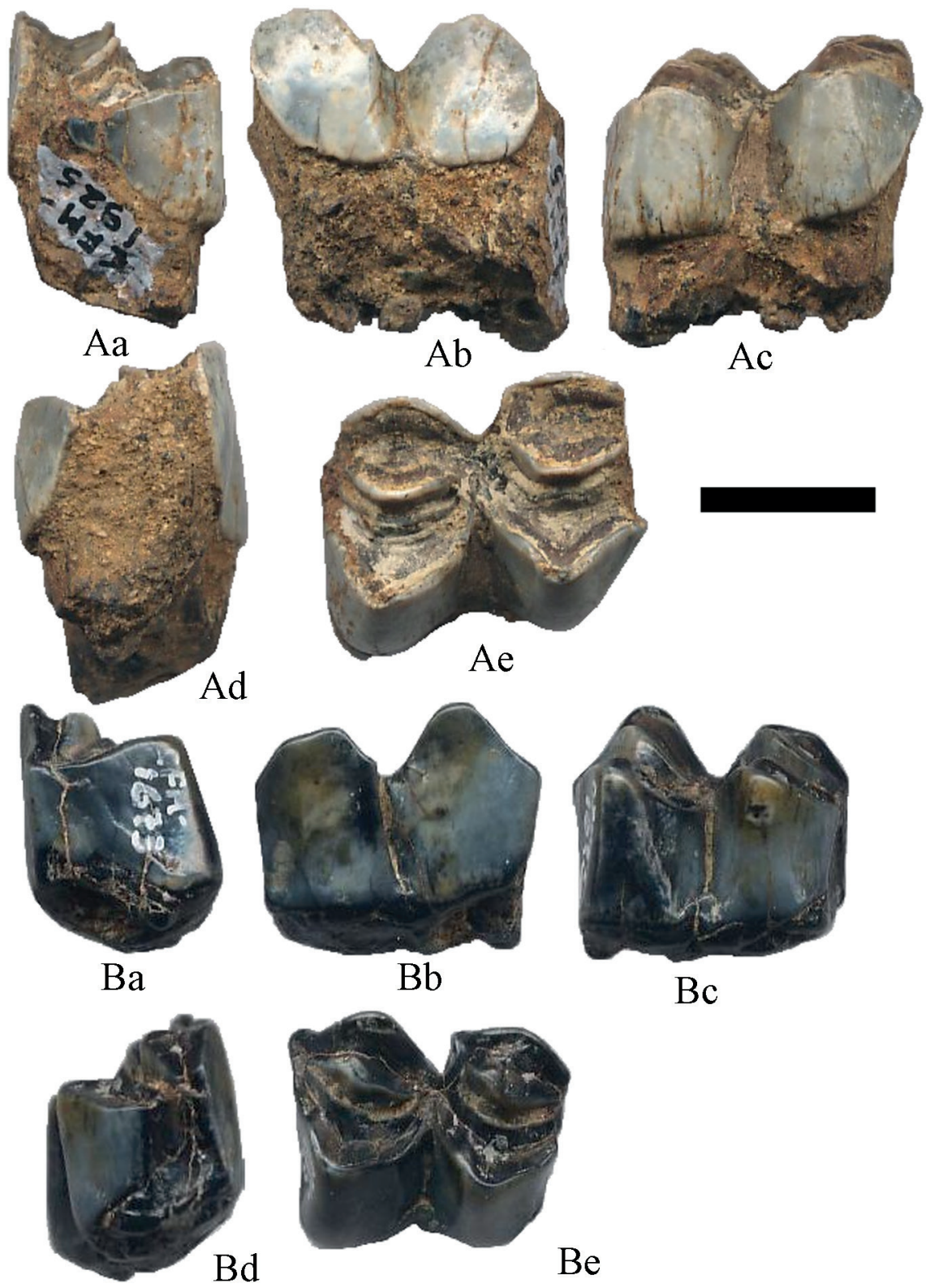

Fig. 8: Hemiauchenia vera Matthew, 1909: A. CFM-1925 un m2 y B. CFM-1673 un m1 en vistas a distal, b labial, c lingual, d mesial y e oclusal. Escala gráfica $1 \mathrm{~cm}$. 


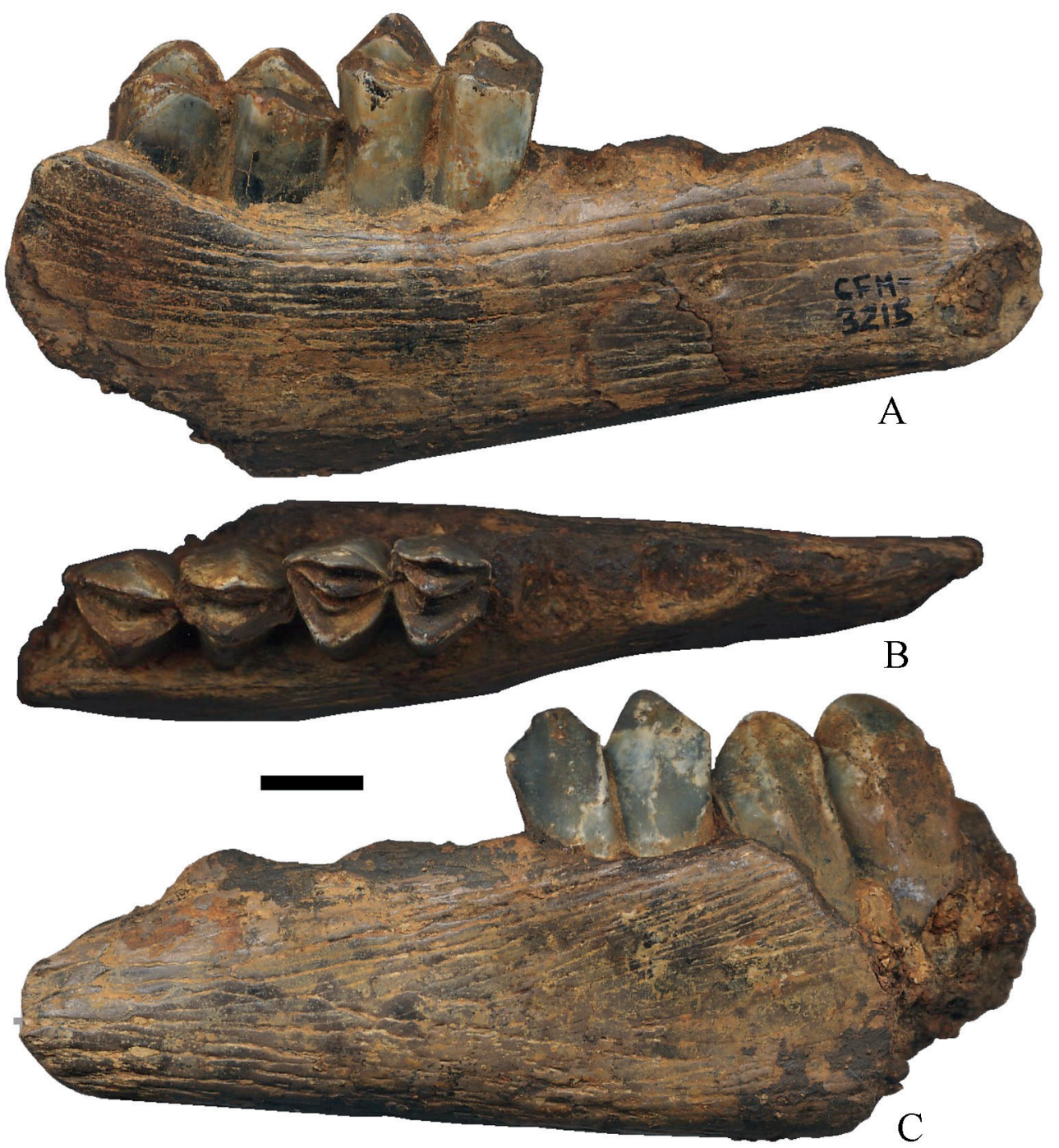

Fig. 9: Hemiauchenia vera Matthew, 1909, CFM- 3215 un fragmento de hemimandíbula con 1m-2m, en vistas a lingual, b oclusal y c. labial. Escala gráfica $1 \mathrm{~cm}$.

se cierra en ángulo recto, la superficie de la patella es próximo-distalmente convexa y cóncava lateralmente, presenta una profunda zona ahuecada en el extremo proximal de la tróclea patelar. Los dos ejemplares presentan numerosas marcas de Gnatichnia originadas posiblemente por cocodrilos.
Tibias

El fragmento proximal de tibia derecha está roto a la altura del foramen nutricio (fig. 19A), el cóndilo medial presenta una superficie lisa y cóncava, mientras que el cóndilo lateral está roto, 


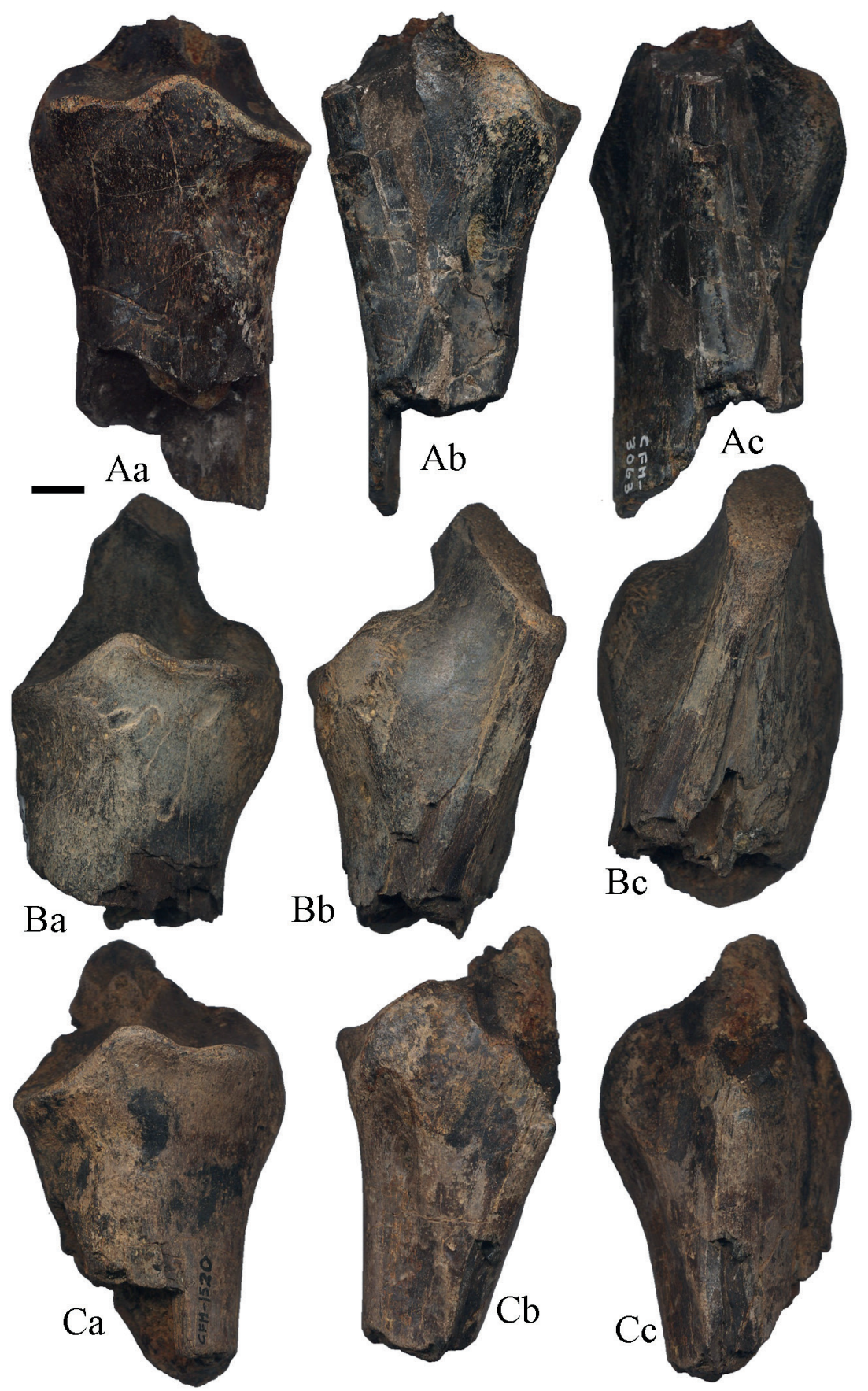

Fig. 10: Hemiauchenia vera Matthew, 1909, radios: A. CFM-3063 fragmento proximal derecho; B. CFM-1106 y C. CFM-1520, fragmentos proximales izquierdos; en vistas: a anterior, b lateral y c posterior. Escala gráfica $1 \mathrm{~cm}$. 

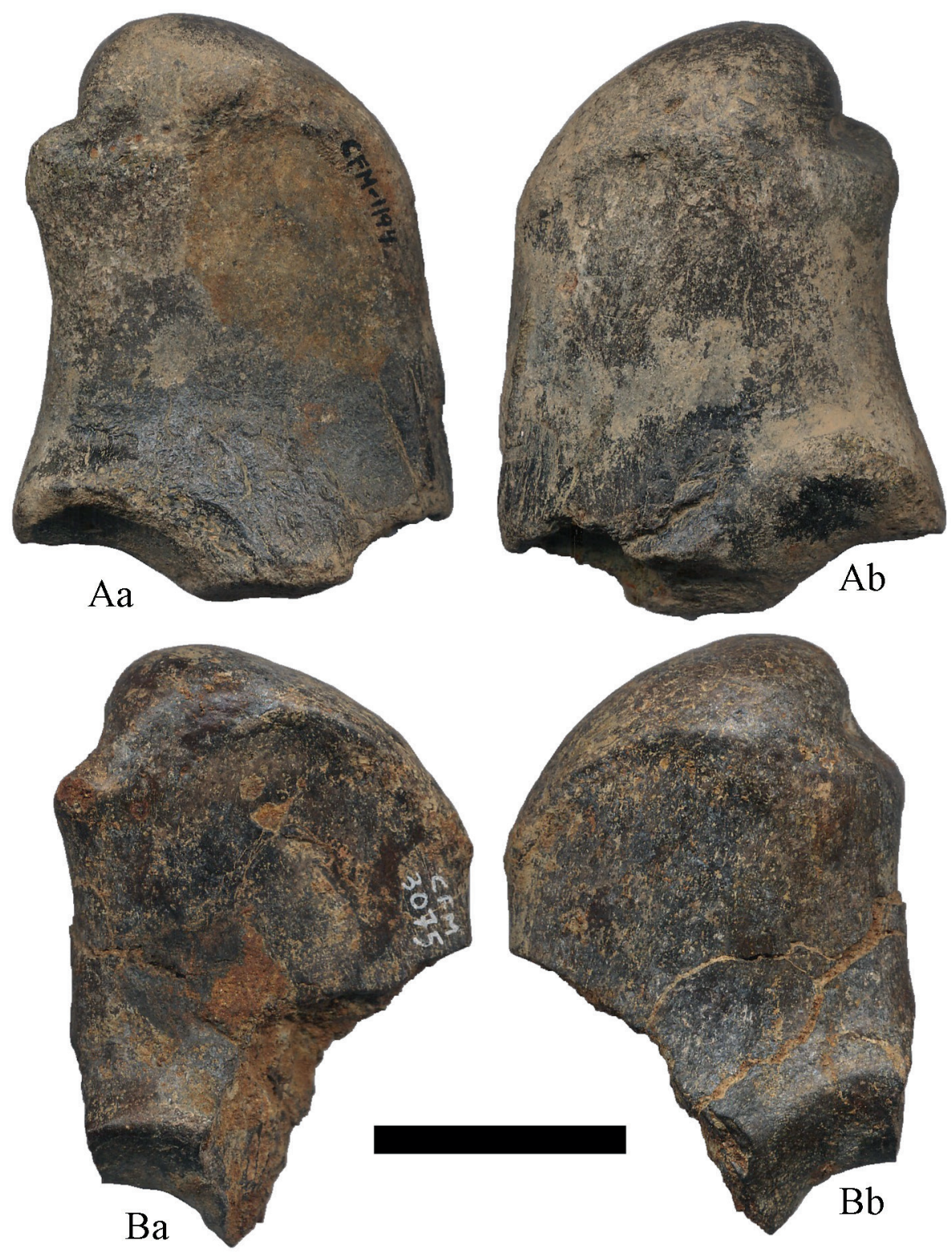

Fig. 11: Fragmentos de ulnas derechas de Hemiauchenia vera Matthew, 1909: A. CFM-1194 y B. CFM-3075 en vistas a medial y b lateral. Escala gráfica $3 \mathrm{~cm}$.

lo que imposibilita comparar las dos superficies, la cresta cnemial o tibial es comprimida lateralmente presentando una concavidad profunda en la parte media de la cara anterior de la tibia.

Los fragmentos proximales ilustrados en las figs. $19 \mathrm{~B}, 19 \mathrm{C}$ y 20 , se atribuyen a ejemplares juveniles ya que no se conservan los cóndilos lateral y medial, el forámen nutricio es alargado y se profundiza ventralmente, la cresta cnemial o tibial se comprime lateralmente presentando una concavidad profunda en la parte media de la cara anterior de la tibia. 


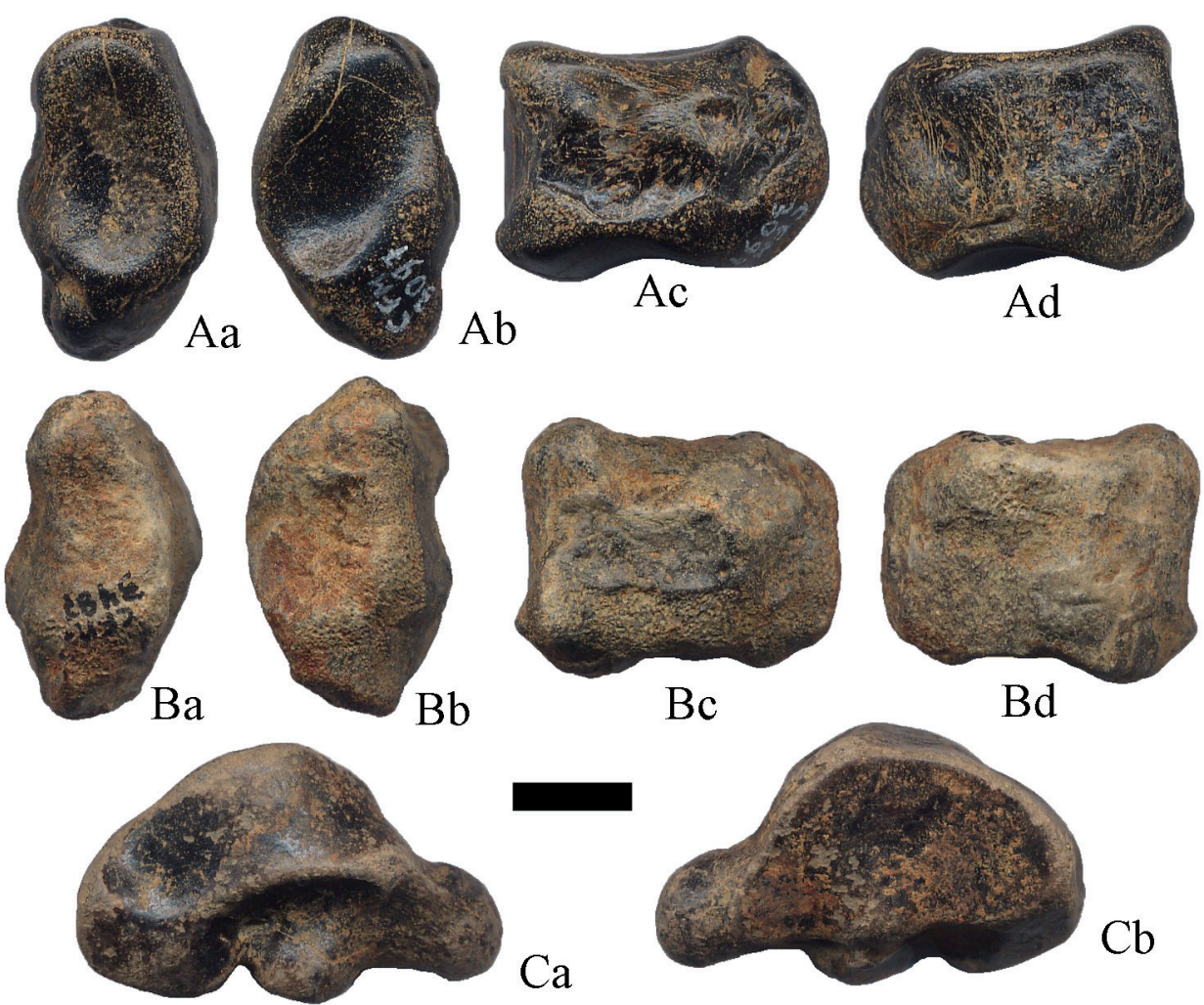

Fig. 12: Huesos carpales, escafoides de Hemiauchenia vera Matthew, 1909: A. CFM-3097 y B. CFM-3487 y C. CFM-3559 unciforme, en vistas: a dorsal, b ventral, c latera y d medial. Escala gráfica $1 \mathrm{~cm}$.

Los extremos distales de las tibias izquierdas (fig. 21) tienen buena preservación, las facetas lateral y medial presentan el mismo ancho y la faceta medial más profunda que la lateral, ambas facetas están separadas por una lengua prominente y roma que se profundiza en su parte media. La porción posterior de la ranura del peroné es mucho más grande que la porción anterior, lo que es característico para Camelops y Lama (Webb, 1965).

\section{Huesos tarsales}

\section{Entocuneiforme}

Es un hueso pequeño bien preservado (fig. 28B), verticalmente alargado con tres facetas. La faceta distal es convexa, angosta y expandida en el extremo lateral. Mientras que las dos facetas proximales, una de ellas para el escafoides, es grande, cóncava y orientada horizontalmente; mientras que la otra faceta para el ectomesocuneiforme, es casi plana.

\section{Astrágalos}

Los astrágalos (figs. 22-23-24) tienen la superficie lateral articular sigmoidea o en forma de "S" con tres pequeñas facetas, el cóndilo lateral es más alto y más estrecho que el cóndilo medial, en el extremo plantar no sobresale la superficie sustentacular. La fosa subsustentacular está bien desarrollada y de forma elongada. En el ejemplar de la fig. 22A, se preservó la cara distal astragalar y parte de la faceta parasustentacular, así como la saliente fibular; la superficie medial está bien preservada, se observa una desarrollada cresta 


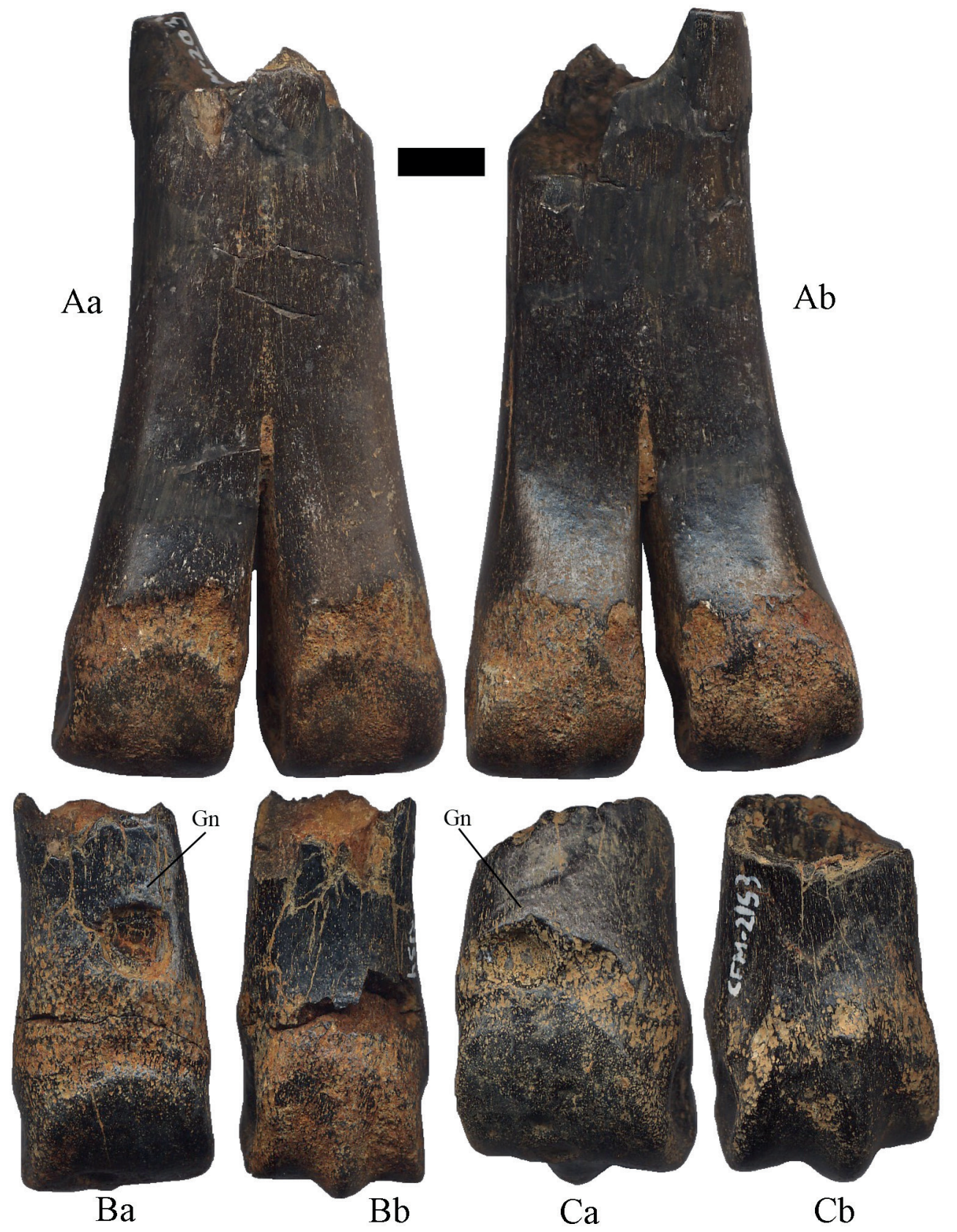

Fig. 13: Metapodiales de Hemiauchenia vera Matthew, 1909: A. CFM-2034, B. CFM-2154 y C. CFM-2153, en vistas a anterior $\mathrm{y} \mathrm{b}$ posterior. Escala gráfica $1 \mathrm{~cm}$. 


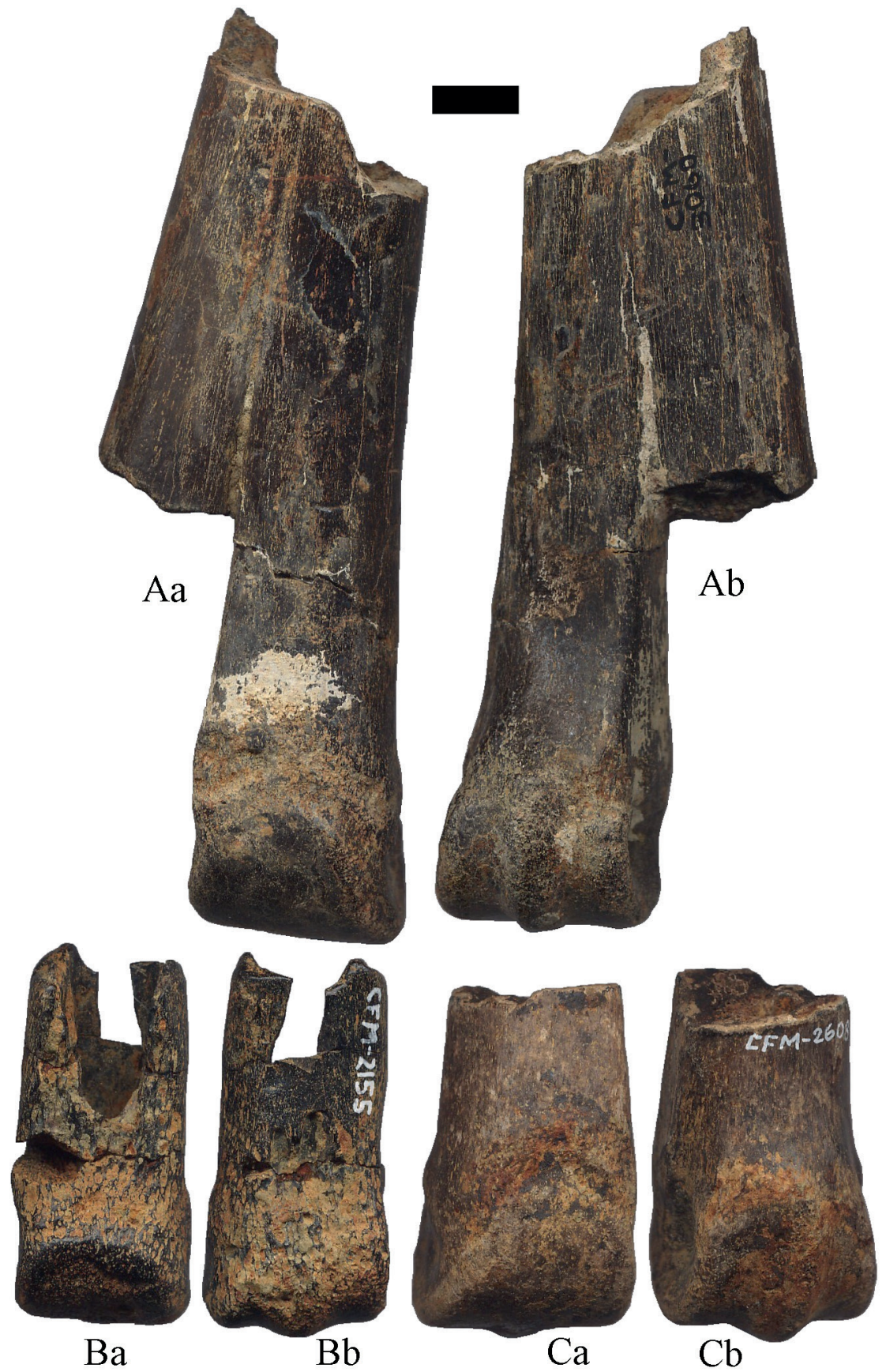

Fig. 14: Metapodiales de Hemiauchenia vera Matthew, 1909: A. CFM-3060, B. CFM-2155 y C. CFM-2608 en vistas a anterior y b posterior. Escala gráfica $1 \mathrm{~cm}$. 

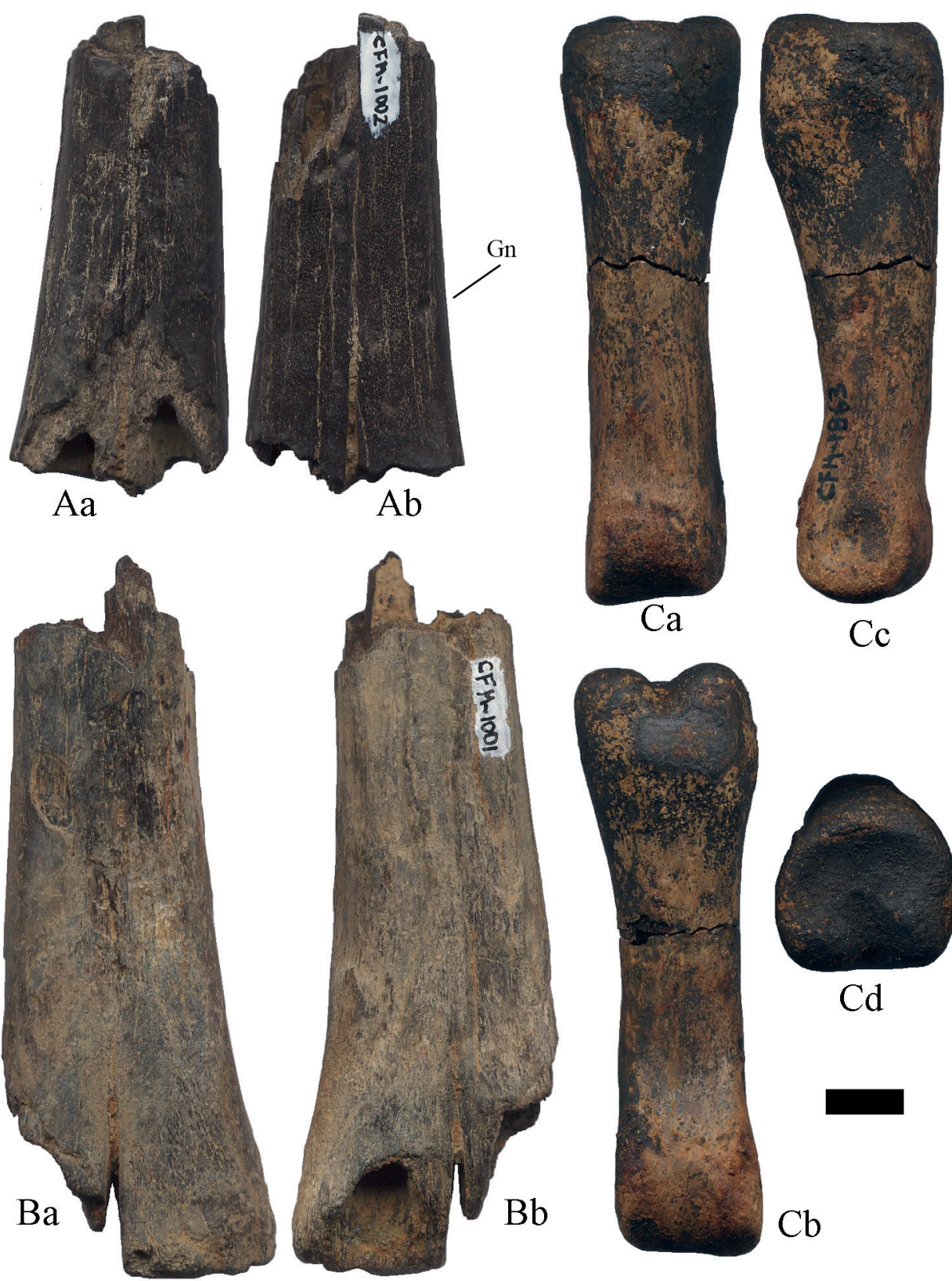

$\mathrm{Cd}$

Fig. 15: Hemiauchenia vera Matthew, 1909. Metapodiales: A. CFM-1002 y B. CFM-1001; el CFM-1863 es una falange I; en vistas $\mathrm{a}$ anterior, $\mathrm{b}$ posterior, c lateral y d proximal. Escala gráfica $1 \mathrm{~cm}$. 

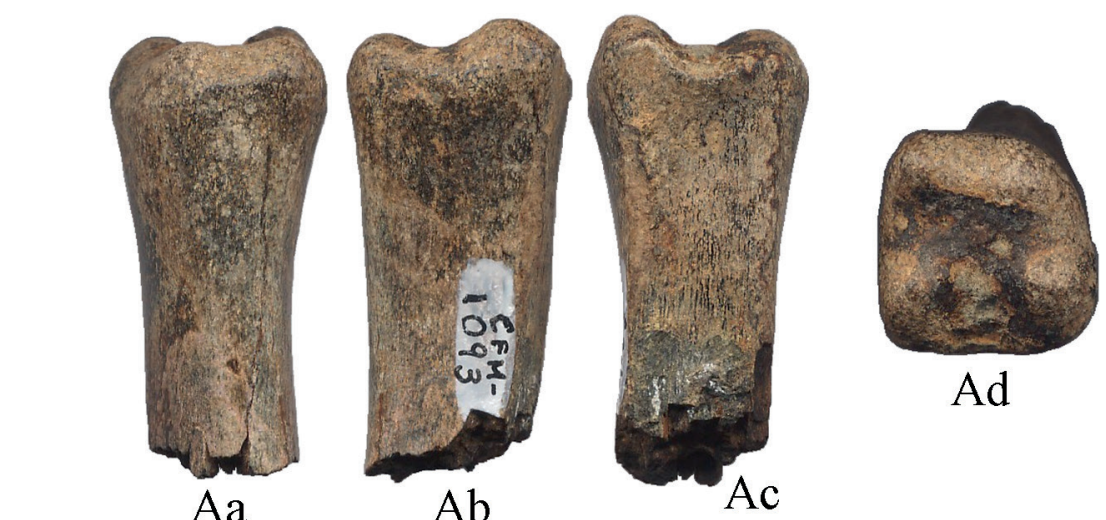

Ad
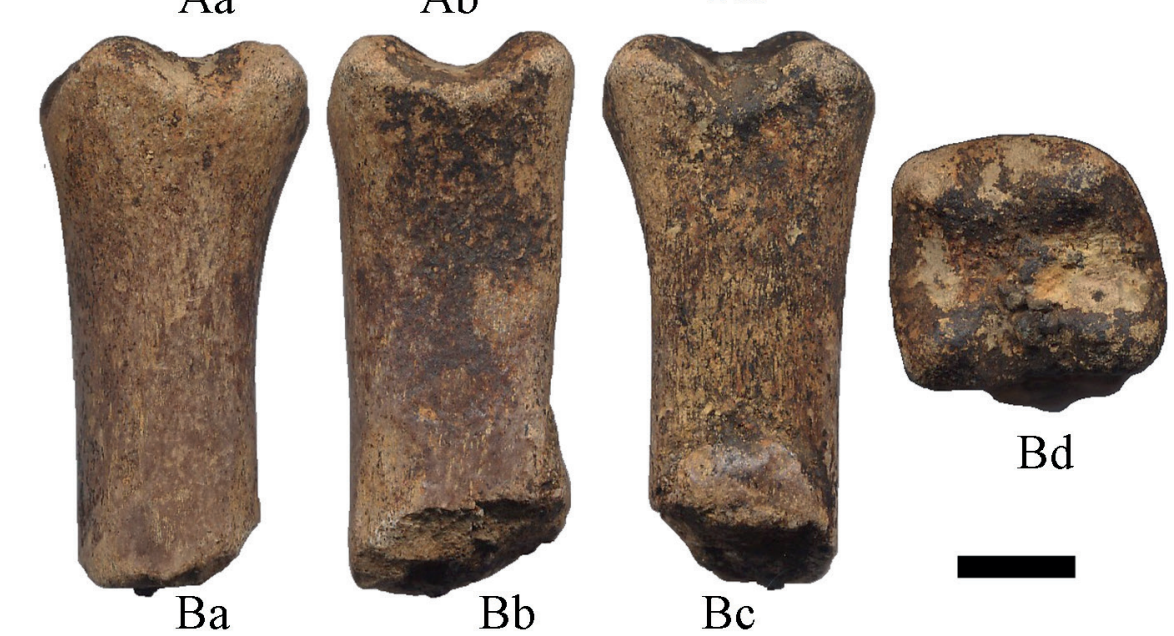

$\mathrm{Bd}$
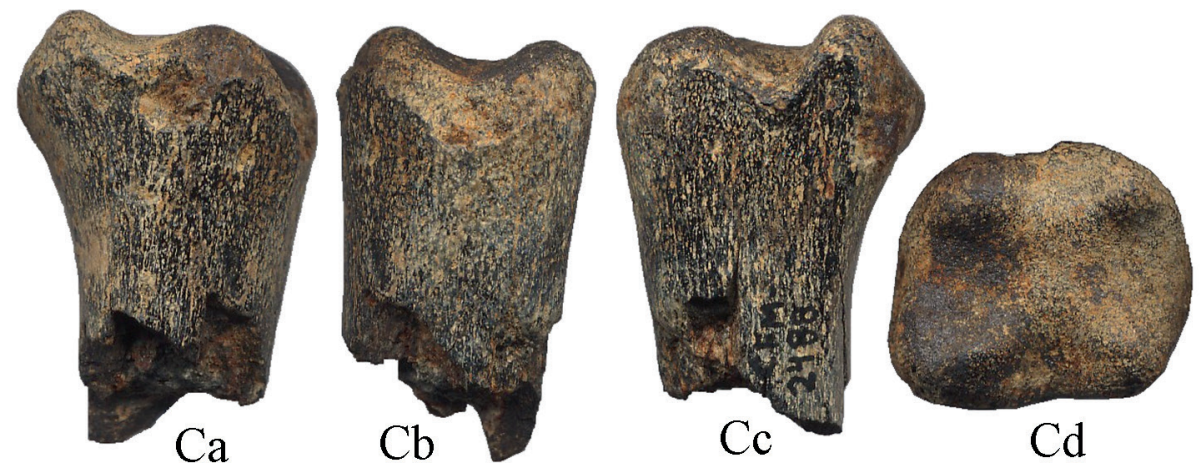

Fig. 16: Fragmentos de falanges I juveniles de Hemiauchenia vera Matthew, 1909: A. CFM-1093, B. CFM-2483 y C. CFM-2488, en vistas: a anterior, b lateral, c posterior y d proximal. Escala gráfica $1 \mathrm{~cm}$. 


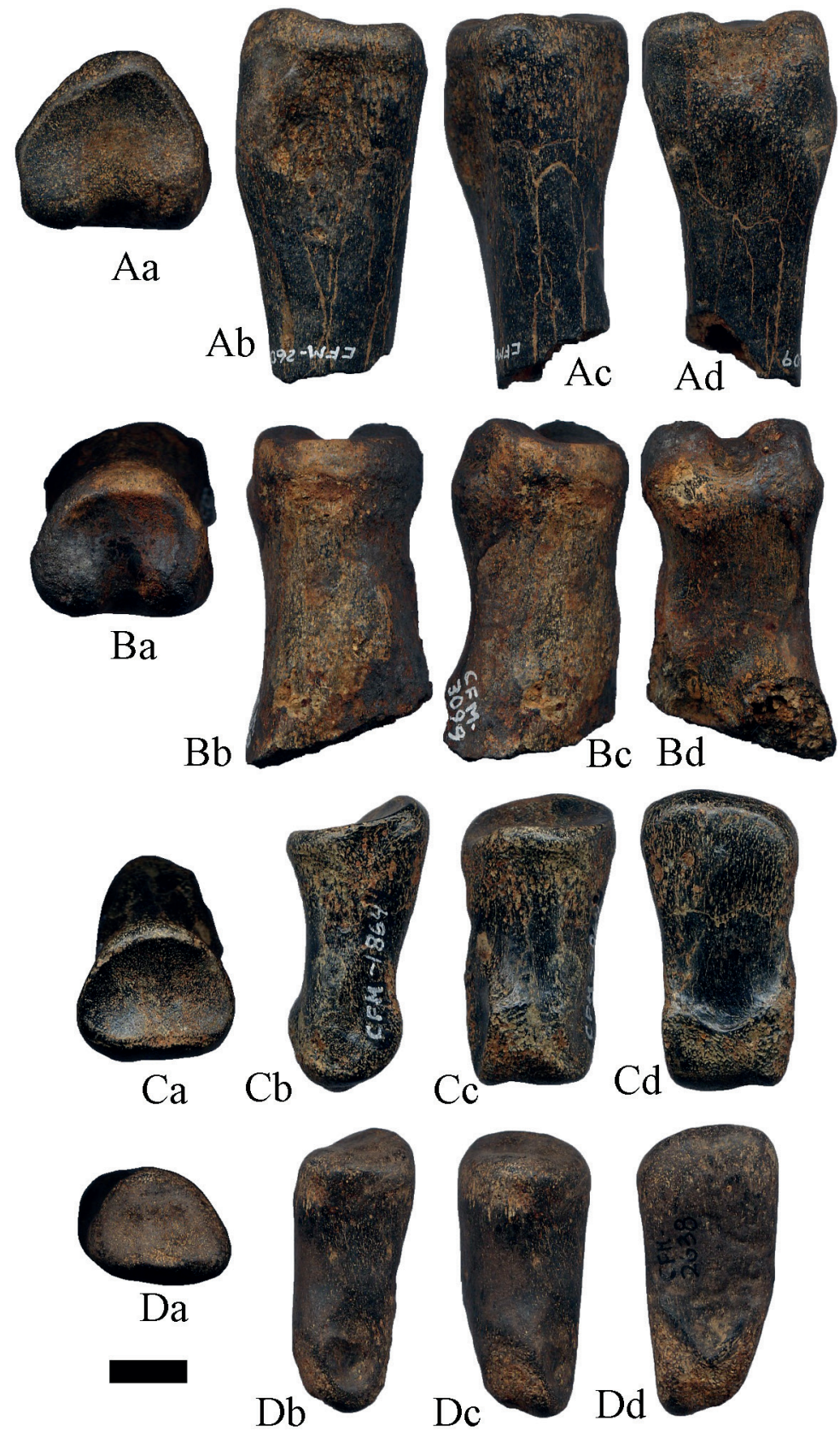

Fig. 17: Hemiauchenia vera Matthew, 1909: A. CFM-2609 y B. CFM-3099 son fragmentos de falanges I y falanges II: C. CFM1864 y D. CFM-2638, en vistas a proximal, b lateral, c anterior y d posterior. Escala gráfica $1 \mathrm{~cm}$. 


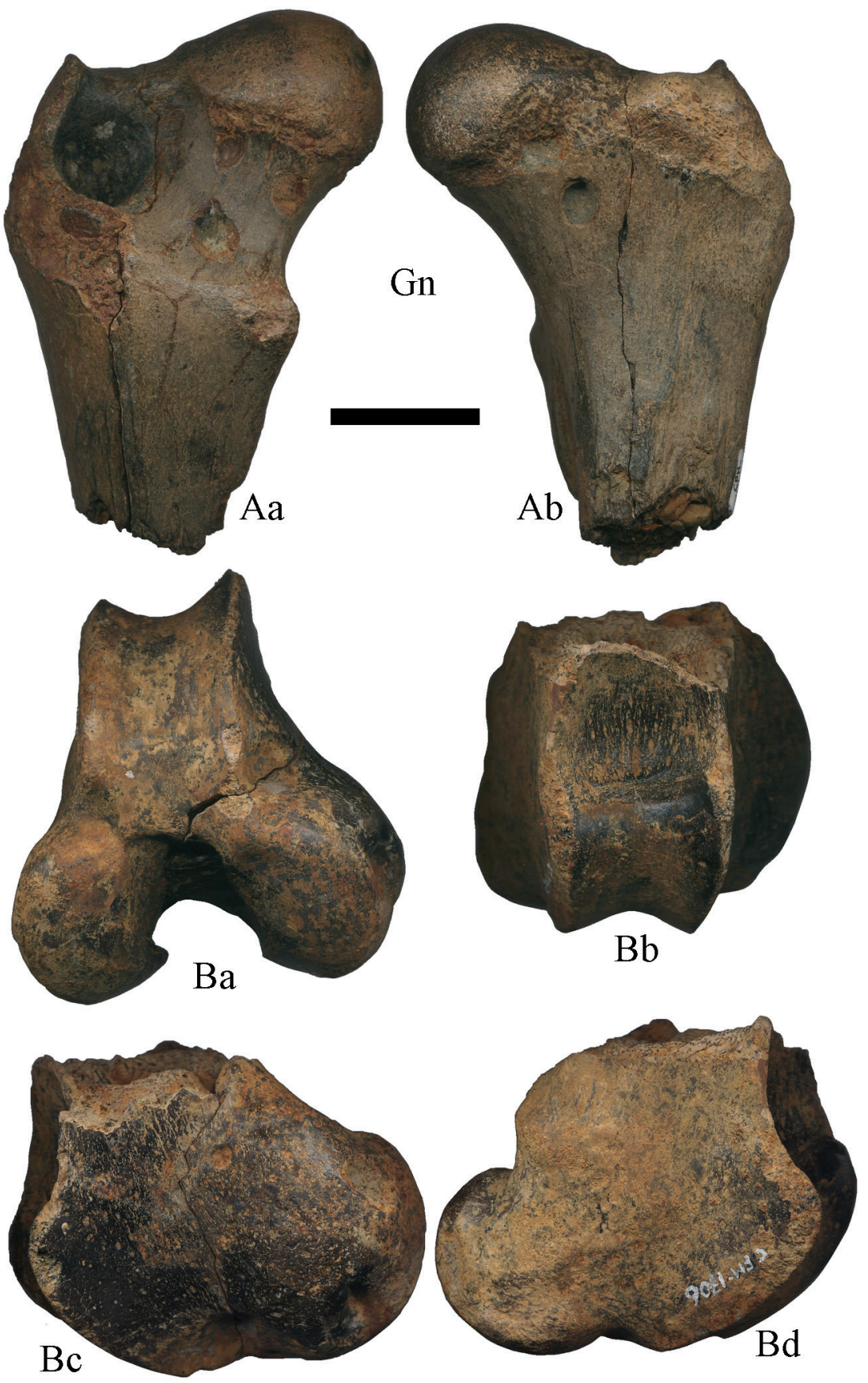

Fig. 18: Hemiauchenia vera Matthew, 1909: fragmentos de fémur, A. CFM-1006 proximal derecho y B. CFM-1706 distal izquierdo, en vistas a distal, b anterior, c lateral externa y d medial. Escala gráfica $3 \mathrm{~cm}$. 

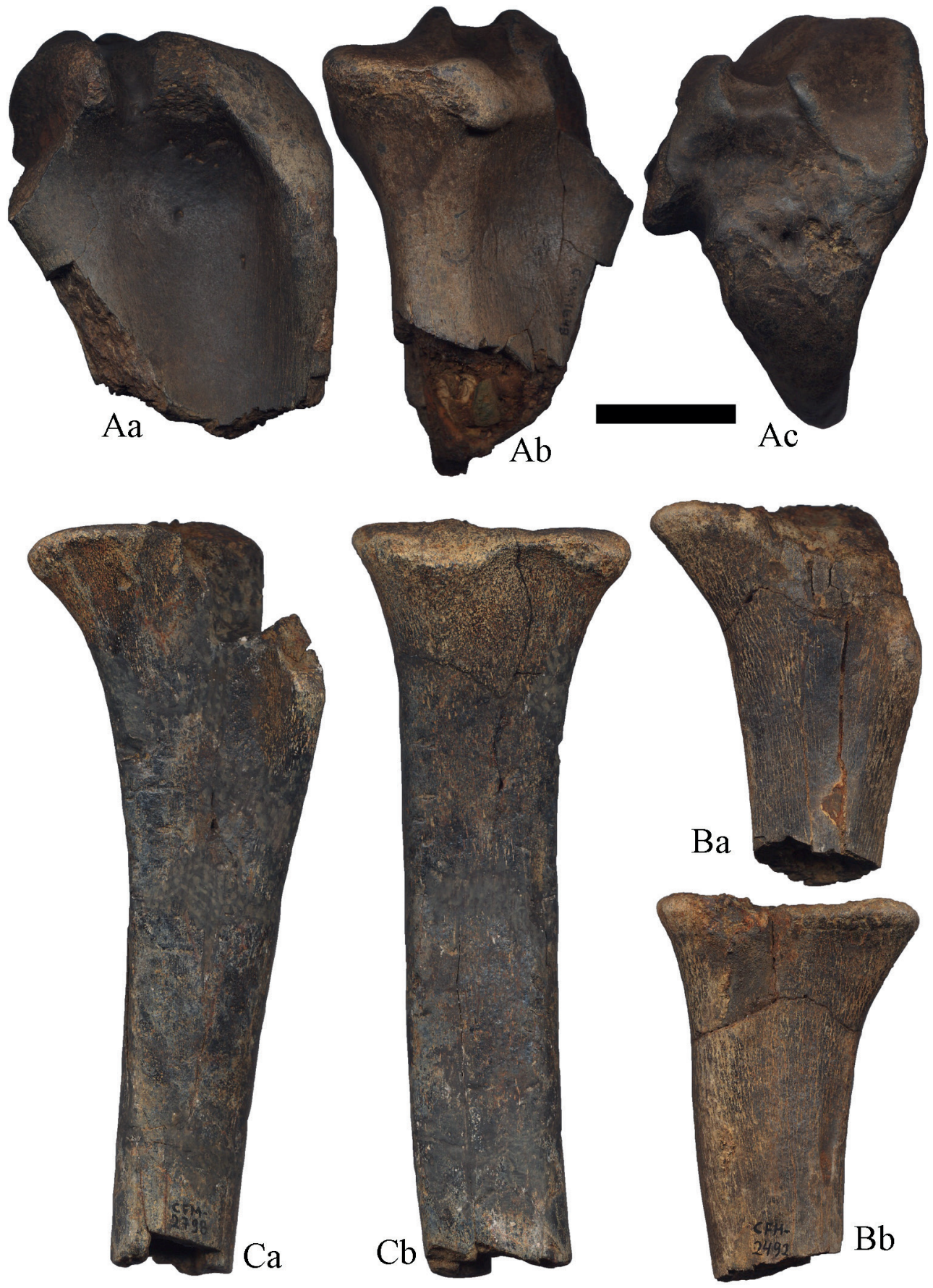

Fig. 19: Hemiauchenia vera Matthew, 1909, fragmentos proximales de tibias derechas, A. CFM-1648; B. CFM-2492 y C. CFM2798 probables fragmentos de juveniles; en vistas: a lateral y b posterior. Escala gráfica $3 \mathrm{~cm}$. 


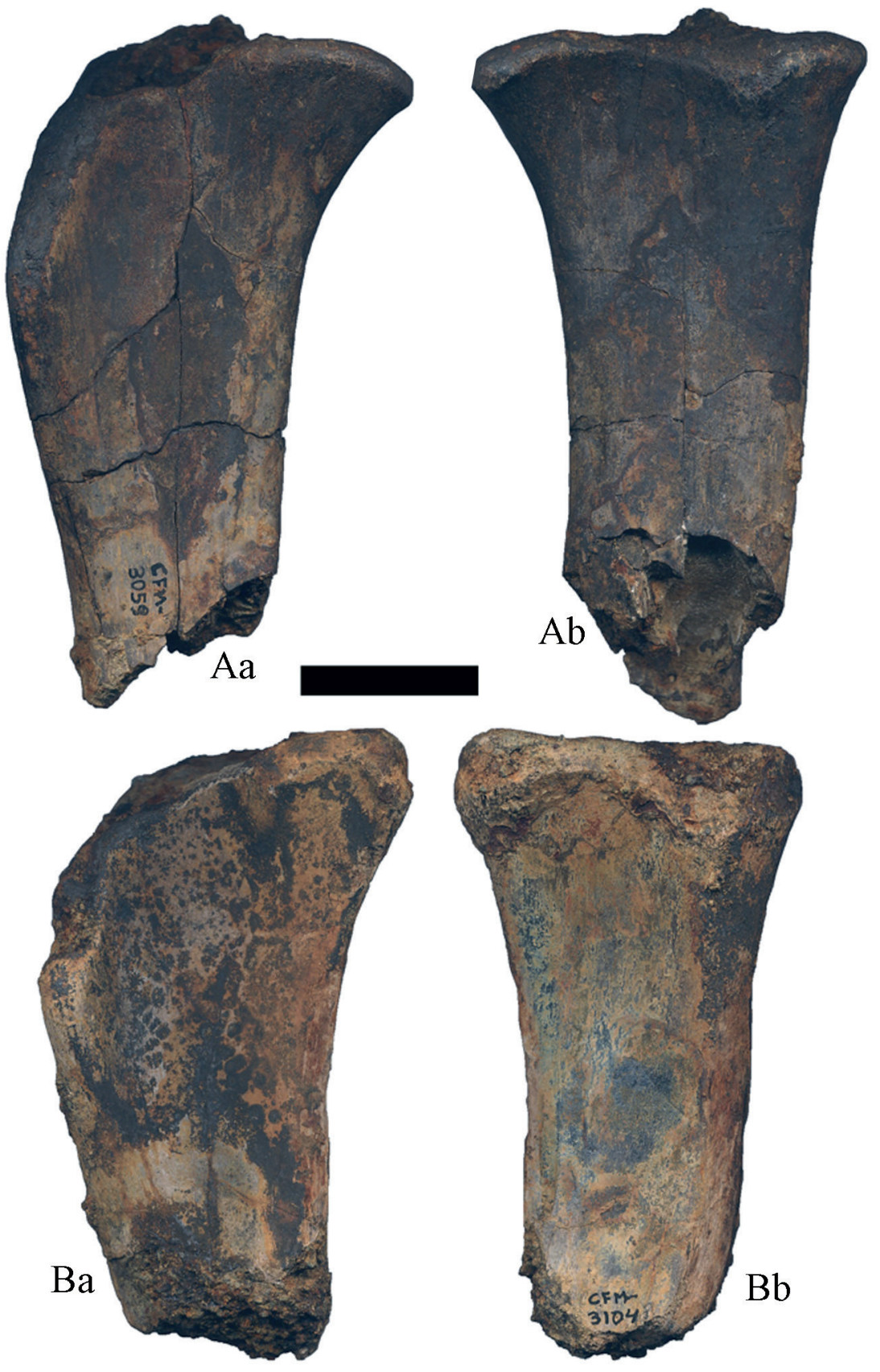

Fig. 20: Hemiauchenia vera Matthew, 1909: fragmentos proximales de tibias izquierdas de probables juveniles, A. CFM-3059 y B. CFM-3104 en vistas: a lateral y b posterior. Escala gráfica $3 \mathrm{~cm}$. 


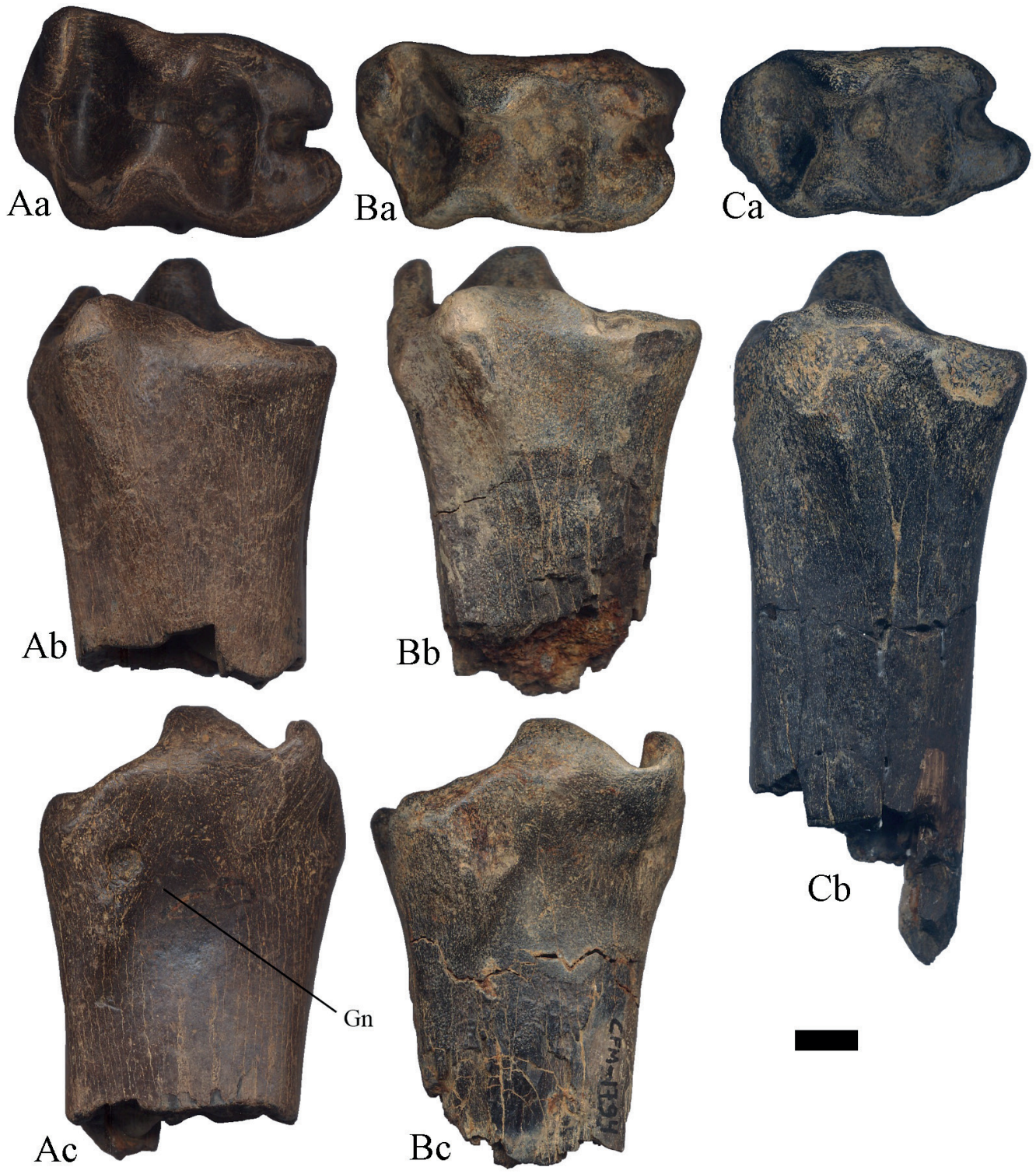

Fig. 21: Hemiauchenia vera Matthew, 1909: fragmentos distales de tibias izquierdas, A. CFM-2838, B. CFM-1794 y CFM-2801, en vistas a distal, b posterior y c anterior. Escala gráfica $1 \mathrm{~cm}$.

troclear medial. La fosa subsustentacular se encuentra bien desarrollada y posee un contorno triangular.

El ejemplar ilustrado en la fig. 23A, no conserva la superficie lateral articular, solamente la cara medial, con la superficie ligamental tibial curva y la faceta navicular redondeada; la fosa subsustentacular bien desarrollada y de contorno triangular. El CFM-1521 (fig. 24C) tiene la superficie lateral articular parcialmente rota a la altura de la faceta parasustentacular, pero si se preservó la saliente fibular y la cara distal astragalar; la superficie medial está fisurada, la fosa subsustentacular es somera y de contorno elongado. El CFM2156 (fig. 23B) con muy mala conservación, solo conserva la cara medial en la que se observa la 

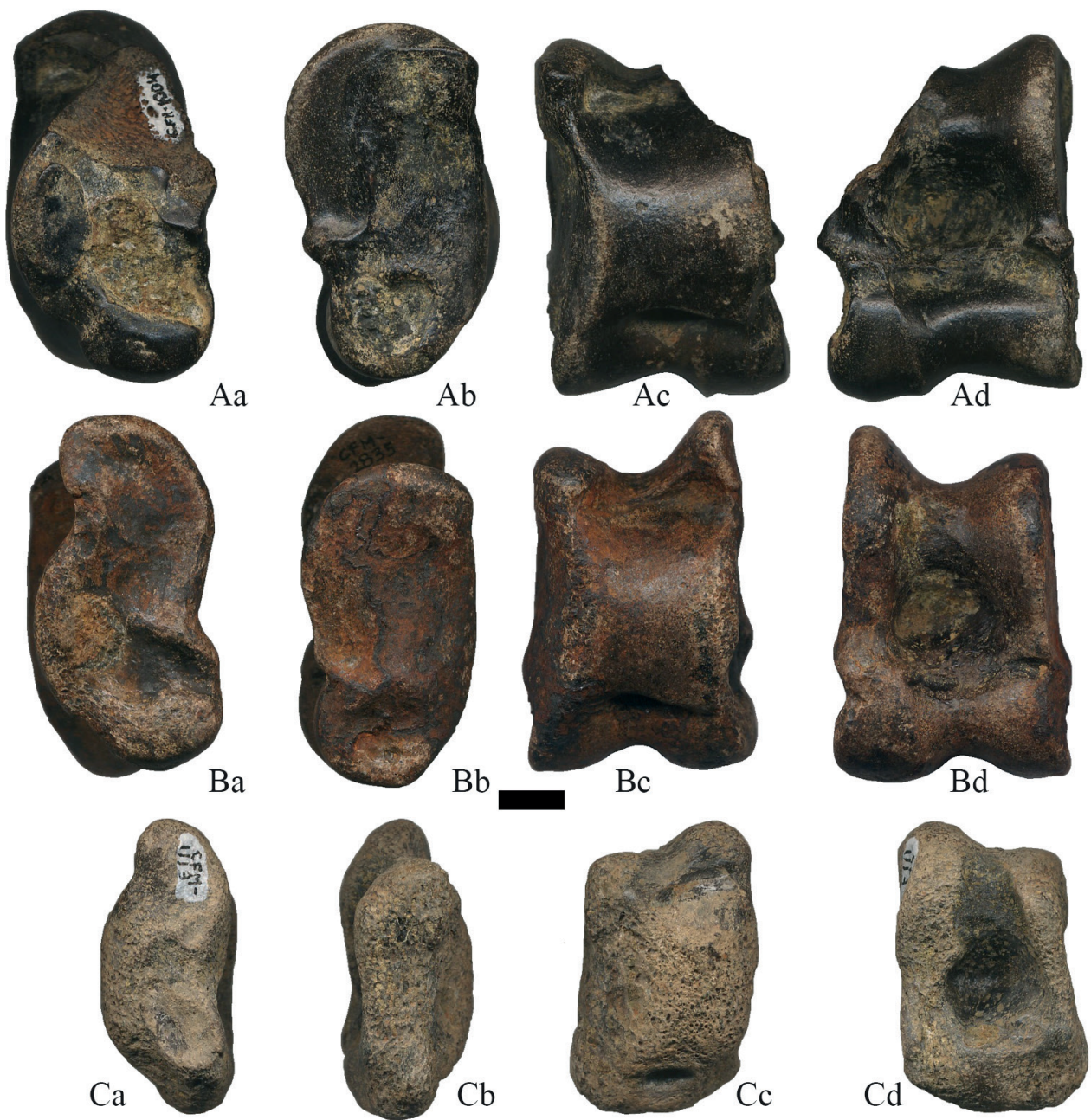

Fig. 22: Astrágalos derechos de Hemiauchenia vera Matthew, 1909: A. CFM-1004, B. CFM-2835 y C. CFM-1113 un juvenil, en vistas a lateral, b medial, c plantar y d proximal. Escala gráfica $1 \mathrm{~cm}$.

faceta navicular redondeada, la fosa subsustentacular bien desarrollada y elongada.

Se recuperaron dos astrágalos posiblemente de individuos juveniles, el astrágalo derecho (fig. 22C) tiene la superficie lateral articular sigmoidea o en forma de "S" pero mal preservada, se preservó la cara distal astragalar y la faceta parasustentacular, la saliente fibular no se preservó; la superficie medial está mal preservada, la cresta troclear medial apenas insinuada, la fosa subsustentacular se encuentra bien desarrollada y posee un contorno redondeado. Por su parte el astrágalo izquierdo (fig. 23C), es un ejemplar mal preservado, la cresta troclear medial apenas insinuada y la fosa subsustentacular somera y elongada, la superficie articular con mala preservación.

\section{Calcáneos}

El calcáneo derecho CFM-1229 de Hemiauchenia vera Matthew, 1909 presenta la tuberosidad ovalada en sentido antero-posterior, con una cresta lateral-medial que separa la tuberosidad 


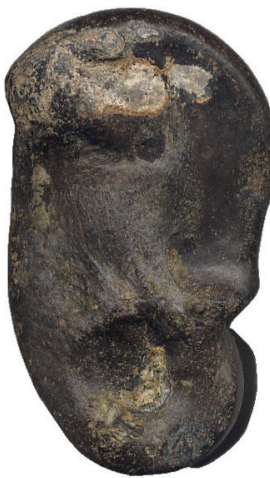

$\mathrm{Aa}$

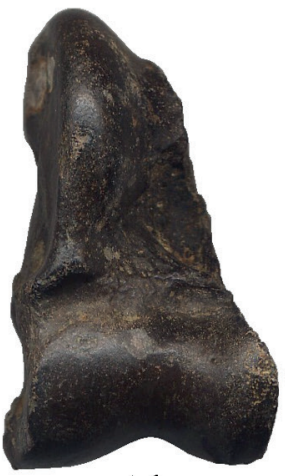

$\mathrm{Ab}$

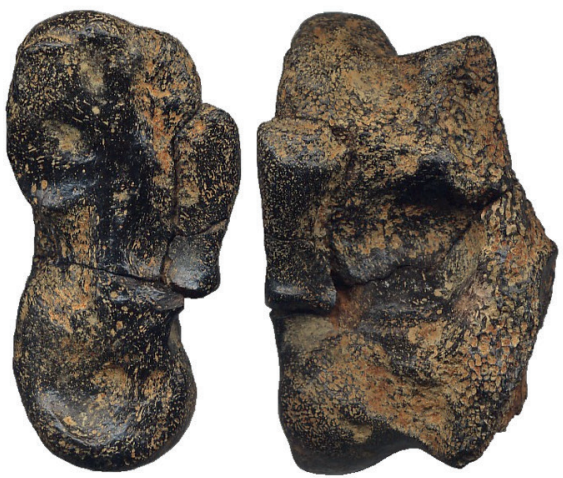

$\mathrm{Bb}$

$\mathrm{Ba}$
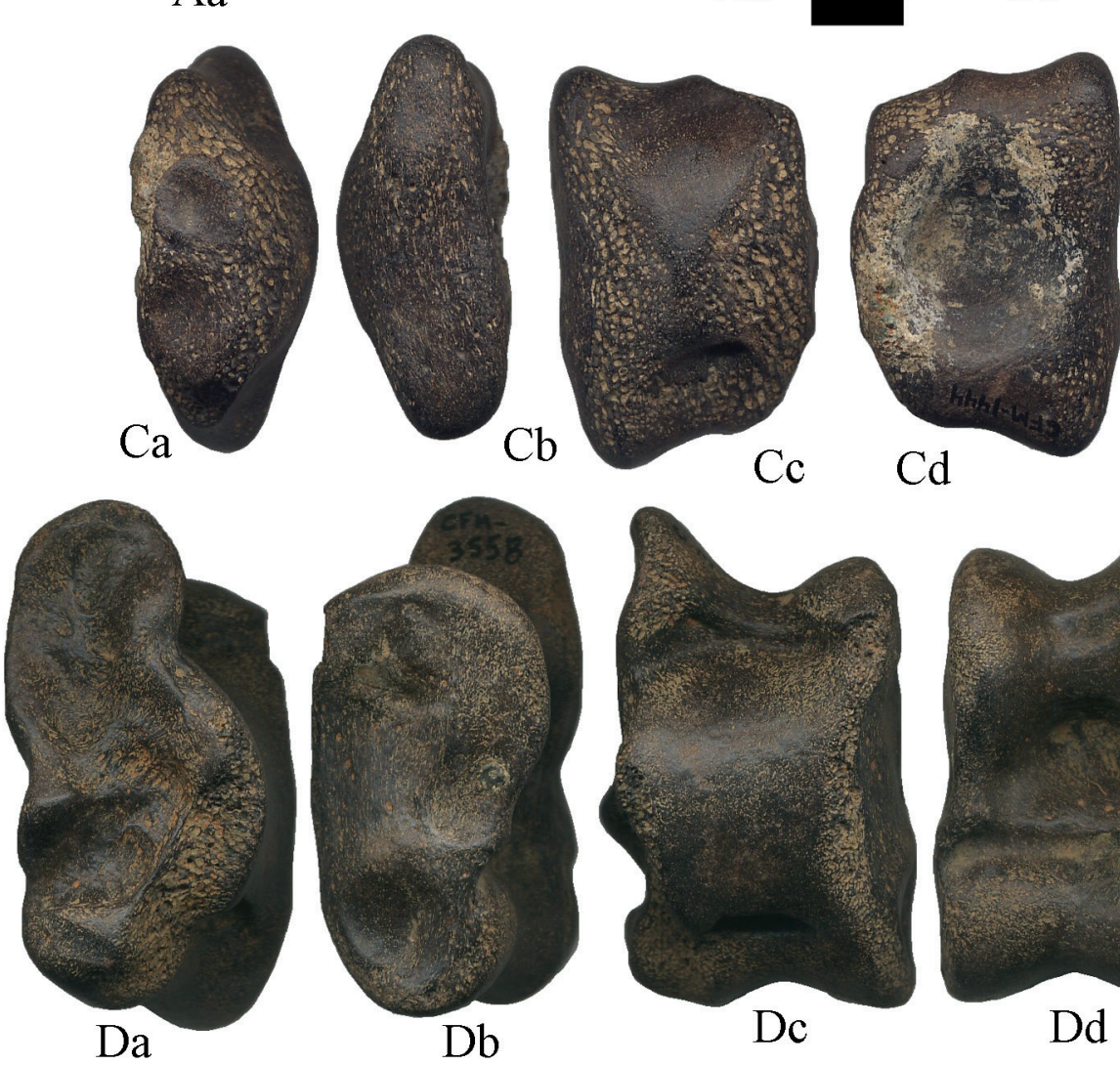

$\mathrm{Cc}$

$\mathrm{Cd}$
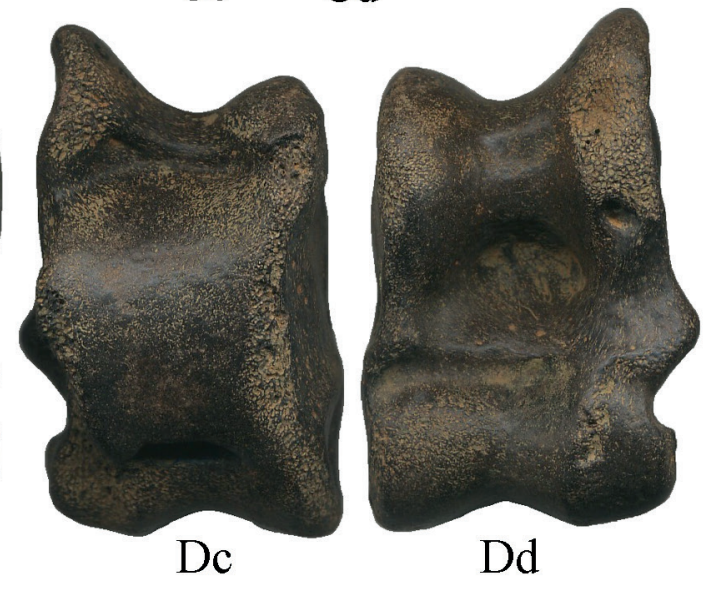

Fig. 23: Astrágalos izquierdos de Hemiauchenia vera Matthew, 1909: A. CFM-1005, B. CFM-2156, C. CFM-1444 y D. CFM3558 , en vistas a lateral, b medial, c plantar y d proximal. Escala gráfica $1 \mathrm{~cm}$. 


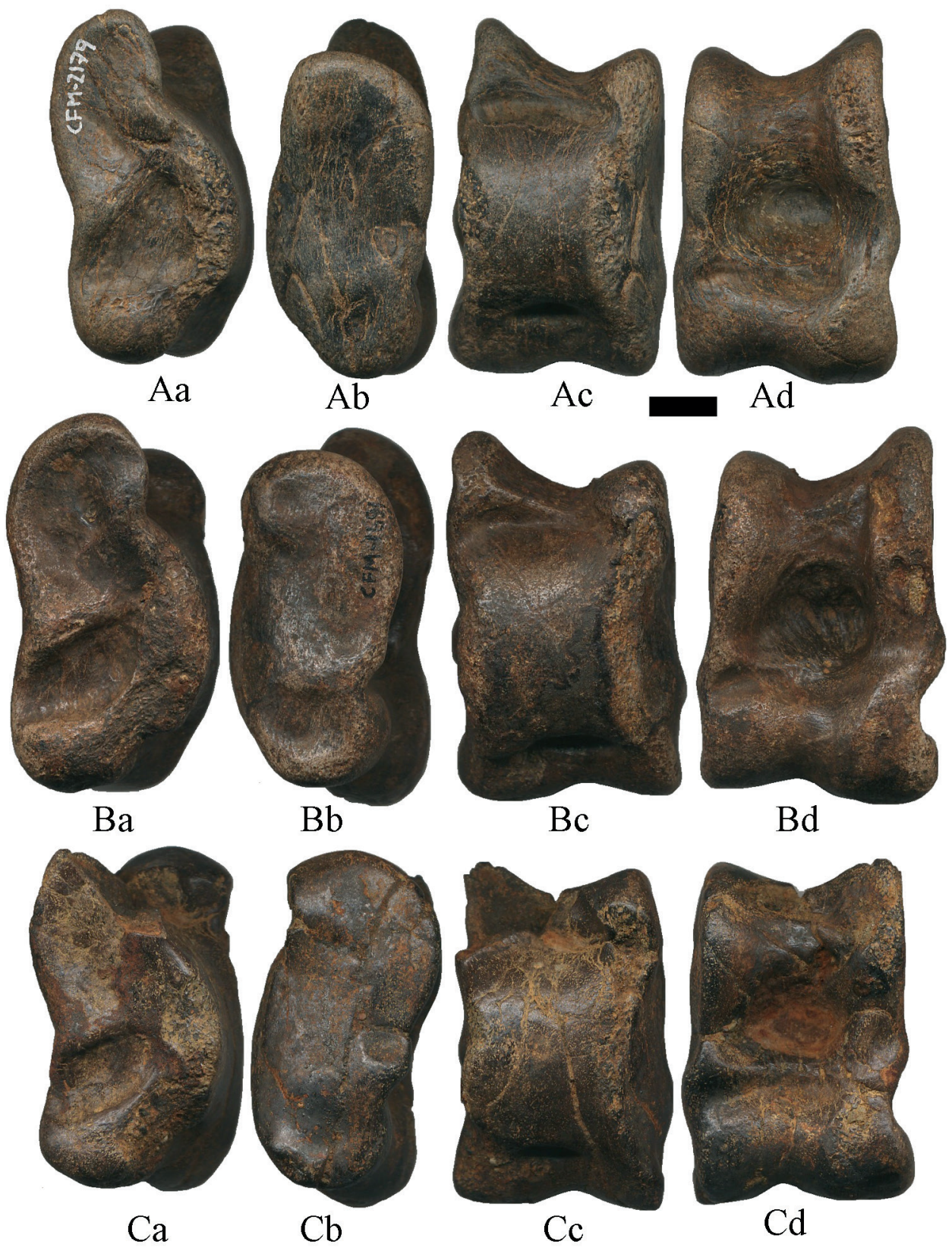

Fig. 24: Astrágalos izquierdos de Hemiauchenia vera Matthew, 1909: A. CFM-2179, B. CFM-1691 у C. CFM-1521, en vistas a lateral, b medial, c plantar y d proximal. Escala gráfica $1 \mathrm{~cm}$. 


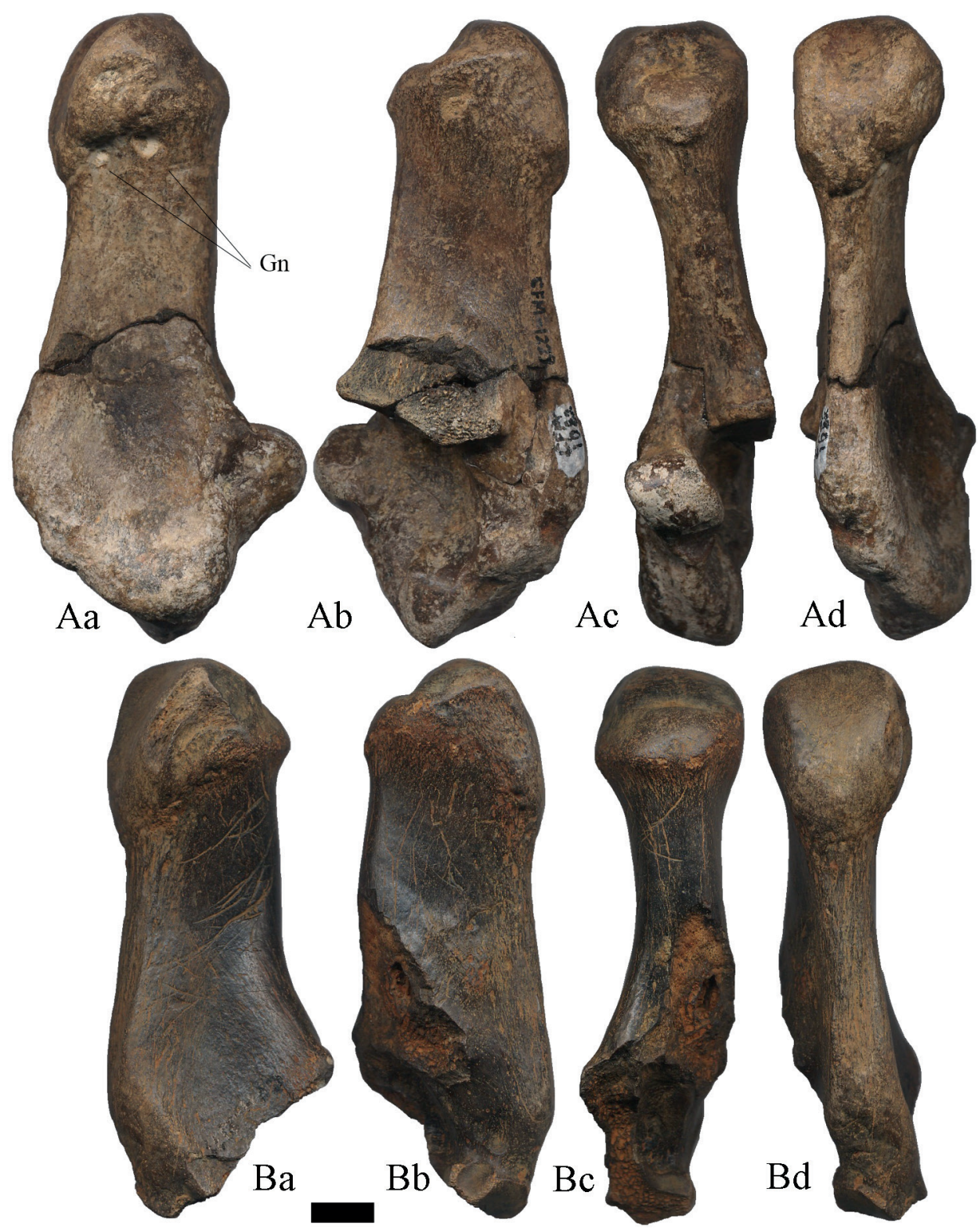

Fig. 25: calcáneos derechos de Hemiauchenia vera Matthew, 1909, CFM-1229 y CFM-2177 en vistas a lateral mediana, b lateral externa, c anterior y d posterior. Escala gráfica $1 \mathrm{~cm}$.

en dos: la posterior con una depresión que disminuye en profundidad del lado plantar y la anterior es plana e inclinada en su parte superior y bulbosa en su parte inferior, se observan marcas de Gnatichnia (fig. 25A). La superficie fibular del calcáneo es doblemente curva, con una parte proximal convexa y una parte distal cóncava; la faceta cuboide es rectangular y plana, la apófisis coracoides está rota y se conserva el surco para el tendón del M. flexor digital lateral. El ejemplar CFM-2177 ilustrado en la fig. 25B solo conserva la tuberosidad y el cuerpo del calcáneo, con las 

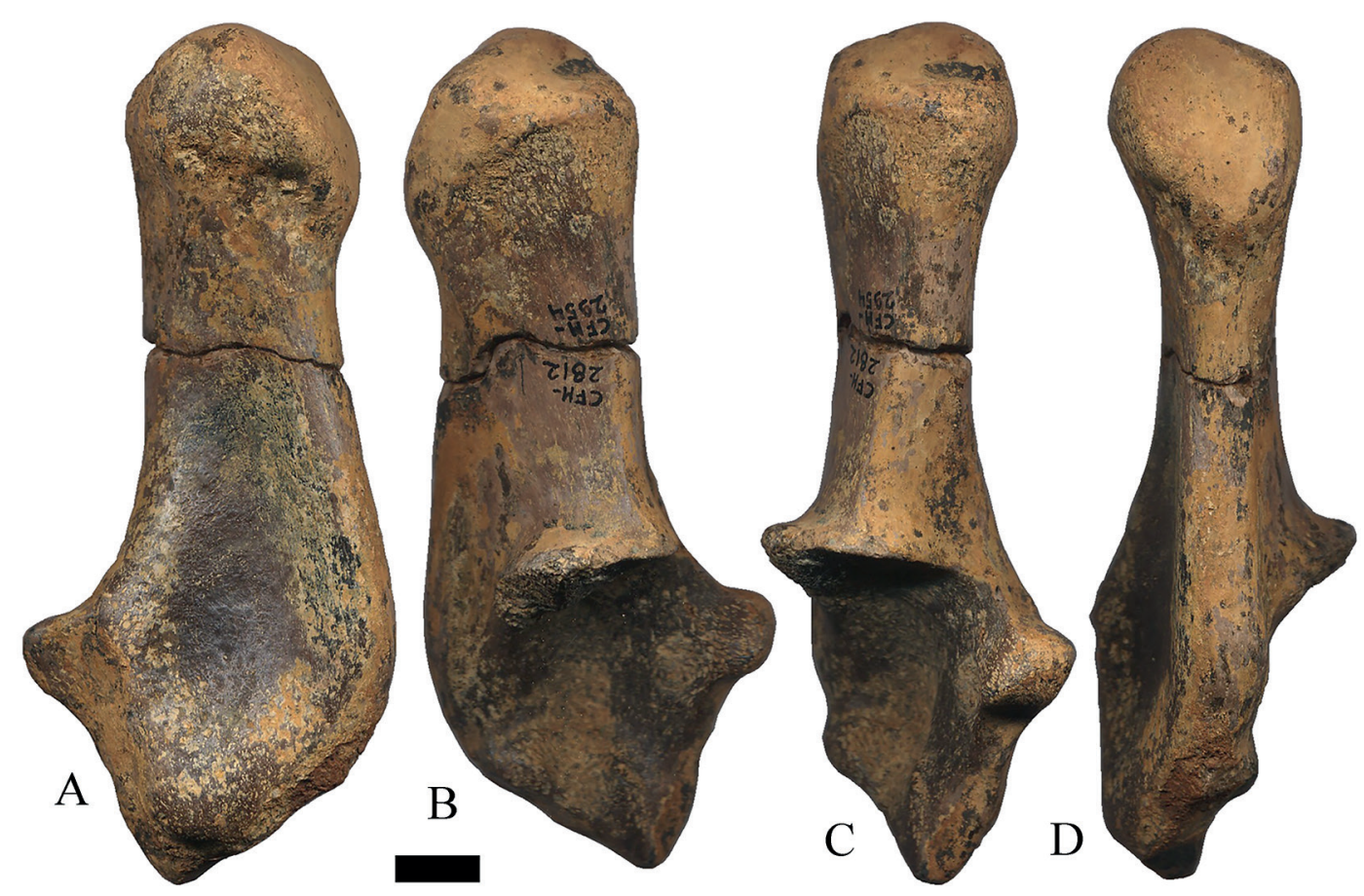

Fig. 26: CFM-2954, calcáneo izquierdo de Hemiauchenia vera Matthew, 1909, en vistas A. lateral mediana, B. lateral externa, C. anterior y D. posterior. Escala gráfica $1 \mathrm{~cm}$.

mismas características del anteriormente descrito. El CFM-2551 corresponde a un fragmento de calcáneo derecho que no conserva la tuberosidad, la apófisis coracoides tiene un borde redondeado y el surco para el tendón del M. flexor digital lateral es profundo.

El calcáneo izquierdo CFM-2954 (fig.26), presenta la tuberosidad levemente desgastada, la apófisis coracoides de borde angular parcialmente roto, también se conservó el surco para el tendón del $M$. flexor digital lateral. El ejemplar CFM3648 que corresponde a una tuberosidad del calcáneo izquierdo y está relleno con una geoda de calcita, mientras que el CFM-2626 tiene marcas de Gnatichnia posiblemente de cocodrilos.

\section{Metatarsos}

En los fragmentos proximales de metatarsos recuperados, las facetas para el ectomesocuneiforme y para el cuboides son reniformes y están separadas por un surco estrecho y profundo. La faceta para el entocuneiforme es ovoide, pequeña y está separada de la faceta del ectomesocuneiforme por un canal estrecho y poco profundo (figs. 27 y 28$)$.

El ejemplar CFM-3803 tiene mala preservación, solo se conservó la faceta para el ectomesocuneiforme, de forma reniforme y parte del surco que la separa de la faceta para el cuboides; mientras que del CFM-1690 solo se conservó la faceta para el ectomesocuneiforme con una forma reniforme.

\section{DISCUSIÓN Y ANALISIS DE LOS RESULTADOS}

Los restos dentales recuperados son escasos y por lo general corresponden a individuos muy viejos, como en los ejemplares CFM-1673, 1925, 2198, 2877, con marcado desgaste oclusal, individuos adultos jóvenes con escaso desgaste como 


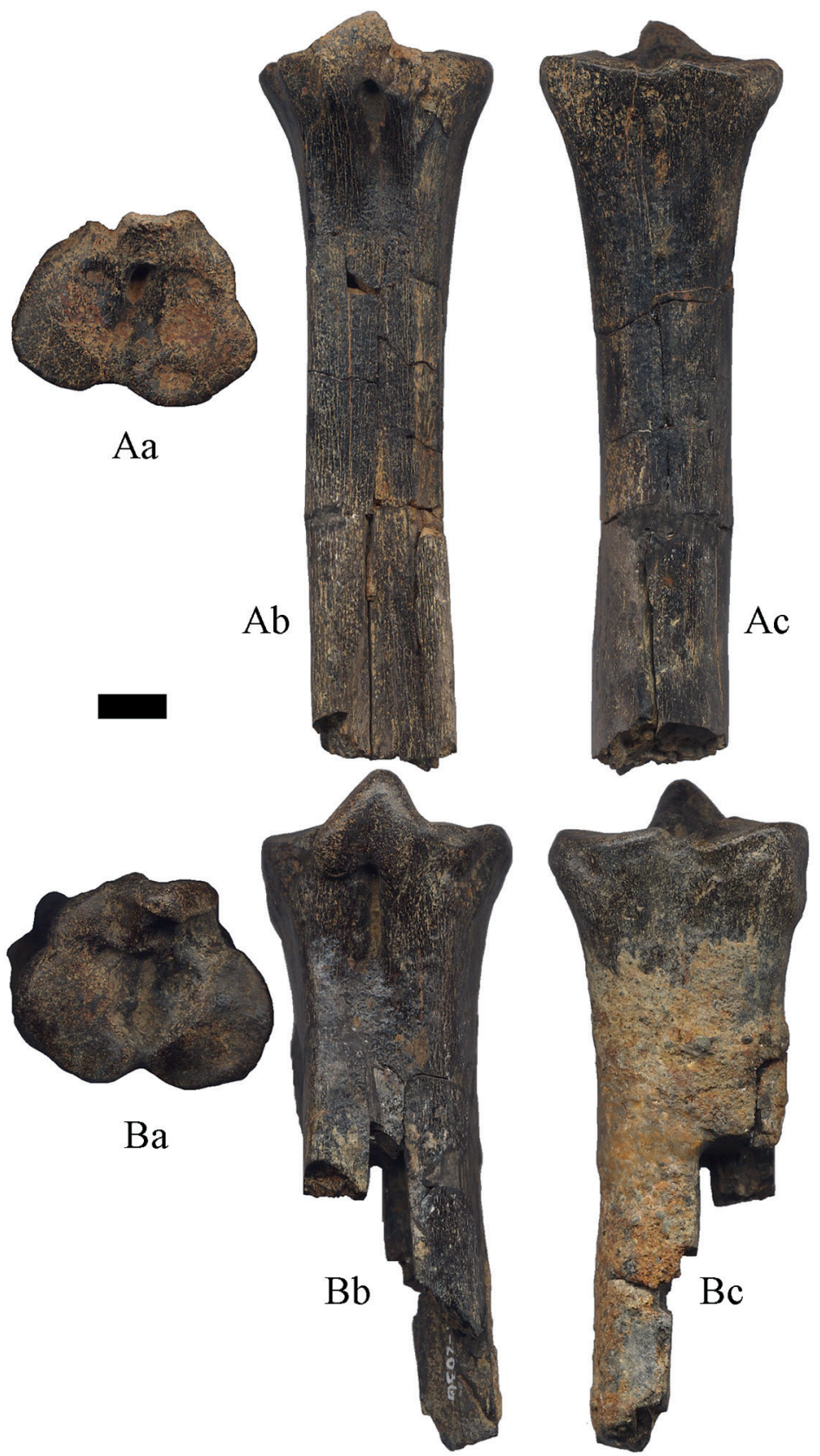

Fig. 27: Hemiauchenia vera Matthew, 1909: A. CFM-1638 metatarso izquierdo y B. CFM-2036 metatarso derecho en vistas a proximal, b posterior y c anterior. Escala gráfica $1 \mathrm{~cm}$.

el caso del ejemplar CFM-3215 o individuos juveniles con dentición de leche como en el caso del ejemplar CFM- 3729. El material dental, en sí mismo, solo es indicativo de la existencia de una especie de lamino, individuos con diferentes estados ontogenéticos que representan una población normal; para confirmar tal determinación específica, como es clásico en la identificación de especies 


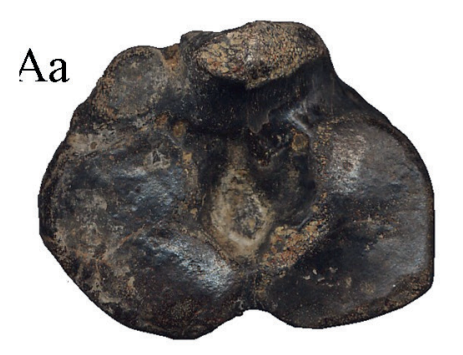

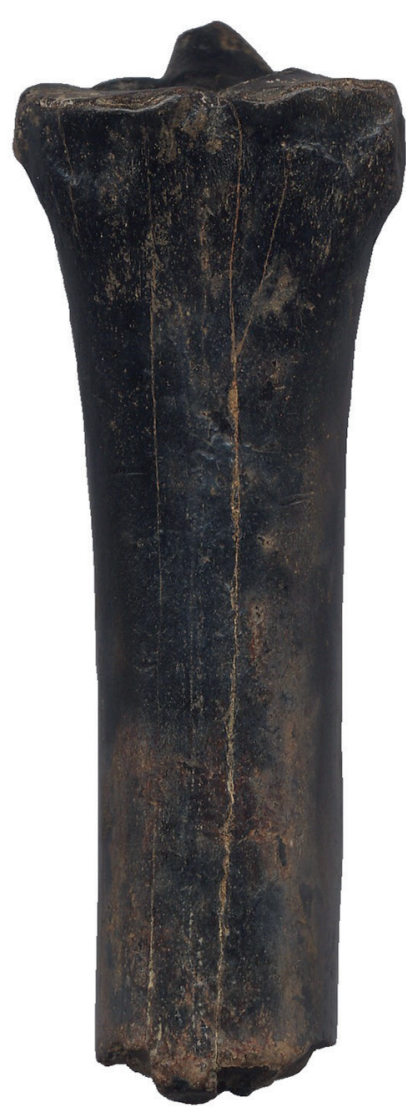

$\mathrm{Ab}$

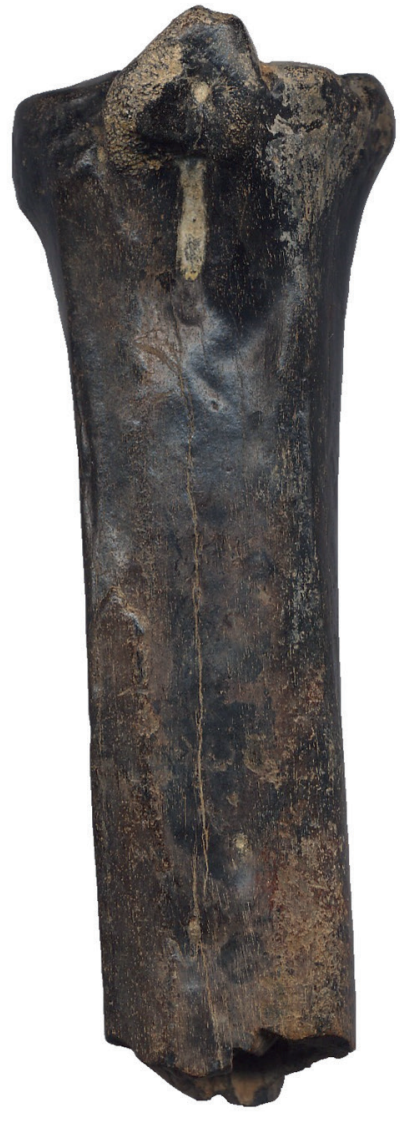

Ac

Fig. 28: Hemiauchenia vera Matthew, 1909: A. CFM-2894 metatarso derecho en vistas a proximal, b anterior y c posterior y B. CFM-1908 entocuneiforme en vistas a distal y b proximal. Escala gráfica $1 \mathrm{~cm}$.

fósiles de camellos, se tuvo que recurrir a elementos postcraneanos, específicamente mediante el análisis bivariado de altura medial y ancho distal de los astrágalos, sobre manera por el estado fragmentario de los huesos largos, en especial los metapodiales. Los datos biométricos de los astrágalos se contrastaron con elementos homólogos de otras especies de camellos laminos, presentes en yacimientos de edad henfiliana y blancana de México y los Estados Unidos.

Los resultados obtenidos que se muestran en la figura 29, sugieren tres grupos de distribución bien definidos, quedando la especie de lamino costarricense inserto en 2 grupos de mediana y pequeña talla, por lo que se descartan las formas grandes y robustas como Alforjas del Mioceno
Tardío y Camelops del Pleistoceno. El astrágalo pequeño corresponde al espécimen CFM-1113 y a pesar de su pequeño tamaño se corresponde con el rango de los adultos y de los especímenes de mayor talla de la especie Hemiauchenia gracilis Meachen, 2005, incluso parece ser más afín a las formas del centro de México que a las formas de la Florida, por ello se asume que pertenece, muy probablemente a una forma juvenil de Hemiauchenia vera Matthew, 1909, una evidencia de ello podría ser el alto grado de porosidad presente en el astrágalo, pero ello no es un criterio definitivo.

Además, el rango biocronológico de Hemiauchenia gracilis Meachen, 2005 es un poco más reciente, abarcando desde el Blancano temprano al Pleistoceno Tardío (Irvingtoniano) sensu 


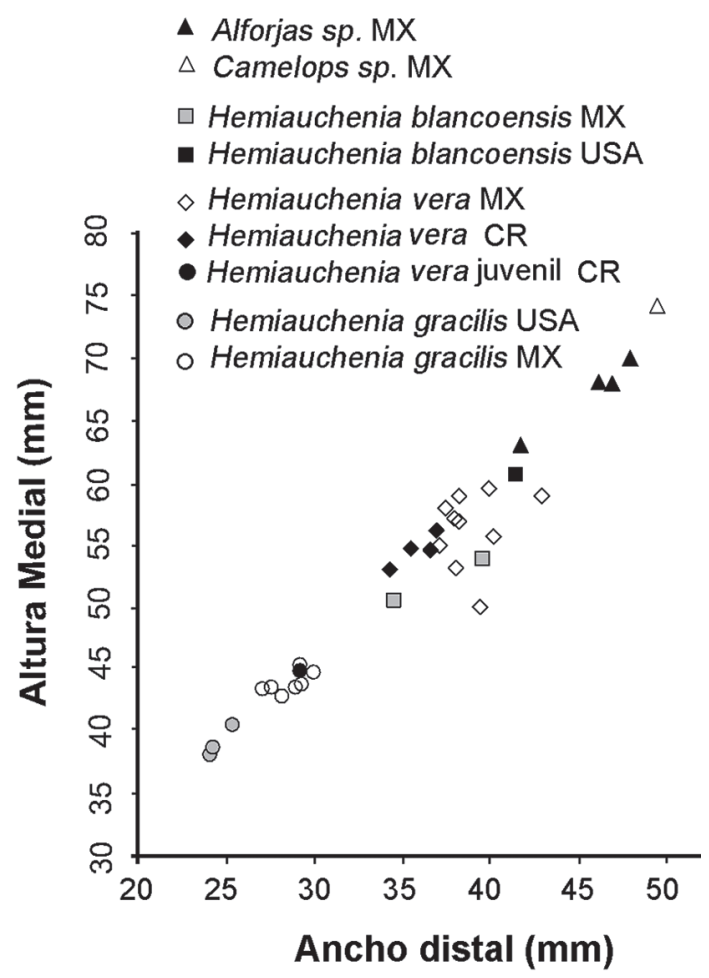

Fig. 29: Gráfica bivariable del ancho distal versus la altura medial de astrágalos de diferentes especies de América del Norte y Central.

Bravo-Cuevas et al. (2012), lo que descarta que esta segunda especie esté presente en San Gerardo de Limoncito.

Por otro lado, los astrágalos restantes caen dentro del grupo intermedio donde se encuentra Hemiauchenia vera y Hemiauchenia blancoensis, se debe tener en cuenta que $H$. blancoensis tiene un rango de distribución que va del Blancano Temprano al Irvingtoniano Temprano sensu Morgan et al. (1997). Si a esta distribución estratigráfica más temprana, añadimos el hecho de que los molares superiores M2 y M1 de H. vera son en general más anchos linguo-labialmente y mucho más cortos, en sentido anteroposterior que en $H$. blancoensis, se asume que se puede descartar la presencia de esta última especie, pero en general a nivel morfológico son muy similares. Sin embargo, al analizar las falanges anteriores y posteriores de Hemiauchenia vera, resalta la falange I anterior o manual CFM-1863, la cual se halla excelentemente preservada y se caracteriza por presentar una longitud mayor de 79,61 mm (ver apéndices 2 y 5), mucho menor que las longitudes mayores de los similares de $H$. blancoensis cercana a los 101-103 mm (Jiménez-Hidalgo, 2005) y además, es mayor a la media de la longitud de las falanges I anteriores de Hemiauchenia gracilis cercana a los 63-64 mm (Jiménez-Hidalgo, 2005). Por otra parte, los datos biométricos de las restantes falanges y metapodiales, aunque sean fragmentarios, tienden a confirmar la presencia de la especie Hemiauchenia vera, dejando de lado cualquier otra posibilidad (ver apéndices 2, 3, 4 y 5).

Por último, Webb \& Meachen, 2004, incluyeron a Hemiauchenia vera Matthew, 1909 en el género Pleiolama como Pleiolama vera (Matthew, 1909) y consideran que Pleiolama difiere del género Hemiauchenia por su pequeño tamaño, corta diastema, premolares $\mathrm{P} 1 / 1$ y P3/3 largos, incisivos inferiores más delicados y una sínfisis más angosta. Sin embargo, para algunos autores tales caracteres no son suficientes como para diferenciar dichos géneros y además, consideran que carecen de implicancias regionales o cronológicas (ver Morgan \& White, 2005; White \& Morgan, 2005; Ferrusquía-Villafranca et al., 2010; CarranzaCastañeda et al., 2013 entre otros).

\section{Distribución paleogeográfica}

Hemiauchenia vera Matthew, 1909 en los Estados Unidos, ha sido registrada en faunas de edad en el límite Blancano temprano-Henfiliano tardío de Matthews Wash y Comosi Wash, Santa Cruz County, Anita Site, Coconino County y Wikieup, Mojave County, todas en la cuenca del río Gila, Arizona (Morgan \& White, 2005, White \& Morgan, 2005) y Ogallala Group (Loup Fork) cerca de Long Island, Phillips County (Hibbard, 1963); en el Henfiliano tardío de las faunas locales de Rhino Hill Quarry, Edson Quarry y West Quarry en Sherman County y noreste de Wallace County, todas localidades de Kansas (Harrison, 1983); en el Henfiliano tardío de Coffee Ranch en Hemphill County y Smart Ranch o Slaton local fauna, Lubbock County, Texas (Hibbard, 1963; 
Dalquest, 1967 y 1980) y en la fauna local de Buis Ranch, Beaver County, Oklahoma de edad henfiliana tardía (Hibbard, 1963; Joyce et al., 2012); Silver Spring y Yerington en Lyon County, Hoye Canyon en Douglas County, Nevada (Kelly, 2000) y Horned Toad Hills en el noroeste del desierto de Mojave en el sur de California (May et al., 2011). En las localidades de Mauvilla en Alabama y Minimum Quarry, Graham County, Kansas de edad henfiliana temprana (Hh2) (Hulbert \& Whitmore, 2006), ver fig. 30.

En México Hemiauchenia vera ha sido registrada en las localidades henfilianas tempranas (Hh2) de La Presa y tardías (Hh3) de Coecillos y en las localidades henfiliano tardías de Tepalcates y la Rinconada (Hh3-Hh4), y blancanas de Rhino Layer y Rancho El Ocote, en la Cuenca de San Miguel Allende, Guanajuato (MontellanoBallesteros, 1989; Jiménez-Hidalgo \& CarranzaCastañeda, 2010; Carranza-Castañeda et al., 2013); así como la localidad de Santo Domingo en la Cuenca de Colotlán-Tlaltenango, Zacatecas (Henfiliano temprano Hh2) y las localidades de La Hacienda y Santa María en la Cuenca de Tecolotlán, Jalisco (Henfiliano tardío, Hh3-Hh4) (Carranza-Castañeda et al., 2013). El registro de Hemiauchenia vera Matthew, 1909 en el Mioceno Superior de Costa Rica, corresponde al registro más austral de la especie (ver figs. 30 y 31 ).

\section{Análisis biocronológico y edad}

Valerio (2010) y Laurito \& Valerio (2010) con base en la presencia de los équidos Calippus hondurensis y Dinohippus mexicanus, luego de que determinaron los taxa de la Familia Equidae, registrados para la localidad de San Gerardo de Limoncito, logran establecer un rango Henfiliano temprano (Hh1-Hh2), y asumen que la edad máxima de dicha fauna probablemente estaría alrededor de $6.57 \mathrm{Ma}$, datum que corresponde con la última ocurrencia o aparición de Calippus hondurensis (Olson \& McGrew, 1941) y la primera aparición de la especie Dinohippus mexicanus (Lance, 1950).

Recientemente, Carranza-Castañeda et al. (2013), publican un extenso análisis biocronológico de la diversa fauna de la Cuenca de Juchipila, en el Estado de Zacatecas en México, donde fundamentados en una importante cantidad de dataciones radiométricas previas logran establecer primeras y últimas apariciones de varios taxa (ver fig. 36), como el registro más reciente del Megalonychidae Pliometanastes establecido por dichos autores, procedente de la localidad ZJ 30 Mixtón que se ubica entre los 5,59 Ma y los 6,53 Ma.; en esa misma localidad (ZJ 30), se obtiene el registro más antiguo de Dinohippus mexicanus (Lance, 1950) para América del Norte y ambos géneros y especies se registran en San Gerardo de Limoncito en Costa Rica. Además, en la localidad de la Presa en la Cuenca de San Miguel Allende, ubican el registro más antiguo conocido del Camelidae Hemiauchenia vera en México, justo en la base de la sección de Coecillos que corresponde con el Henfiliano temprano $\mathrm{Hh} 2$ con una edad ligeramente menor a los 6,53 Ma. Todo ello, permite correlacionar el conjunto de mamíferos presente en la localidad de San Gerardo de Limoncito, con las diversas localidades del Henfiliano temprano-tardío (Hh2) de México (sensu Jiménez-Hidalgo, 2005; JiménezHidalgo \& Carranza-Castañeda, 2010; CarranzaCastañeda et al., 2013), como El Mixtón, donde se registra Pliometanastes, Calippus hondurensis y Dinohippus mexicanus y El Resbalón donde se registra Pliometanastes y Calippus hondurensis, ambas en la Cuenca de Juchipila; Zietla en la Cuenca de Zacualtipán, Hidalgo, donde registran Pliometanastes? y Calippus hondurensis, y La Presa, donde registran Calippus hondurensis y Hemiauchenia vera en la Cuenca de San Miguel Allende, Guanajuato. Dentro de esta última cuenca es posible hacer una correlación entre la localidad de San Gerardo de Limoncito y la localidad de Coecillos que aunque con un rango ligeramente más joven Henfiliano Tardío-Temprano (Hh3), comparten Dinohippus mexicanus y Hemiauchenia vera (sensu Jiménez-Hidalgo, 2005; Carranza-Castañeda et al., 2013).

En relación con las localidades de Estados Unidos (fig. 31), sobresale la fauna McGehee Farm (cf. los registros de Hirschfeld \& Webb, 1968; Hulbert, 1988) en La Florida de edad más antigua, Henfiliano Temprano-Temprano (Hh1), con la que la localidad de San Gerardo de 


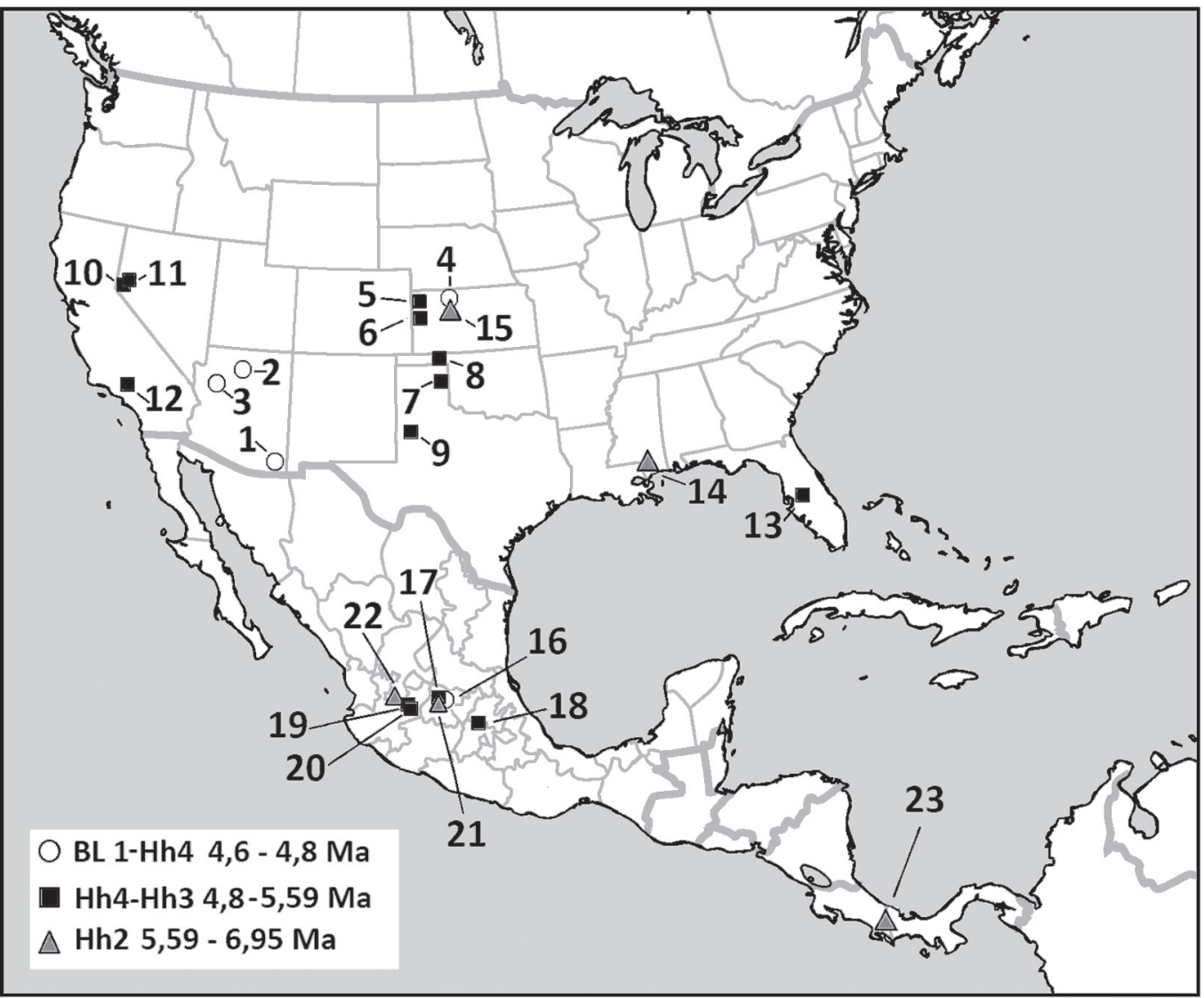

Fig.30: Distribución geográfica y temporal de Hemiauchenia vera Matthew, 1909, especímenes procedentes de localidades de: Estados Unidos, límite Bl1-Hh4: 1. Matthews Wash y Comosi Wash, Santa Cruz County; 2. Anita Site, Coconino County y 3. Wikieup, Mojave County, todas en la cuenca del río Gila, Arizona, 4. Ogallala Group (Loup Fork) cerca de Long Island, Phillips County; localidades de edad Hh4 y Hh3: 5. de Rhino Hill Quarry, Edson Quarry y West Quarry en Sherman County y 6. noreste de Wallace County, Kansas; 7 Coffee Ranch en Hemphill County y 8. Smart Ranch, Lubbock County, Texas; 9. Buis Ranch, Beaver County, Oklahoma; 10. Hoye Canyon en Douglas County y 11. Silver Spring y Yerington en Lyon County County, Nevada; 12. Horned Toad Hills, Desierto de Mojave, California; 13. Bone Valley, Palmetto y Phosphoria Mine, Polk County, Florida; localidades de edad Hh2: 14. Mauvilla, Mobile County, Alabama, 15. Minimum Quarry, Graham County, Kansas. México, límite B11-Hh4: 16. Rhino Layer y Rancho El Ocote, en la Cuenca de San Miguel Allende, Guanajuato; localidades de edad Hh4 y Hh3: 17. Coecillos, también, en la Cuenca de San Miguel Allende, Guanajuato; 18. Localidad de La Plegaria, Tepeji del Río, Hidalgo; 19. Santa María y 20. La Hacienda, Cuenca de Tecolotlán, Jalisco; localidades de edad Hh2: 21. La Presa, Cuenca de San Miguel Allende, Guanajuato y 22. Santo Domingo, Cuenca de Colotlán-Tlaltenango, Zacatecas. Hh2 de América Central: 23. San Gerardo de Limoncito, Formación Curré, Puntarenas, Costa Rica.

Limoncito comparte Protohippus gidleyi Hulbert, 1988, Calippus hondurensis (Olson \& McGrew, 1941) y Pliometanastes sp., y las localidades Henfiliano Temprano-Tardío (Hh2) de Mauvilla en Alabama y las Grandes Planicies de América del Norte, específicamente el conjunto compuesto por las localidades Wray, Box T, Minimum
Quarry y Cambridge (sensu Hulbert \& Whitmore, 2006) con las que comparte Protohippus gidleyi Hulbert, 1988 y Hemiauchenia vera (Matthew, 1909). Este tipo de correlación paleobiogeográfica, supone algún grado de continuidad climática y paleoecológica con todas las localidades septentrionales arriba mencionadas. 


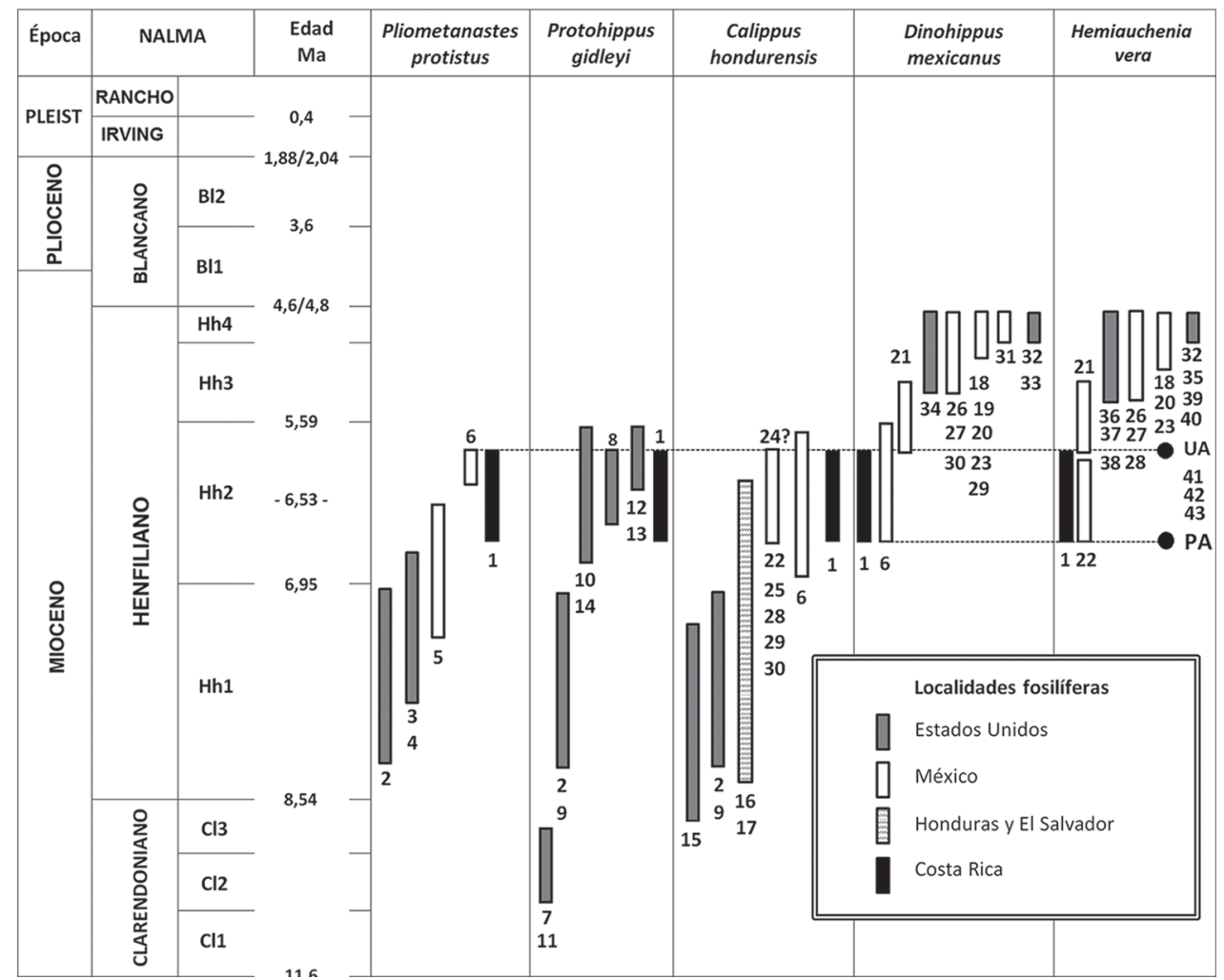

Fig. 31: Rangos cronológicos y biocronológicos de algunas especies de mamíferos asociadas a la paleomastofauna de 1. Localidad de San Gerardo de Limoncito, Costa Rica; 2. McGehee Farm, Florida (Hirschfeld \& Webb, 1968 y Morgan, 2005); 3. Siphon Canal Locality, California (Hirschfeld, 1981), 4.Chamita Fauna (Lindsay et al., 1984), Nuevo México; 5. Estado de Nuevo León (CarranzaCastañeda \& Miller, 2004), 6. Cuenca de Juchipila (El Mixtón y El Resbalón), Zacatecas, México (Carranza-Castañeda et al., 2008, 2013), 7. East Kat Quarry, Leparctus Quarry, West Line Kat Quarry, Xmas Quarry, Nebraska y 8. Sitio Mauvilla, Mobile County, Sur de Alabama (MacFadden \& Dobie, 1998; Hulbert \& Whitmore, 2006, Hulbert, com. escrita, 21/11/2014); Florida: 9. Mixson's Bone Bed en el Condado de Levy; 10. Withlacoochee River Site en los Condados de Marion y Citrus (MacFadden \& Dobie, 1998); 11.Long Island Quarry y Jack Swayze Quarry, Kansas; 12.Box T, Texas y 13. Cambridge Fauna en el Condado de Frontier, Nebraska; 14. Formación Wray, Yuma, Colorado (Hulbert, 1988 y Hulbert, comunicación personal en MacFadden \& Dobie, 1998, Hulbert \& Whitmore, 2006); 15. Tyner Farm, Western Alachua, Florida (Hulbert et al., 2002); 16. Fauna de Corinto, El Salvador, 17. Localidades de Año Nuevo, Rancho Lobo y Tepusuna o Mangual, Honduras. Cuenca de San Miguel Allende, Guanajuato, México: 18. Rancho el Ocote (Rino layer), 19. Rinconada, 20. Tepalcates, 21. Coecillos y 22. La Presa; 23. Cuenca de Tepeji del Río, Hidalgo localidad de Plegaria; Cuenca de Zacualtipán, Hidalgo: 24. Tehuitzila, 25. Zietla; Cuenca de Tecolotlán, Jalisco: 26. Santa María, 27. La Hacienda, 28. Santo Domingo, 29. Teocaltiche y 30. Jalostitlán (sensu Montellano-Ballesteros, 1989; Carranza-Castañeda et al., 2013); 31. Yepómera, Chihuahua (Lance, 1950; MacFadden, 1984, 1998a y b); 32. Upper Bone Valley: Palmetto Mine, Chicoria Mine, Fort Green Mine, Kingsfort Mine, Payne Creek Mine, Swift Mine, Tiger Bay Miney Phosphoria Mine, Florida (Webb et al., 2008); 33. Walnut Canyon, Northern Grant County, Formación Gila Group, Nuevo México (Morgan \& Sealey, 1995); 34. las localidades de Axtel, Christian Ranch y Currie Ranch de la Formación Goodnight Beds (Johnston \& Savage, 1955) y 35. Smart Ranch, Lubbock (Dalquest, 1967, Honey et al., 1998); Texas; 36. Faunas de Hoye Canyon, Yerington y Silver Springs, Nevada (Kelly, 2000); 37.Localidades de Edson Quarry y Rhino Hill, Kansas (Harrison, 1983); 38. Minimum Quarry, Kansas (Hulbert \& Whitmore, 2006); 39. Beaver County y Coffee Ranch, Oklahoma (Dalquest, 1980; Hibbard, 1963; Harrison, 1983; Joyce et al., 2012); 40. Horned Toad Hills, Desierto de Mojave, Sur de California (May et al., 2011); 41. Matthews Wash y Comosi Wash, Santa Cruz County y 42.Anita Site, Coconino County, cuenca del río Gila, Arizona y 43. Wikieup, Mojave County, Arizona PA- Primera aparición de la especie Dinohippus mexicanus (Lance, 1950) que corresponde a la localidad de La Presa, Cuenca de San Miguel Allende, mismo donde también se registra la aparición más temprana de Hemiauchenia vera Matthew, 1909 y UA- última aparición del género Pliometanastes que corresponde a la localidad de Juchipila, Estado de Zacatecas (Carranza-Castañeda et al., 2008, 2013). El signo de ?, hace referencia a registros de Calippus cf. C. hondurensis y Hemiauchenia $\mathrm{cf}, \mathrm{H}$. vera. 


\section{Paleoecología}

Comparada con otras especies de Hemiauchenia, Hemiauchenia vera Matthew, 1909 de acuerdo a Feranec (2003) es la menos hipsodonta y el análisis de los isótopos estables de carbono realizado por dicho autor le permiten concluir una dieta intermedia y considera que la hipsodoncia de los laminos no está relacionada de manera estricta a una dieta apacentadora. Teniendo en cuenta lo anterior, Hemiauchenia vera Matthew, 1909 tenía una dieta mixta de tipo ramoneador-pacedor, sus molares de acuerdo con Feranec (2003), presentan valores isotópicos de carbono, $\delta^{13} \mathrm{C}=-5,6 \%$ o, lo equivale a una dieta $50 \%$ ramoneadora y $50 \%$ apacentadora, en contraposición, por ejemplo, a otras especies de laminos como Hemiauchenia gracilis que de acuerdo a Meachen $(2003,2005)$ presenta valores isotópicos de carbono, $\delta^{13} \mathrm{C}=-8,0 \%$, lo que equivale a una dieta mayoritariamente ramoneadora con una pequeña porción de pasto, enfocada en material vegetal no abrasivo. El registro fósil de Hemiauchenia vera Matthew, 1909 en la localidad de San Gerardo, demuestra que cohabitó y compitió de manera directa con otros mamíferos herbívoros, como los caballos, tayasuidos, mastodontes y xenartras por alimento, pero es probable que al igual que estos herbívoros, tuviera una dieta mixta, lo que supone una partición efectiva de los recursos disponibles.

\section{CONCLUSIONES Y RECOMENDACIONES}

Se registra por primera vez para Costa Rica y América Central la especie Hemiauchenia vera Matthew, 1909, éste hallazgo constituye el registro más austral de la especie en el hemisferio norte y extiende su rango latitudinal entre $\operatorname{los} 9^{\circ} \mathrm{y}$ poco menos de los $40^{\circ}$ norte.

Los camellos laminos junto con los tayasuidos, son los únicos representantes del orden Artiodactyla que forman parte de la fauna de herbívoros de San Gerardo de Limoncito. Desde el punto de vista trófico, la especie Hemiauchenia vera estuvo en franca competencia con los Perissodactyla, representados por las tres especies de caballos: Protohippus gidleyi Hulbert, 1988, Calippus hondurensis (Olson \& McGrew, 1941) y Dinohippus mexicanus (Lance, 1950), los xenartras, representados por Pliometanastes, un Megatheriidae y un posible Mylodontidae, y el proboscídeo Gomphotherium hondurensis (Laurito \& Valerio, 2005, 2010, 2013; Valerio \& Laurito, 2008, 2014). Lo anterior sugiere una partición de los recursos alimentarios. Para ello, se recomienda la realización de análisis de isótopos estables que a futuro permitan comparar de manera efectiva la dieta del conjunto de herbívoros.

El presente registro de Hemiauchenia vera (Matthew, 1909) en asociación con Pliometanastes sp. cf. P. protistus Hirschfeld \& Webb, 1968 y los caballos arriba mencionados, permiten asignar una edad NALMA, Henfiliano Temprano-Tardío (Hh2) a la localidad de San Gerardo de Limoncito.

Por otra parte, el registro de Hemiauchenia vera Matthew, 1909 en Costa Rica, junto con los de las localidades de Mauvilla, Alabama y Minimum Quarry en las Grandes Planicies, en Estados Unidos y La Presa en la Cuenca de San Miguel Allende en México, constituyen los registros más antiguos conocidos hasta ahora para ésta especie.

\section{AGRADECIMIENTOS}

A la Dra. Marisol Montellano Ballesteros del Departamento de Paleontología del Instituto de Geología (UNAM), cuyas valiosas observaciones al manuscrito permitieron mejorar notablemente la versión final del texto.

\section{REFERENCIAS}

BRAVO-CUEVAS, V., JIMÉNEZ-HIDALGO, E., CUEVAS-RUIZ, G. \& CABRALPERDOMO, M., 2012: A small camelid 
Hemiauchenia from the Late Pleistocene of Hidalgo, central Mexico.- Acta Palaeontol. Polonica, 57(3): 497-508.

BREYER, J., 1977: Intra and interspecific variation in the lower jaw of Hemiauchenia.- J. Paleontol. 51(3): 527-535.

CARRANZA-CASTAÑEDA，O. \& MILLER, W., 2004: Late Tertiary Terrestrial Mammals from Central Mexico and their relationship to South American Immigrants.- Rev. Brasileira de Paleontol. 7(2): 249-261.

CARRANZA-CASTAÑEDA，O., WANG，X., ARANDA, J. J., TZENG, J., TRONCOSO, H. \& CERVANTES, J., 2008: Mastofauna del Terciario Tardío de la Formación Juchipila, Estado de Zacatecas y su correlación bioestratigráfica con las faunas del centro de México.- Geos, 28(2): 191.

CARRANZA-CASTAÑEDA, O., ARANDAGÓMEZ, J. J., WANG, X. \& IRIONDO, A., 2013: The Early-Late Hemphillian (Hh2) faunal assemblage from Juchipila Basin, State of Zacatecas, Mexico, and its biochronologic correlation with other Hemphillian faunas in Central Mexico.Contrib. in Sci. 521: 13-49.

CIONE,A.\& TONNI, E., 1995: Chronostratigraphy and "Land-Mammal Ages"; in the Cenozoic of Southern South America: principles, practices, and the "Uquian" problem.- J. Paleontol. 69(1): 135-169.

CISNEROS, J. C., 2005: New Pleistocene Vertebrate Fauna from El Salvador.- Rev. Bras. de Paleontol. 8(3): 239-255.

DALQUEST, W., 1967: Mammals of the Pleistocene Slaton Local Fauna of Texas.The Southwestern Naturalist, 12(1): 1-30.
DALQUEST, W., 1980: Camelidae from the Coffee Ranch Local Fauna (Hemphillian Age) of Texas.- J. Paleontol. 54(1): 109-117.

FERANEC, R. S., 2003: Stable isotopes, hypsodonty, and the paleodiet of Hemiauchenia (Mammalia: Camelidae) a morphological specialization creating ecological generalization.- Paleobiology, 29(2): 230-242.

FERRUSQUÍA-VILLAFRANCA， I., ARROYOCABRALES,J.,MARTÍNEZ-HERNÁNDEZ, E., GAMA-CASTRO, J., RUÍZ-GONZÁLEZ, J., POLACO, O. J. \& JOHNSON, E., 2010: Pleistocene mammals of Mexico: A critical review of regional chronofaunas, climate change response and biogeographic provinciality.Quaternary Int. 217: 53-104.

FLYNN, L. J., 1997: Late Neogene mammalian events in North China.- En: AGUILAR, J. P., LEGENDRE, S., \& MICHAUX, J. (eds): Actes du Congres BiochroM'97, Mèmoires et Travaux EPHE, Institut Montpellier, 21: 183-192.

FRICK, C., 1933: New remains in trilophodonttetrabelodont mastodonts.- Amer. Mus. Nat. Hist. Bull. 59: 505-652.

GIBERT, L., SCOTT, G. R., MONTOYA, P., RUIZ-SÁNCHEZ, F. J., MORALES, J., LUQUE, L., ABELLA, J. \& LERÍA, M., 2013: Evidence for an African-Iberian mammal dispersal during the pre-evaporitic Messinian.- Geol. 41: 691-694.

GREGORY, J. T., 1942: Pliocene vertebrates from Big Spring Canyon South Dakota.- Univ. of California Publ. Bull. Depto. Geol. Sci. 26(4): 307-446.

HARRISON, J., 1983: The Carnivora of the Edson Local Fauna (Late Hemphillian), Kansas.Smithsonian Contrib. Paleobiol. 54: 1-42. 
HIBBARD, C. W., 1963: Tanupolama vera (Matthew) from the Late Hemphillian of Beaver County, Oklahoma.- Transactions of the Kansas Acad. Sci. 66(2): 267-269.

HIRSCHFELD, S. E., 1981: Pliometanastes protistus (Edentata, Megalonychidae) from Knight's Ferry, California, with discussions of early Hemphillian megalonychids.- PaleoBios, 36: 1-16.

HIRSCHFELD, S. E. \& WEBB, S. D., 1968: PIio-Pleistocene megalonychid sloths of North America.- Bull. Florida State Mus. Biol. Sci. 12(5): 213-296.

HOFFSTETTER, R., 1952: Les mammifères pléistocènes de la République de l'Equateur.- 391 págs. Mémoire de la Société géologique de France, N.S. 31: $1-4,66$.

HONEY, J. G., HARRISON, J.A., PROTHERO, D. R. \& STEVENS, M. S., 1998: Camelidae.En: JANIS, C. M., SCOTT, K. M. \& JACOBS, L. L., (eds): Evolution of Tertiary Mammals of North America.- Cambridge Univ. Press, Cambridge: 439-462.

HULBERT, R. C., 1988: Calippus and Protohippus (Mammalia, Perissodactyla, Equidae) from the Miocene (BarstovianEarly Hemphillian) of the Gulf Coastal Plain.- Bull. Florida State Mus. Biological Sci. 32(3): 221-340.

HULBERT, R. C. \& WHITMORE, F. C., 2006: Late Miocene mammals from the Mauvilla Local Fauna, Alabama.- Bull. Florida Mus. Natural Hist. 46(1): 1-28.

HULBERT, R. C., POYER, A. R. \& WEBB, S. D., 2002: Tyner Farm, a new early Hemphillian local fauna from north-central Florida.- J. Vertebrate Paleontol. 22(3, supplement): 68A.
JIMÉNEZ-HIDALGO, E., 2005: Bioestratigrafía de los artiodáctilos (Tylopoday Ruminantia) de las faunas del Terciario Tardío de la Faja Volcánica Transmexicana.- 226 págs. Univ. Nacional Autónoma de México, México, D.F. [Tesis Ph.D].

JIMÉNEZ-HIDALGO, E. \& CARRANZACASTAÑEDA, O., 2010: Blancan camelids from San Miguel de Allende, Guanajuato, Central México.- J. Paleontol. 84(1): 51-65.

JOHNSTON, C. S. \& SAVAGE, D. E., 1955: A survey of various late Cenozoic vertebrate faunas of the panhandle of Texas. Part I. Introduction, description of localities, preliminary faunal lists.- Univ. of California Publ. in Geol. Sci. 31: 27-49.

JOYCE, W. G., PETRIČEVIĆ, A., LYSON, T. R. \& CZAPLEWSKI, N. J., 2012: A New Box Turtle from the Miocene/Pliocene Boundary (Latest Hemphillian) of Oklahoma and a refined Chronology of Box Turtle Diversification.- J. Paleontol. 86(1): 177-190.

KELLY, T. S., 1994: Two Pliocene (Blancan) Vertebrate Faunas From Douglas County, Nevada.- PaleoBios, 16(1): 1-24.

KELLY, T. S., 2000: A new Hemphillian (Late Miocene) mammalian fauna from Hoye Canyon, West Central Nevada.- Contrib. Science, 481: 1-21.

LANCE, J. F., 1950: Paleontología y Estratigrafía del Plioceno de Yepómera, Estado de Chihuahua $1^{\text {a }}$ parte: Equidos, excepto Neohipparion.- Univ. Nac. Autónoma de México, Inst. de Geol. 54: 1-81.

LAURITO, C. \& VALERIO, A., 2005: First record of Rhynchotherium blicki (Frick, 1933) for the Late Cenozoic of Costa Rica.- Rev. Geol. Amér. Central, 33: $75-82$. 
LAURITO, C. \& VALERIO, A., 2010: Los caballos fósiles de la Formación Curré, cantón de Coto Brus, Costa Rica.- 131 págs. Mus. Nac. Costa Rica, San José.

LAURITO, C. \& VALERIO, A., 2012a: Paleobiogeografía del arribo de mamíferos suramericanos al sur de América Central previo al gran intercambio biótico americano: Un vistazo al GABI en América Central.- Rev. Geol. Amér. Central, 46: 123-144.

LAURITO, C. \& VALERIO, A., 2012b: Primer registro fósil de Pliometanastes sp. (Mammalia, Xenarthra, Megalonychidae) para el Mioceno Superior de Costa Rica, América Central. Una nueva pista en la comprensión del Pre-GABI.- Rev. Geol. Amér. Central, 47: 95-108.

LAURITO, C. \& VALERIO, A., 2013: Scirrotherium antelucanus una nueva especie de Pampatheriidae (Mammalia, Xenarthra, Cingulata) del Mioceno Superior de Costa Rica, América Central.Rev. Geol. Amér. Central, 49: 45-62.

LAURITO, C., VALERIO, A., GÓMEZ, L., MEAD, J., PÉREZ, E. \& PÉREZ, L., 2005: A Trionychidae (Reptilia: Testudines, Cryptodira) from the Pliocene of Costa Rica, Southern Central America.- Rev. Geol. Amér. Central, 32: 7-11.

LIKIUS, A., BRUNET, M., GERAADS, D. \& VIGNAUD, P., 2003: Le plus vieux Camelidae (Mammalia, Artiodactyla) d'Afrique: limite Mio-Pliocène, Tchad.- Bull. de la Soc. Geol. de France, 174: 187-193.

LINDSAY, E.H., OPDYKE, N.D. \& JOHNSON, N.M., 1984: Blancan-Hemphillian Land Mammal Ages and Late Cenozoic Mammal Dispersal Events.- Annual Rev. of Earth and Planetary Sci. 1984: 445-488.
LORING, S.H. \& WOOD, A.E., 1969: Deciduous premolars of some North American Tertiary Camels (Family Camelidae).- J. Paleontol. 43(5): 1199-1209.

MATTHEW, W. D., 1909: Faunal lists of the Tertiary Mammalia of the West. - En: OSBORN, H.F. (ed.): Cenozoic Mammal horizons of western North America.- Bull. U.S. Geol. Surv. 361: 91-120.

MACFADDEN, B. J., 1984: Astrohippus and Dinohippus from the Yepómera Local Fauna (Hemphillian, Mexico) and Implications for the Phylogeny of OneToed Horses.- En: MACFADDEN, B. J., (ed.): Origin and Evolution of the Cenozoic Vertebrate Fauna of Middle America.- J. Vertebrate Paleontol. 4(2): 273-283.

MACFADDEN, B. J., 1998 a: Equidae. - En: JANIS, C., SCOTT, K. M. \& JACOBS, L. L., (eds): Evolution of Tertiary Mammals of North America. Vol. 1: Terrestrial carnivores, ungulates and ungulatelike mammals.- Cambridge Univ. Press., Cambridge: 537-559.

MACFADDEN, B. J., 1998 b: Fossil horses of Mexico: 55 Millions years of evolution of the family Equidae. Avances en investigación- Paleontología de Vertebrados.- Univ. Autónoma del Estado de Hidalgo. Publ. Esp. 1: 80-84.

MACFADDEN, B.J. \& DOBIE, J.L., 1998: Late Miocene Three-Toed Horse Protohippus (Mammalia, Equidae) from Southern Alabama.- J. Paleont. 72(1): 149-152.

MAY, S. R., WOODBURNE, M. O., LINDSAY, E. H., ALBRIGHT, L. B., SARNAWOJCICKI, A., WAN, E. \& WAHL, D. B., 2011: Geology and mammalian paleontology of the Horned Toad Hills, Mohave Desert, California, USA.- Palaeontologia Electronica 14(3) 38A: 1-63. 
MCGREW, P. O., 1942: Special correspondence: Field Museum Paleontological expedition to Honduras.- Sci. 96: 85.

MEACHEN, J. A., 2003: A new species of Hemiauchenia (Camelidae, Lamini) from the Plio-Pleistocene of Florida.- 58 págs. Univ. of Florida [Tesis M.Sc.].

MEACHEN, J. A., 2005: A new species of Hemiauchenia (Artiodactyla, Camelidae) from the Late Blancan of Florida.- Bull. Fla. Mus. Nat. Hist. 45(4): 435-447.

MONTELLANO-BALLESTEROS, M., 1989: Pliocene Camelidae of Rancho El Ocote, Central Mexico.- J. Mamm. 70(2): 359-369.

MORALES, J., SORIA, D. \& AGUIRRE, E., 1980: Camélido finimioceno en Venta del Moro. Primera cita para Europa Occidental.- Estudios Geol. 36: 139-142.

MORGAN, G. S., 2005: The Great American Biotic Interchange in Florida.- Bull. Fla. Mus. Nat. Hist. 45(4): 271-311.

MORGAN, G. S. \& SEALEY, P. L., 1995: Late Miocene and Pliocene (Hemphillian and Blancan) vertebrate fossils from the Gila Group, southwestern New Mexico.- New Mexico Geol. 17(2): 30.

MORGAN, G. S., SEALEY, P. L., LUCAS, S. \& HECKERF, A. B., 1997: Pliocene (Latest Hemphillian and Blancan) vertebrate fossils from the Mangas Basin, southwestern New Mexico.En: LUCAS, S. G., ESTEP, J. W., WILLIAMSON, T. E. \& MORGAN, G. S. (eds): New Mexico's Fossil Record 1.- New Mexico Mus. Natural Hist. and Sci. Bull. 11: 97-128.
MORGAN, G. S. \& WHITE, R. S., 2005: Miocene and Pliocene vertebrates from Arizona. - New Mexico Mus. of Natural Hist. and Sci. Bull. 29: 115-136.

OLSON, E. C. \& MCGREW, P. O., 1941: Mammalian fauna from the Pliocene of Honduras.- Bull. Geol. Soc. Amer. 52: 1219-1244.

PÉREZ, E., 2013: Los mamíferos fósiles del distrito de Puente de Piedra (Xenarthra, Glyptodontidae; Artiodactyla, Camelidae, Lamini) Grecia, provincia de Alajuela, Costa Rica.- Rev. Geol. Amér. Central, 49: 33-44.

PICKFORD, M., MORALES, J. \& SORIA, D., 1993: First fossil camels from Europe.Nature, 365: 701.

PICKFORD, M., MORALES, J. \& SORIA, D., 1995: Fossil camels from the Upper Miocene of Europe: Implications for biogeography and faunal change.- Geobios, 28: 641-650.

PROTHERO, D. R. \& SCHOCH, R. M., 2002: Horns, tusks, and flippers. The evolution of hoofed mammals.- 384 págs. The Johns Hopkins Univ. Press, Baltimore.

REGUERO, M. A, CANDELA, A. M \& ALONSO, R. N., 2007: Biochronology and biostratigraphy of the Uquía Formation (Pliocene-early Pleistocene, NW Argentina) and its significance in the Great American Biotic Interchange.J. South Amer. Earth Sci. 23: 1-16.

RINCÓN, A. F., BLOCH, J., SUAREZ, C., MACFADDEN, B. J. \& JARAMILLO, C., 2012: New Floridatragulines (Mammalia, Camelidae) from the Early Miocene 
Las Cascadas Formation, Panama.- J. Vertebrate Paleontol. 32(2): 456-475.

RYBCZYNSKI, N., GOSSE, J. C., HARRINGTON, C., WOGELIUS, R. A., HIDY, A. J. \& BUCKLEY, M., 2013: MidPliocene warm-period deposits in the high arctic yield insight into camel evolution.Nat. Commun. 4:1550, DOI: 10.1038/ ncomms2516 (2013).

TITOV, V., 2008a: Earliest Paracamelus of the Old World.- The $33^{\text {rd }}$ Int. Geol. Congr. Oslo: 1173.

TITOV, V., 2008b: Habitat conditions for Camelus knoblochi and factors in its extinction.Quaternary Int. 179 (2008): 120-125.

TITOV, V. V. \& LOGVYNENKO, V. N., 2006: Early Paracamelus (Mammalia, Tylopoda) in Eastern Europe.- Acta Zoologica Cracoviensia, 49A(1-2): 163-178.

VALERIO, A. L., 2010: Paleontología, bioestratigrafía y paleoecología de los caballos fósiles de la Formación Curré en el cantón de Coto Brus, Costa Rica (análisis basado en material dental).- 353 págs. Univ. de Costa Rica, San José [Tesis Lic.].

VALERIO, A. L. \& LAURITO, C. A., 2008: Dental remains of inmature individuals of Rhynchotherium blicki (Frick 1933) of San Gerardo de Limoncito, Coto Brus, Costa Rica.- Rev. Geol. Amér. Central, 39: 87-91.

VALERIO, A. L. \& LAURITO, C. A., 2012: Cetáceos fósiles (Mammalia, Odontoceti, Eurhinodelphinoidea, Inioidea, Physeterioidea) de la Formación Curré,
Mioceno Superior (Hemphilliano temprano tardío) de Costa Rica.- Rev. Geol. Amér. Central, 46: 151-160.

VALERIO, A. L. \& LAURITO, C.A., 2013: Primer registro de aves fósiles (Pelecaniformes: Pelecanidae y un probable Odontopterygiformes: Pelagornithidae) para el Mioceno Superior de Costa Rica.Rev. Geol. Amér. Central, 49: 25-32.

VALERIO, A. L. \& LAURITO, C. A., 2014: Nueva evidencia de un estadio juvenil de Pliometanastes protistus y su relación con ? Pliometanastes galushai Hirschfeld \& Webb, 1968 (Xenarthra, Megalonychidae) para el Mioceno Superior de Costa Rica.Rev. Geol. Amér. Central, 51: 159-163.

VAN DER MADE, J., MORALES, J., SEN, S. \& ASLAN, F., 2002: The first camel from the Upper Miocene of Turkey and the dispersal of the camels into the Old World.- Comptes Rendus Palevol, 1: 117-122.

WEBB, D., 1965: The osteology of Camelops.Bull. Los Angeles County Mus. 1: 1-54.

WEBB, D., 1974: Pleistocene Mammals of Florida.- 270 págs. Univ. Press of Florida, Gainesville.

WEBB, D. \& PERRIGO, S., 1984: Late Cenozoic vertebrates from Honduras and $\mathrm{El}$ Salvador.- J. Vertebrate Paleontol. 4(2): 237-254.

WEBB, D. \& MEACHEN, J., 2004: On the origin of Lamine Camelidae including a new genus from the Late Miocene of the High Plains.- Carnegie Mus. Natural Hist. Bull. 36: 349-362. 
WEBB, D., HULBERT, R.C., MORGAN, G.S. \& EVANS, H.F., 2008: Terrestrial mammals of the Palmetto Fauna (early Pliocene, latest Hemphillian) from the Central Florida Phosphate District.- En: WANG, X. \& BARNES, L.G. (eds.): Geology and vertebrate Paleontology of Western and Southern North America. Contrib. in honor of David P. Wistler.- Natural Hist. Mus. of Los Angeles County. Sci. Ser. 41: 293-312.
WHITE, R. S . \& MORGAN, G. S ., 2005: Arizona Blancan vertebrate faunas in regional perspective.- En: MCCORD, R. D. (ed.): Vertebrate Paleontology of Arizona.Mesa Southwest Mus. Bull. 11: 117-138.

WORTMAN, J. L., 1898: The extinct Camelidae of North America and some associated forms.- Bull. Amer. Mus. Nat. Hist. 10: 93-143.

Apéndice 1

Medidas de los molares de Hemiauchenia vera Matthew, 1909 en mm

\begin{tabular}{|c|c|c|c|c|}
\hline Número de catálogo & Orientación del diente & $\begin{array}{c}\text { Longitud } \\
\text { (antero-posterior) }\end{array}$ & Ancho (lingual-labial) & $\begin{array}{c}\text { Altura corona } \\
\text { (medido en mesostilo o } \\
\text { metastílido) }\end{array}$ \\
\hline CFM-3729 & dpm4 & 24,56 & 9,60 & 9,51 \\
\hline CFM-1672 & $3 \mathrm{PM}$ & 15,15 & 11,22 & 10,28 \\
\hline CFM-2198 & $1 \mathrm{M}$ & 22,42 & 18,44 & 23,92 \\
\hline CFM-1671 & $2 \mathrm{M}$ & 24,23 & 17,63 & 15,82 \\
\hline CFM-2877 & $2 \mathrm{M}$ & 24,71 & 19,32 & 15,94 \\
\hline CFM-1673 & $\mathrm{m} 1$ & 16,16 & 10,48 & 9,16 \\
\hline CFM-1925 & $\mathrm{m} 2$ & 17,58 & 13,18 & 7,58 \\
\hline \multirow[t]{2}{*}{ CFM-3215 } & $(\mathrm{m} 1-\mathrm{m} 2) \quad \mathrm{m} 1$ & 20,88 & 10,73 & 13,69 \\
\hline & $\mathrm{m} 2$ & 22,35 & 11,34 & 15,05 \\
\hline \multirow[t]{3}{*}{ CFM-2612 } & $(\mathrm{m} 1-\mathrm{m} 3) \mathrm{m} 1$ & Roto & 10,55 & Roto \\
\hline & $\mathrm{m} 2$ & 22,28 & 13,10 & Roto \\
\hline & $\mathrm{m} 3$ & Roto & 12,11 & No eruptado \\
\hline
\end{tabular}


Apéndice 2

Medidas de elementos postcraneales de Hemiauchenia vera, Matthew, 1909 en mm. GL longitud mayor, BP amplitud de la terminación proximal, $\mathrm{BD}$ amplitud de la terminación distal, $\mathrm{SD}$ el más pequeño diámetro de la diáfisis. Medidas solo para la ulna: LO longitud del olécranon de la ulna, SDO menor profundidad del olécranon, DPA profundidad a través del proceso anconal

\begin{tabular}{|c|c|c|c|c|c|c|c|c|}
\hline $\begin{array}{l}\text { Número de } \\
\text { catálogo }\end{array}$ & Elemento & GL & $\mathrm{BP}$ & $\mathrm{BD}$ & SD & LO & SDO & DPA \\
\hline CFM-1194 & Fragmento ulna derecha & & & & & 67,41 & 46,67 & 54,72 \\
\hline CFM-3063 & Fragmento radio derecho & & 58,03 & & & & & \\
\hline CFM-1106 & Fragmento radio izquierdo & & 55,73 & & & & & \\
\hline CFM-1107 & Fragmento radio izquierdo & & 47,72 & & & & & \\
\hline CFM-1520 & Fragmento radio izquierdo & & 55,38 & & & & & \\
\hline CFM-2479 & Fragmento radio izquierdo & & 54,91 & & & & & \\
\hline CFM-2611 & Fragmento radio izquierdo & & 52,22 & & & & & \\
\hline CFM-2836 & Fragmento radio izquierdo & & 61,51 & & & & & \\
\hline CFM-1006 & Fragmento fémur derecho & & 80,87 & & 33,78 & & & \\
\hline CFM-1706 & Fragmento fémur izquierdo & & & 87,78 & & & & \\
\hline CFM-1001 & Metapodial & & & & 24,74 & & & \\
\hline CFM-1002 & Metapodial & & & & 22,90 & & & \\
\hline CFM-2034 & Metapodial & & & 48,30 & 29,46 & & & \\
\hline CFM-3060 & Metapodial & & & & 30,97 & & & \\
\hline CFM-1638 & Fragmento metatarso & & 40,52 & & 22,83 & & & \\
\hline CFM-1690 & Fragmento metatarso & & 40,73 & & 23,44 & & & \\
\hline CFM-2036 & Fragmento metatarso & & 43,54 & & & & & \\
\hline CFM-2894 & Fragmento metatarso & & 46,65 & & 28,76 & & & \\
\hline CFM-3272 & Fragmento metatarso & & 47,64 & & & & & \\
\hline CFM-3557 & Fragmento metatarso & & 43,28 & & & & & \\
\hline CFM-1093 & Fragmento falange I & & 19,15 & & 13,84 & & & \\
\hline CFM-1863 & Falange I & 79,61 & 25,21 & 19,94 & 17,59 & & & \\
\hline CFM-2483 & Fragmento falange I & & 23,88 & & 17,09 & & & \\
\hline CFM-2487 & Fragmento falange I & & 26,35 & & & & & \\
\hline CFM-2488 & Fragmento falange I & & 27,10 & & & & & \\
\hline CFM-2491 & Fragmento falange I & & 24,12 & & & & & \\
\hline CFM-2609 & Fragmento falange I & & 26,74 & & 16,00 & & & \\
\hline
\end{tabular}


Apéndice 2 (continuación)

Medidas de elementos postcraneales de Hemiauchenia vera, Matthew, 1909 en mm. GL longitud mayor, BP amplitud de la terminación proximal, $\mathrm{BD}$ amplitud de la terminación distal, $\mathrm{SD}$ el más pequeño diámetro de la diáfisis. Medidas solo para la ulna: LO longitud del olécranon de la ulna, SDO menor profundidad del olécranon, DPA profundidad a través del proceso anconal

\begin{tabular}{|c|c|c|c|c|c|c|c|c|}
\hline $\begin{array}{l}\text { Número de } \\
\text { catálogo }\end{array}$ & Elemento & GL & $\mathrm{BP}$ & $\mathrm{BD}$ & $\mathrm{SD}$ & LO & SDO & DPA \\
\hline CFM-2783 & Fragmento falange I & & & 18,36 & & & & \\
\hline CFM-3099 & Fragmento falange I & & 24,70 & & & & & \\
\hline CFM-1864 & Falange II & 41,41 & 21,13 & 16,84 & 17,88 & & & \\
\hline CFM-2489 & Fragmento falange II & & 21,52 & & & & & \\
\hline CFM-2638 & Falange II & 39,37 & 19,82 & & 14,15 & & & \\
\hline CFM-1715 & Fragmento tibia derecha & & & 52,74 & 40,08 & & & \\
\hline CFM-2180 & Fragmento tibia derecha & & & 48,40 & 35,43 & & & \\
\hline CFM-2492 & Fragmento tibia derecha & & & 57,20 & & & & \\
\hline CFM-2798 & Fragmento tibia derecha & & 62,65 & & 33,22 & & & \\
\hline CFM-3105 & Fragmento tibia derecha & & & 53,24 & 38,76 & & & \\
\hline CFM-3730 & Fragmento tibia derecha & & & 57,36 & & & & \\
\hline CFM-1794 & Fragmento tibia izquierda & & & 53,82 & 39,19 & & & \\
\hline CFM-2801 & Fragmento tibia izquierda & & & 51,25 & 38,94 & & & \\
\hline CFM-2838 & Fragmento tibia izquierda & & & 54,90 & 42,10 & & & \\
\hline CFM-3059 & Fragmento tibia izquierda & & 66,54 & & & & & \\
\hline CFM-3061 & Fragmento tibia izquierda & & & 59,34 & & & & \\
\hline CFM-3104 & Fragmento tibia izquierda & & 60,86 & & & & & \\
\hline CFM-3789 & Fragmento tibia izquierda & & & 50,26 & 33,54 & & & \\
\hline
\end{tabular}


Apéndice 3

Datos biométricos de astrágalos de diferentes especies de América del Norte y Central, todas las medidas están dadas en mm; * probable forma juvenil

\begin{tabular}{|c|c|c|c|c|}
\hline Especie & Ancho distal & Altura medial & Ejemplar & Referencia \\
\hline Hemiauchenia vera $\mathrm{MX}$ & 38,3 & 57 & IGCU 703 & Jiménez-Hidalgo, 2005 \\
\hline Hemiauchenia vera $\mathrm{MX}$ & 37,2 & 55 & IGCU 12218 & Jiménez-Hidalgo, 2005 \\
\hline Hemiauchenia vera $\mathrm{MX}$ & 38,3 & 59 & IGCU 745 & Jiménez-Hidalgo, 2005 \\
\hline Hemiauchenia vera $\mathrm{MX}$ & 40,2 & 55,8 & IGCU 3266 & Jiménez-Hidalgo, 2005 \\
\hline Hemiauchenia vera $\mathrm{MX}$ & 43 & 59 & IGCU 753 & Jiménez-Hidalgo, 2005 \\
\hline Hemiauchenia vera $\mathrm{MX}$ & 38 & 57,2 & IGCU 8572 & Jiménez-Hidalgo, 2005 \\
\hline Hemiauchenia vera $\mathrm{MX}$ & 37,5 & 58 & IGCU 8780 & Jiménez-Hidalgo, 2005 \\
\hline Hemiauchenia vera $\mathrm{MX}$ & 40 & 59,6 & IGCU 8908 & Jiménez-Hidalgo, 2005 \\
\hline Hemiauchenia vera $\mathrm{MX}$ & 39,5 & 50,2 & IGCU 10700 & Jiménez-Hidalgo, 2005 \\
\hline Hemiauchenia vera $\mathrm{MX}$ & 38,1 & 53,3 & IGCU 7512 & Jiménez-Hidalgo, 2005 \\
\hline Hemiauchenia gracilis MX & 27,1 & 43,3 & IGCU 12235 & Jiménez-Hidalgo, 2005 \\
\hline Hemiauchenia gracilis MX & 29 & 43,4 & IGCU 3262 & Jiménez-Hidalgo, 2005 \\
\hline Hemiauchenia gracilis MX & 28,2 & 42,6 & IGCU 3914 & Jiménez-Hidalgo, 2005 \\
\hline Hemiauchenia gracilis MX & 29,3 & 43,6 & IGCU 10251 & Jiménez-Hidalgo, 2005 \\
\hline Hemiauchenia gracilis $\mathrm{MX}$ & 29,2 & 45,1 & IGCU 10252 & Jiménez-Hidalgo, 2005 \\
\hline Hemiauchenia gracilis MX & 27,6 & 43,4 & IGCU 10255 & Jiménez-Hidalgo, 2005 \\
\hline Hemiauchenia gracilis MX & 30 & 44,6 & IGCU 11038 & Jiménez-Hidalgo, 2005 \\
\hline Hemiauchenia vera $\mathrm{CR}$ & 36,97 & 56,23 & CFM-1691 & Presente trabajo \\
\hline Hemiauchenia vera $\mathrm{CR}$ & 34,3 & 53,11 & CFM-2179 & Presente trabajo \\
\hline Hemiauchenia vera $\mathrm{CR}$ & 35,55 & 54,86 & CFM-3558 & Presente trabajo \\
\hline Hemiauchenia vera $\mathrm{CR}$ & 36,65 & 54,73 & CFM-2835 & Presente trabajo \\
\hline Hemiauchenia vera* $\mathrm{CR}$ & 29,91 & 41,87 & CFM-1113 & Presente trabajo \\
\hline Hemiauchenia vera $\mathrm{CR}$ & 29,24 & 44,62 & CFM-1444 & Presente trabajo \\
\hline Hemiauchenia gracilis USA & 24,1 & 38 & UF210722 & Meachen, 2003 \\
\hline Hemiauchenia gracilis USA & 25,4 & 40,4 & UF10281 & Meachen, 2003 \\
\hline Hemiauchenia gracilis USA & 24,3 & 38,6 & UF210706 & Meachen, 2003 \\
\hline Hemiauchenia blancoensis $\mathrm{MX}$ & 39,6 & 54 & IGCU921 & Jiménez-Hidalgo, 2005 \\
\hline Hemiauchenia blancoensis $\mathrm{MX}$ & 34,6 & 50,7 & IGCU5660 & Jiménez-Hidalgo, 2005 \\
\hline Hemiauchenia blancoensis USA & 41,5 & 60,7 & UCMP 139239 & Kelly 1994 \\
\hline Alforjas sp. MX & 41,8 & 63 & IGCU4352 & Jiménez-Hidalgo, 2005 \\
\hline Alforjas sp. MX & 46,2 & 68,1 & IGCU4514 & Jiménez-Hidalgo, 2005 \\
\hline Alforjas sp. MX & 48 & 70 & IGCU9418 & Jiménez-Hidalgo, 2005 \\
\hline Alforjas sp. MX & 47 & 68 & IGCU7383 & Jiménez-Hidalgo, 2005 \\
\hline Camelops sp. MX & 49,5 & 74,2 & IGCU 3735 & Jiménez-Hidalgo, 2005 \\
\hline
\end{tabular}


Apéndice 4

Datos biométricos comparativos de los metapodiales de diferentes especies de Hemiauchenia de América del Norte y Central en $\mathrm{mm}$. GL longitud mayor, BP amplitud de la terminación proximal, BD amplitud de la terminación distal, SD el más pequeño diámetro de la diáfisis

\begin{tabular}{|c|c|c|c|c|c|c|}
\hline Especie & GL & $\mathrm{BP}$ & $\mathrm{BD}$ & SD & Ejemplar & Referencia \\
\hline Hemiauchenia vera & & & & 24,74 & CFM-1001 & Presente trabajo \\
\hline H. vera & & & & 22,90 & CFM-1002 & Presente trabajo \\
\hline H. vera & & & 48,30 & 29,46 & CFM-2034 & Presente trabajo \\
\hline H. vera & & & & 30,97 & CFM-3060 & Presente trabajo \\
\hline H. vera & & 40,52 & & 22,83 & CFM-1638 & Presente trabajo \\
\hline H. vera & & 40,73 & & 23,44 & CFM-1690 & Presente trabajo \\
\hline H. vera & & 43,54 & & & CFM-2036 & Presente trabajo \\
\hline H. vera & & 46,65 & & 28,76 & CFM-2894 & Presente trabajo \\
\hline H. vera & & 47,64 & & & CFM-3272 & Presente trabajo \\
\hline H. vera & & 43,28 & & & CFM-3557 & Presente trabajo \\
\hline H. gracilis & 320,00 & 33,00 & 39,40 & 19,10 & UF 176935 & Meachen, 2005 \\
\hline H. gracilis & & & 38,20 & & UF 18236 & Meachen, 2005 \\
\hline H. gracilis & & 31,10 & & 16,80 & UF 210720 & Meachen, 2005 \\
\hline H. gracilis & & 34,90 & & & UF 210711 & Meachen, 2005 \\
\hline H. gracilis & & 34,20 & & & UF 210726 & Meachen, 2005 \\
\hline Hemiauchenia sp. & 360,00 & 43,20 & & & NMMNH P-26812 & Morgan et al., 1997 \\
\hline H. vera & 413,00 & 50,40 & & 29,80 & $\begin{array}{c}5573 \\
\text { (Midwestern State University) }\end{array}$ & Dalquest, 1980 \\
\hline H. vera & 408,00 & 47,00 & & 28,00 & $\begin{array}{c}5673 \\
\text { (Midwestern State University) }\end{array}$ & Dalquest, 1980 \\
\hline Hemiauchenia sp. & 400,00 & & & 26,80 & & Dalquest, 1980 \\
\hline H. macrocephala & 342,90 & 45,10 & 51,40 & 28,20 & UF133908 & Hulbert, 2001 \\
\hline H. gracilis & & & 43,20 & & UAHMP-357 & Bravo-Cuevas et al., 2012 \\
\hline H. gracilis & 330,00 & 39,70 & & 25,30 & UAHMP-962 & Bravo-Cuevas et al., 2012 \\
\hline
\end{tabular}


Apéndice 5

Datos biométricos comparativos de las falanges I de diferentes especies de Hemiauchenia de América del Norte y Central en $\mathrm{mm}$. GL longitud mayor, BP amplitud de la terminación proximal, BD amplitud de la terminación distal, SD el más pequeño diámetro de la diáfisis

\begin{tabular}{|c|c|c|c|c|c|c|}
\hline Especie & GL & $\mathrm{BP}$ & $\mathrm{BD}$ & SD & Ejemplar & Referencia \\
\hline Hemiauchenia vera & & 19,15 & & 13,84 & CFM-1093 & Presente trabajo \\
\hline H. vera & 79,61 & 25,21 & 19,94 & 17,59 & CFM-1863 & Presente trabajo \\
\hline H. vera & & 23,88 & & 17,09 & CFM-2483 & Presente trabajo \\
\hline H. vera & & 26,35 & & & CFM-2487 & Presente trabajo \\
\hline H. vera & & 27,10 & & & CFM-2488 & Presente trabajo \\
\hline H. vera & & 24,12 & & & CFM-2491 & Presente trabajo \\
\hline H. vera & & 26,74 & & 16,00 & CFM-2609 & Presente trabajo \\
\hline H. vera & & & 18,36 & & CFM-2783 & Presente trabajo \\
\hline H. vera & & 24,70 & & & CFM-3099 & Presente trabajo \\
\hline H. gracilis & 63,00 & 19,00 & 15,20 & & IGM 8819 & Jiménez-Hidalgo \& Carranza-Castañeda, 2010 \\
\hline H. blancoensis & 103,20 & 28,80 & 24,00 & 17,00 & IGM 2338 & Jiménez-Hidalgo \& Carranza-Castañeda, 2010 \\
\hline H. gracilis & 74,50 & 17,80 & 14,90 & 11,30 & UF 97203 & Meachen, 2003 \\
\hline H. gracilis & 82,60 & 18,50 & 16,00 & 10,70 & UF 179638 & Meachen, 2003 \\
\hline H. gracilis & 84,20 & 19,60 & 14,60 & 11,10 & UF 179639 & Meachen, 2003 \\
\hline H. gracilis & 71,20 & 17,80 & 14,40 & 10,80 & UF 18237 & Meachen, 2003 \\
\hline H. gracilis & 66,20 & 17,70 & 14,10 & 10,40 & UF 210704 & Meachen, 2003 \\
\hline H. gracilis & 78,50 & 18,30 & 15,80 & 10,30 & UF 210708 & Meachen, 2003 \\
\hline H. gracilis & 67,90 & 18,10 & 14,90 & 10,60 & UF 210712 & Meachen, 2003 \\
\hline H. gracilis & 67,70 & 18,10 & 14,50 & 10,40 & UF 210703 & Meachen, 2003 \\
\hline H. gracilis & 82,70 & 20,30 & 19,30 & 13,70 & UAHMP-759a & Bravo-Cuevas et al., 2012 \\
\hline H. gracilis & 80,90 & 28,90 & 18,70 & 13,40 & UAHMP-759b & Bravo-Cuevas et al., 2012 \\
\hline
\end{tabular}


